Prepared for the U.S. Department of Energy under Contract DE-AC05-76RL01830

\title{
Experimental and Sampling Design for the INL-2 Sample Collection Operational Test
}

\author{
GF Piepel \\ BG Amidan \\ BD Matzke
}

Statistics and Sensor Analytics

Pacific Northwest National Laboratory

Richland, WA

February 2009

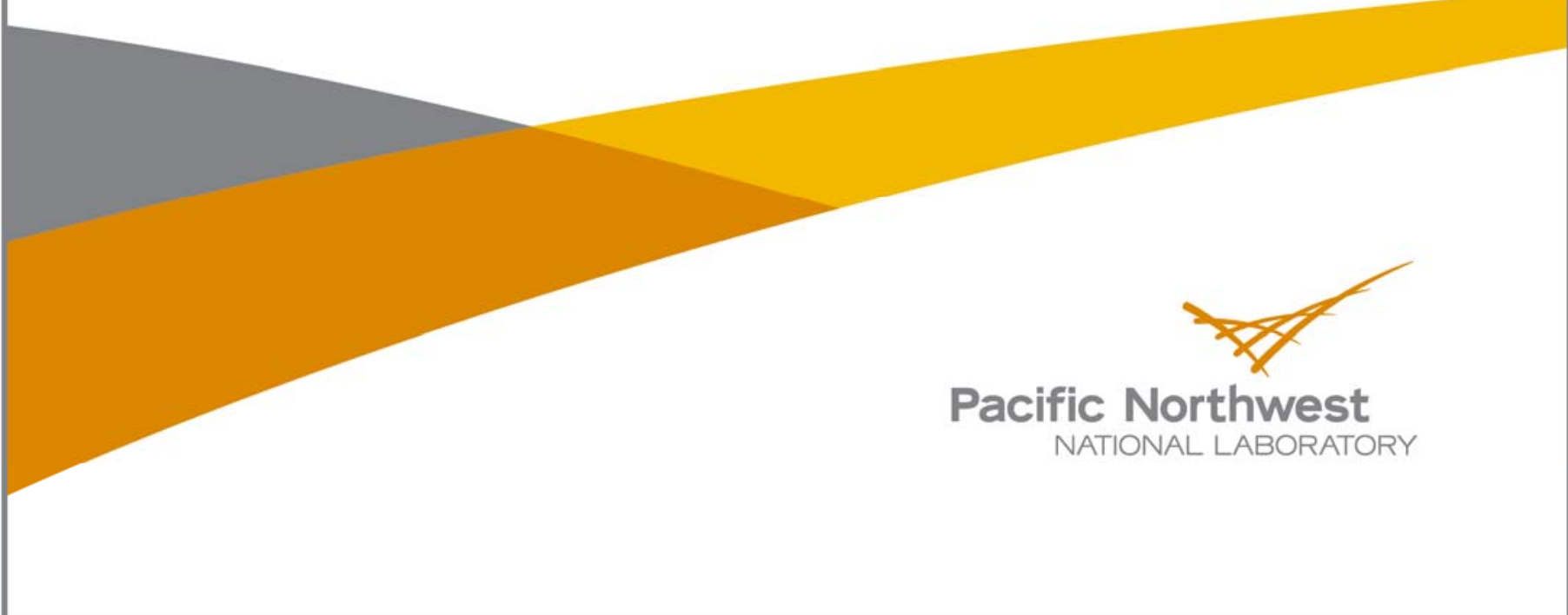




\title{
DISCLAIMER
}

This report was prepared as an account of work sponsored by an agency of the United States Government. Neither the United States Government nor any agency thereof, nor Battelle Memorial Institute, nor any of their employees, makes any warranty, express or implied, or assumes any legal liability or responsibility for the accuracy, completeness, or usefulness of any information, apparatus, product, or process disclosed, or represents that its use would not infringe privately owned rights. Reference herein to any specific commercial product, process, or service by trade name, trademark, manufacturer, or otherwise does not necessarily constitute or imply its endorsement, recommendation, or favoring by the United States Government or any agency thereof, or Battelle Memorial Institute. The views and opinions of authors expressed herein do not necessarily state or reflect those of the United States Government or any agency thereof.

\author{
PACIFIC NORTHWEST NATIONAL LABORATORY \\ operated by \\ BATTELLE \\ for the \\ UNITED STATES DEPARTMENT OF ENERGY \\ under Contract DE-AC05-76RL01830
}

Printed in the United States of America
Available to DOE and DOE contractors from the
Office of Scientific and Technical Information,
P.O. Box 62, Oak Ridge, TN 37831-0062;
ph: (865) 576-8401
fax: (865) 576-5728
email: reports@adonis.osti.gov

\footnotetext{
Available to the public from the National Technical Information Service, U.S. Department of Commerce, 5285 Port Royal Rd., Springfield, VA 22161 ph: (800) 553-6847 fax: (703) 605-6900

email: orders@ntis.fedworld.gov online ordering: http://www.ntis.gov/ordering.htm
} 


\title{
Experimental and Sampling Design for the INL-2 Sample Collection Operational Test
}

\author{
GF Piepel \\ BG Amidan \\ BD Matzke
}

Statistics and Sensor Analytics

Pacific Northwest National Laboratory

Richland, Washington

February 2009

Prepared for

U.S. Department of Homeland Security

Science and Technology Directorate

Test and Evaluation/Standards Division

Standards Office

Prepared for the U.S. Department of Energy

under Contract DE-AC05-76RL01830

Pacific Northwest National Laboratory

Richland, Washington 99352 


\section{Executive Summary}

This report describes the test events and numbers of samples comprising an experimental and sampling design developed to assess sampling approaches and methods for detecting contamination in a building and clearing the building for use after decontamination. Idaho National Laboratory (INL) identified Building PBF-632 as a test-bed facility for evaluating protocols for response to potential contamination by biological agents. Building PBF-632 is an unoccupied, two-story office building with each floor having an area of $4025 \mathrm{ft}^{2}$. The first floor has 11 offices, a reception area (lobby), men's and women's restrooms, and a mechanical room. The second floor has 15 offices, two storage rooms, men's and women's restrooms, and a mechanical room. Building PBF-632 will be contaminated with BG (Bacillus globigii, subsequently Bacillus subtilis var. niger, and recently renamed Bacillus atrophaeus), a simulant for Bacillus anthracis (BA). The contamination, sampling, decontamination, and re-sampling will occur as specified by the experimental and sampling design. This study is referred to as the INL-2 Sample Collection Operational Test, which is being planned by the Validated Sampling Plan Working Group (VSPWG). The INL-2 study is a follow-up to the INL-1 Sample Collection Operational Test conducted in 2007.

The VSPWG developed five objectives for the INL-2 study. These objectives are listed in Section 1.2. The primary objectives that influenced developing the experimental and sampling design presented in this report are summarized below.

- Evaluate judgmental and probabilistic sampling for characterization as well as probabilistic and hybrid (judgmental and probabilistic) sampling approaches for clearance.

- Conduct these evaluations for gradient contamination (from low or moderate down to absent or not detectable) for different initial concentrations of the contaminant.

- Explore judgmental composite sampling approaches to reduce sample numbers.

- Collect baseline data to serve as an indication of the actual levels of simulant contamination in the tests.

The hybrid approach is referred to as the combined judgmental and random (CJR) approach. The CJR approach uses Bayesian methodology to combine judgmental and random (probabilistic) samples to make clearance statements of the form " $\mathrm{X} \%$ confidence that at least $\mathrm{Y} \%$ of an area (or floor of the building) does not contain detectable contamination." These are referred to as $\mathrm{X} \% / \mathrm{Y} \%$ clearance statements. $^{\text {(a) }}$

The INL-2 experimental design described in this report includes five test events, the first of which is an Operational Readiness Inspection (ORI). The test events 1) vary the floor of the INL building on which the contaminant will be released, 2) provide for varying or adjusting the amount of contaminant released to obtain desired concentration gradients across a floor of the building, and 3) investigate overt as well as covert release of contaminants (i.e., the responders either know or do not know the release point of the contaminant). Desirable contaminant gradients would have moderate to low concentrations

(a) The $\mathrm{X} \% / \mathrm{Y} \%$ clearance statements of the CJR method are based on the posterior predictive distribution from a modification of the Beta-Binomial Bayesian model (see Gelman et al. 2003). The X\%/Y\% clearance statements can also be made using only probabilistic samples with continuous-variable responses based on the statistical theory for $\mathrm{X} \% / \mathrm{Y} \%$ tolerance intervals (see Hahn and Meeker 1991). 
of contaminant in rooms near the release point, with concentrations down to zero (i.e., not contaminated) in one or more rooms. Such gradients would provide a range of contamination levels (from moderate to low and down to zero) to challenge the sampling, sample extraction, and analytical methods that will be used in the INL-2 study.

For each of the five test events, the specified floor of the INL PBF-632 building will be contaminated with BG. The BG contaminant will be disseminated from a point-release device located in the room specified in the experimental design for each test event. Then quality control (QC), reference material coupon (RMC), judgmental, and probabilistic samples will be collected according to the pre-specified sampling plan for each test event. Judgmental samples will be selected based on professional judgment and prior information. Probabilistic samples were selected with a random aspect and in sufficient numbers to provide desired confidence for detecting contamination or clearing uncontaminated (or decontaminated) areas. Following sample collection for a given test event, the INL PBF-632 building will be decontaminated using $\mathrm{Cl}_{2} \mathrm{O}$ gas.

For possibly contaminated areas (which may be individual rooms or a whole floor of the INL PBF632 building), the numbers of probabilistic samples were chosen to provide $95 \%$ confidence of detecting contaminated areas of specified sizes. The numbers of judgmental samples were chosen based on guidance from experts in judgmental sampling. For rooms that may be uncontaminated (or have undetectable contamination) following a contamination event, or for whole floors after decontamination, the numbers of judgmental and probabilistic samples were chosen using the CJR sampling approach. The numbers of samples were chosen to support making $\mathrm{X} \% / \mathrm{Y} \%$ clearance statements with $\mathrm{X}=95 \%$ and $\mathrm{Y} \sim$ $98 \%$ for clearing a whole floor, and $\mathrm{X}=90 \%$ and $\mathrm{Y}=94-96 \%$ for clearing a set of two offices. The experimental and sampling design also provides for making $\mathrm{X} \% / \mathrm{Y} \%$ clearance statements using only probabilistic samples.

For each test event, the numbers of characterization and clearance samples were selected within limits based on operational considerations while still maintaining high confidence for detection and clearance aspects. The sampling design for all five test events specifies a total of 2085 samples, with 1142 after contamination (characterization and clearance) and 943 after decontamination (clearance). These numbers include QC, RMC, judgmental, and probabilistic samples. The experimental and sampling design specified in this report provides a good statistical foundation for achieving the objectives of the INL-2 Sample Collection Operational Test, despite some limitations of the experimental and sampling design (discussed in Section 6).

In general, it is recommended that statisticians be involved in planning and developing experimental and sampling designs, and conducting data analyses of future validation work as described in the Interagency Strategic Plan. ${ }^{\text {(a) }}$ Statistical involvement is critical to planning experimental studies and analyzing the data that result from them. Statistical involvement provides for using resources efficiently, accounting for testing and analytical uncertainties, and making conclusions with the desired statistical confidence. Statistical planning combined with proper statistical analysis of data leads to defensible conclusions that satisfy the research objectives.

(a) Interagency Strategic Plan for Validation of Environmental Sampling Methods Used in Detection and Cleanup of B. Anthracis Contamination in Facilities, June 29, 2007. 


\section{Acronyms}

BA Bacillus anthracis

BG Bacillus globigii, subsequently Bacillus subtilis var. niger (recently renamed Bacillus atrophaeus)

CDC Centers for Disease Control and Prevention

CFU Colony Forming Unit

CJR Combined judgmental and random (probabilistic)

DHS U. S. Department of Homeland Security

DoD U. S. Department of Defense

DOE U. S. Department of Energy

EPA Environmental Protection Agency

FBI Federal Bureau of Investigation

FNR False Negative Rate

GAO Government Accountability Office

HVAC Heating, Ventilation, and Air Conditioning

INL Idaho National Laboratory

JHU-APL Johns Hopkins University, Applied Physics Laboratory

JPEO-CBD Joint Program Executive Office for Chemical and Biological Defense

NIST National Institute of Standards and Technology

ORI Operational Readiness Inspection

PNNL Pacific Northwest National Laboratory

QC Quality Control

RMC Reference Material Coupon

RV-PCR Rapid Viability Polymerase Chain Reaction

S\&T Science and Technology Directorate

VSP Visual Sample Plan (software)

VSPWG Validated Sampling Plan Working Group 


\section{Acknowledgments}

The Pacific Northwest National Laboratory (PNNL) work summarized in this report was funded by the Standards Office of the Test and Evaluation/Standards Division in the Science and Technology Directorate (S\&T) of the U.S. Department of Homeland Security (DHS). The interest of Bert Coursey (Standards Portfolio Executive) in the experimental sampling design capabilities of the Statistics and Sensor Analytics group at PNNL (which led to this work) is gratefully acknowledged. We also acknowledge Tod Companion (DHS) for his efforts in getting the contract and funding in place.

Although there were many contributions by several members of the Validated Sampling Plan Working Group (VSPWG), there were a few who contributed directly to the necessary inputs and direction of this work. The authors would like to specifically thank the following: Dino Mattorano (Environmental Protection Agency) for his willingness to share his judgmental sampling expertise and to provide the necessary inputs related to sampling; Ken Martinez [National Institute for Occupational Safety and Health, Centers for Disease Control and Prevention (NIOSH/CDC)] for his sampling expertise and direction in clearance sampling; Michael Walter [Joint Program Executive Office for Chemical and Biological Defense (JPEO-CBD)] for his guidance and inputs during initial planning as well as throughout the work; Kristin Korté (JPEO-CBD) and Eric Van Gieson [Johns Hopkins University, Applied Physics Laboratory (JHU-APL)] for key inputs to the experimental and sampling design; and Randy Long (DHS) for his leadership of the VSPWG and general guidance on this work.

The authors acknowledge and thank the following PNNL staff members: 1) Landon Sego for discussions about the capabilities and statistical basis for the CJR approach to clearance sampling in the Visual Sample Plan software (Matzke et al. 2007) and for reviewing and providing comments on the draft report and 2) Wayne Cosby for editing, formatting, and preparing the report for publication. 


\section{Contents}

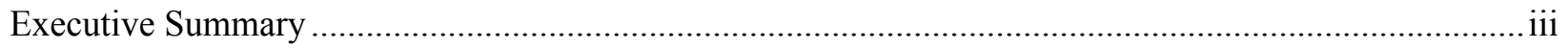

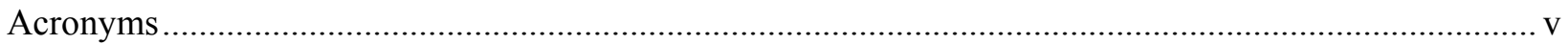

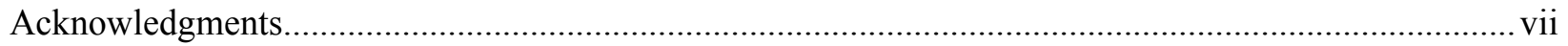

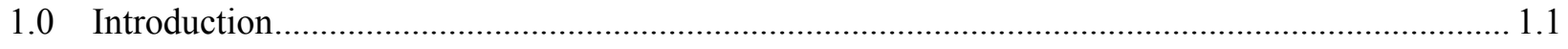

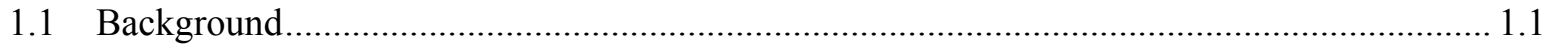

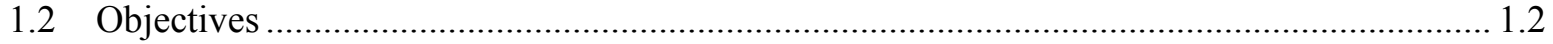

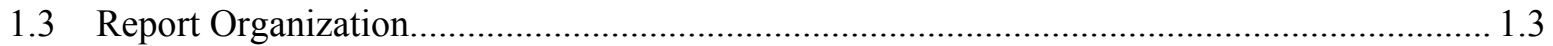

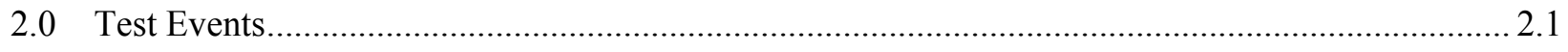

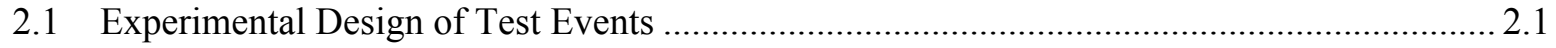

2.2 Amounts of Contaminant Released and Resulting Gradients............................................. 2.1

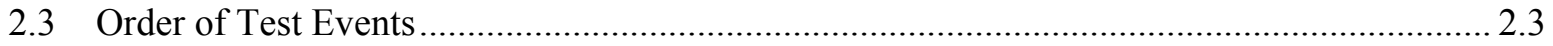

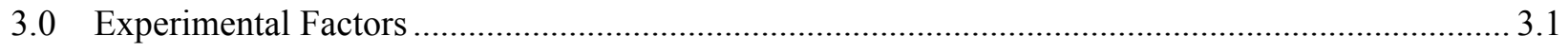

3.1 Factors Controlled During the Experiment..................................................................... 3.1

3.2 Factors Not Controlled but Measured or Recorded .............................................................. 3.3

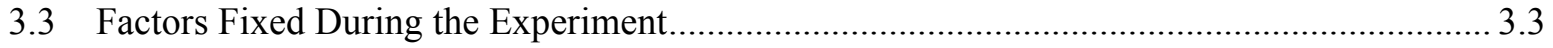

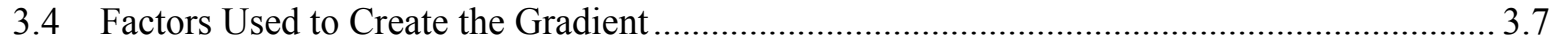

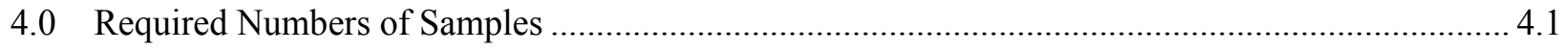

4.1 Characterization of Contamination in a Possibly Contaminated Area .................................. 4.1

4.2 Clearance of a Non-Contaminated or Decontaminated Area ................................................ 4.4

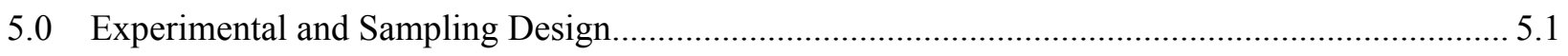

5.1 Guidance for Characterization and Clearance Sampling Designs ...................................... 5.1

5.1.1 Guidelines on the Maximum Numbers of Samples for Characterization and

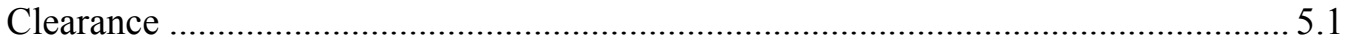

5.1.2 Limited Investigation of Composite Sampling ............................................................ 5.2

5.2 Rationales for Characterization and Clearance Sampling ….............................................. 5.3

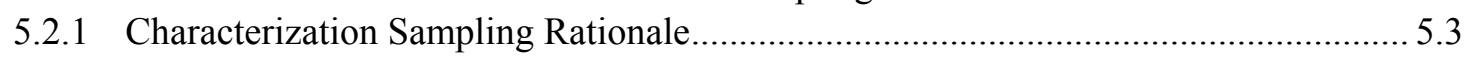

5.2.2 Clearance Sampling Rationale ……................................................................... 5.3

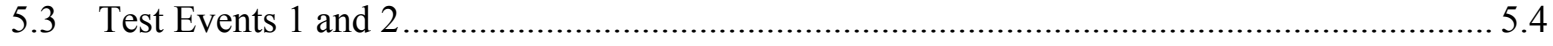

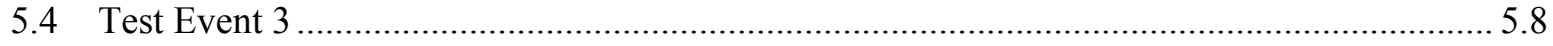

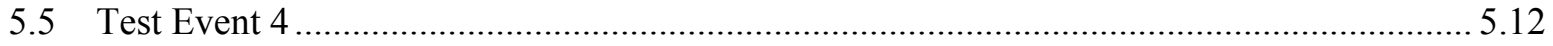

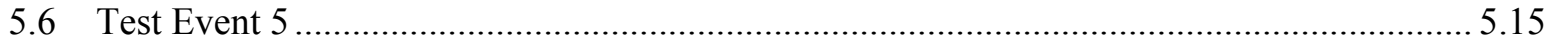

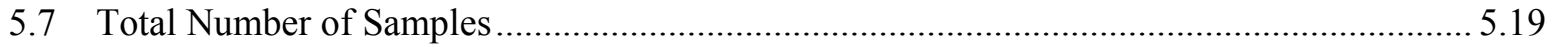


5.8 Experimental and Sampling Design Details

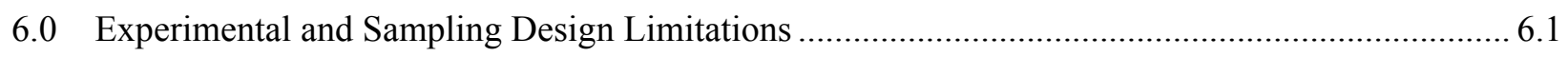

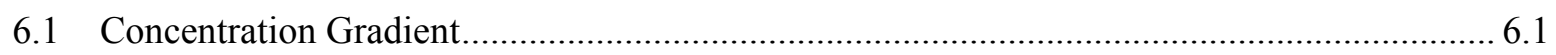

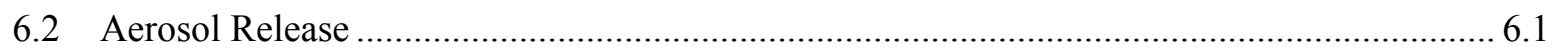

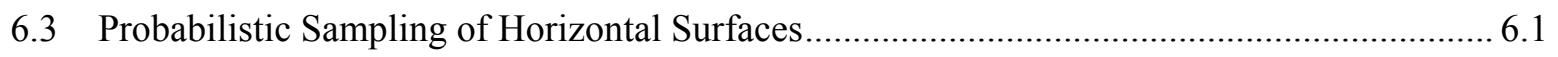

6.4 Limited Knowledge of Information Required to Calculate Numbers of Samples.................. 6.2

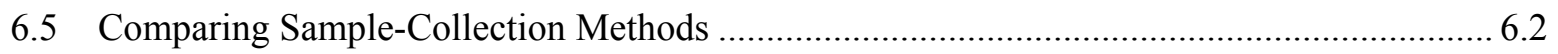

6.6 Comparing Judgmental and Probabilistic Samples to RMC Samples ................................... 6.2

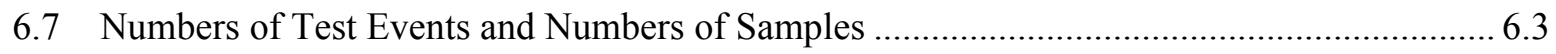

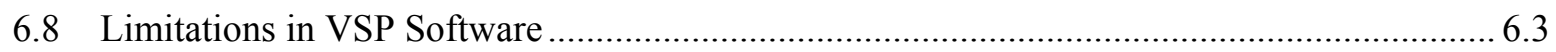

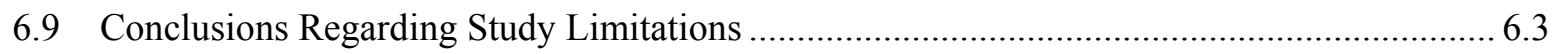

7.0 Summary and Recommendations for Any Future Studies ........................................................ 7.1

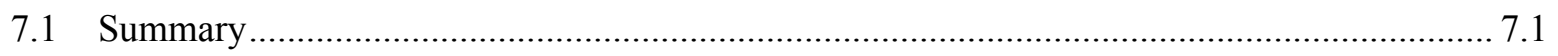

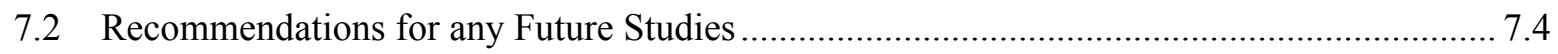

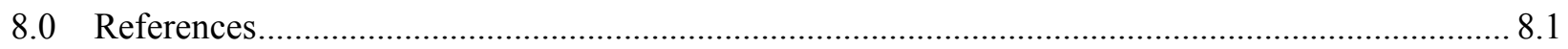

Appendix A: Numbers of Probabilistic Samples ........................................................................... A.1

Appendix B: Details to be Included in the Eventual Complete Test Matrix............................................1

Appendix C: Breakdowns of Numbers and Types of Samples for Characterization and Clearance

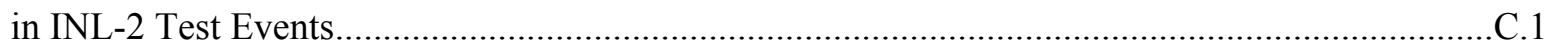

Appendix D: Coordinates and Sample Types for Probabilistic Sample Locations................................ D.1 


\section{Figures}

3.1. Furniture Configuration for the First Floor of the INL PGF-632 Building .................................... 3.4

3.2. Furniture Configuration for the Second Floor of the INL PGF-632 Building ............................... 3.5

4.1. Number of Probabilistic Samples Required to Detect with 95\% Confidence a Circular Contaminated Area of a Given Diameter (represented by the colored lines) within a Typical Room of the INL PBF-632 Building....

4.2. Number of Probabilistic Samples Required to Detect with $95 \%$ Confidence a Circular Contaminated Area of a Given Diameter (represented by the colored lines) within a Single Floor of the INL PBF-632 Building.

4.3. Number of Negative Probabilistic Samples Required to be $95 \%$ Confident that $95 \%$ or $99 \%$ of Two Rooms in the INL PBF-632 Building Do Not Contain Detectable Contamination Given Various Numbers of Negative Judgmental Samples....

4.4. Number of Negative Probabilistic Samples Required to be $99 \%$ Confident that at Least 97\% of a Typical Floor in the INL PBF-632 Building Does Not Contain Detectable Contamination Given Various Numbers of Negative Judgmental Samples ....

4.5. Number of Probabilistic Samples Required to Determine if a Given Percentage of Two Typical Rooms in the INL PBF-632 Building Does Not Contain Detectable Contamination (x-axis) with a Given Level of Confidence (color lines).

4.6. Number of Probabilistic Samples Required to Determine if a Given Percentage of a Typical Floor in the INL PBF-632 Building Does Not Contain Detectable Contamination (x-axis) with a Given Level of Confidence (color lines)

5.1. Map of Probabilistic Sample Locations and Types for Characterization Sampling of the First Floor of the INL Building During INL-2 Test Events 1 and 2

5.2. Map of Probabilistic Sample Locations and Types for Clearance Sampling of the First Floor of the INL Building During INL-2 Test Events 1, 2, and 4.

5.3. Map of Probabilistic Sample Locations and Types for Characterization Sampling of the Second Floor of the INL Building During INL-2 Test Event 3

5.4. Map of Probabilistic Sample Locations and Types for Clearance Sampling of the Second Floor of the INL Building During INL-2 Test Events 3 and 5

5.5. Map of Probabilistic Sample Locations and Types for Characterization Sampling of the First Floor of the INL Building During INL-2 Test Event 4.

5.6. Map of Probabilistic Sample Locations and Types for Characterization Sampling of the Second Floor of the INL Building During INL-2 Test Event 5 


\section{Tables}

2.1. Test Events of the INL-2 Experimental Design for Contamination-Decontamination Testing of the INL PBF-632 Building.

3.1. Experimental Factors in the INL-2 Experimental Design for Contamination-Decontamination Testing of the INL PBF-632 Building

4.1. Statistical Statements Given the Number of Probabilistic Samples Per Room and Per Floor for Characterizing the INL PBF-632 Building ......

4.2. Statistical Statements Given the Number of Probabilistic and Judgmental Samples for Clearance of a Decontaminated or Non-Contaminated Area in the INL PBF-632 Building.....

5.1. Numbers of Samples for INL-2 Test Events 1 and 2 on the First Floor of the INL PBF-632 Building

5.2. Numbers of Samples for INL-2 Test Event 3 on the Second Floor of the INL PBF-632 Building

5.3. Numbers of Samples for INL-2 Test Event 4 on the First Floor of the INL PBF-632 Building. This event involves an overt release from Office 101A.

5.4. Numbers of Samples for INL-2 Test Event 5 on the Second Floor of the INL PBF-632 Building

5.5. Summary of the Numbers of Samples Needed for All INL-2 Test Events in the PBF-632 Building 


\subsection{Introduction}

This report describes the final experimental and sampling design for a contamination and decontamination exercise conducted in an unoccupied building at the Idaho National Laboratory (INL). The experimental and sampling design consists of the scenarios for five test events, as well as the numbers of quality control (QC), reference material coupon (RMC), judgmental, and probabilistic samples for characterization and clearance sampling in each test event.

The experimental and sampling design was developed by staff in the Statistics and Sensor Analytics group at Pacific Northwest National Laboratory (PNNL). The specific contributors are listed as authors of this report. Members of the Validated Sampling Plan Working Group (VSPWG) provided guidance and input needed to develop the experimental and sampling design. Specific individuals who provided inputs or guidance are listed in the Acknowledgments.

The PNNL work was funded by the Standards Office of the Test and Evaluation/Standards Division in the Science and Technology Directorate (S\&T) of the U.S. Department of Homeland Security (DHS). The work was funded under the prime contract between the U.S. Department of Energy (DOE) and the operator of PNNL for research, testing, evaluation, and/or development activities and pursuant to Section 309(a)(1)(c) of the Homeland Security Act of 2002 (Public Law 107-296), which authorizes DHS to task the DOE national laboratories on a "work for others" basis.

\subsection{Background}

The experience with Bacillus anthracis (BA) contamination of the Hart Senate office building in Washington, DC and postal facilities that processed the mail containing BA demonstrated weaknesses in the procedures and methods used to characterize and clear buildings contaminated by BA. A congressional inquiry as well as the Government Accountability Office (GAO) identified two main weaknesses (GAO 2005a, 2005b). One weakness was the reliance on sampling specific areas in postal facilities where it was thought BA would be found. This type of sampling approach is referred to as targeted sampling or judgmental sampling. The GAO reports identified the need to use probabilistic sampling so that when all results are negative, a building (or area within a building) can be cleared with a known level of statistical confidence. The second main weakness was that the sample collection and analytical methods used were not validated, which raised questions about the reliability of the negative results from sampling the postal facilities.

The VSPWG was formed in July 2006 in response to the congressional inquiry and GAO reports. The VSPWG is headed by DHS S\&T and includes experts from the Department of Defense (DoD), the Environmental Protection Agency (EPA), the Centers for Disease Control and Prevention (CDC), National Institute of Standards and Technology (NIST), and the Federal Bureau of Investigation (FBI). The VSPWG is working towards the overall validation of sampling plans, including 1) sampling approach (e.g., appropriate uses of judgmental and probabilistic sampling), 2) sample collection methods, 3) transportation of samples, 4) sample extraction methods (i.e., extraction of the contaminant from samples), and 5) sample analysis (i.e., analytical methods). 
An interagency testing effort led by the DoD, Joint Program Executive Office for Chemical and Biological Defense (JPEO-CBD) and DHS S\&T was planned to partially address some of these concerns. This testing effort will consist of a series of contamination, sampling and sample analysis, and decontamination events in an unoccupied two-story office building at INL facilities located outside of Idaho Falls, ID. The study is referred to as the INL-2 Sample Collection Operational Test. The INL-2 testing leverages work performed in 2006-2007 by the Applied Physics Laboratory at Johns Hopkins University (JHU-APL) for the JPEO-CBD to test sample-collection methods in a small-scale operational environment. ${ }^{(a)}$ The INL-2 study relied heavily on work and lessons learned in the INL-1 Sample Collection Operational Test performed in late 2007. ${ }^{(\mathrm{b})}$ In both the INL-1 and INL-2 studies, BG (Bacillus globigii, subsequently Bacillus subtilis var. niger, and recently renamed Bacillus atrophaeus) was used as a simulant contaminant for BA.

\subsection{Objectives}

The VSPWG developed five objectives for the INL-2 study, which are listed here verbatim.

- Operationally evaluate judgmental and probabilistic sampling for characterization, as well as evaluate and compare probabilistic and hybrid (judgmental and probabilistic) sampling approaches for clearance, in a building with gradient contamination (from low or moderate down to absent or not detectable) for different initial concentrations of the contaminant.

- Explore judgmental composite sampling approaches as a mechanism to reduce sample numbers but retain the robustness of coverage for characterization.

- Identify operational factors that affect the minimum detectable concentration observed for agreed sampling methods in the field compared to laboratory-validated performance data.

- Operationally compare an alternative analytical method for assessing contamination [Rapid Viability Polymerase Chain Reaction (RV-PCR)] and evaluate the utility of filter-plate and spiralplate culturing methods.

- Collect baseline data to serve as an indication of the actual levels of simulant contamination in the tests.

The hybrid sampling approach is referred to as the combined judgmental and random (CJR) approach. The CJR approach uses Bayesian methodology to combine judgmental and random (probabilistic) samples. This approach provides for making clearance statements of the form " $\mathrm{X} \%$ confidence that at least $\mathrm{Y} \%$ of an area (or floor of the building) does not contain detectable contamination." These are referred to as $\mathrm{X} \% / \mathrm{Y} \%$ clearance statements ${ }^{(\mathrm{c})}$ in the rest of the report.

(a) Test and Evaluation of Surface Sampling Approaches Before and After Small-Scale Fumigation-Based Decontamination Events, NSTD-07-0592 (July 10, 2007 draft), John Hopkins University-Applied Physics Laboratory.

(b ) September 2007: Indoor Field Evaluation of Sample Collection Methods and Strategies at Idaho National Laboratory, May 2008 (For Official Use Only).

(c) $\mathrm{The} \mathrm{X} \% / \mathrm{Y} \%$ clearance statements of the CJR method are based on the posterior predictive distribution from a modification of the Beta-Binomial Bayesian model (see Gelman et al. 2003). The X\%/Y\% clearance statements can also be made using only probabilistic samples with continuous-variable responses based on the statistical theory for X\%/Y\% tolerance intervals (see Hahn and Meeker 1991). 


\subsection{Report Organization}

The remainder of this report describes the experimental and sampling design of the INL-2 Sample Collection Operational Test and the basis for its development. The report is organized as follows. The five test events that form the main structure for the experimental design are discussed in Section 2. The experimental factors that will be varied or held fixed (constant) in the experimental design are discussed in Section 3. The methods used to determine the numbers of samples required to make statistical detection or clearance statements are presented in Section 4. The experimental and sampling design and the basis for its development are presented in Section 5. The limitations of the experimental and sampling design for the INL-2 Sample Collection Operational Test are discussed in Section 6. The conclusions for the work and recommendations for any future studies are presented in Section 7. The references cited in describing the experimental and sampling design, and the methods used to generate it, are listed in Section 8 . 


\subsection{Test Events}

The test events were designed based on the dissemination characteristics of the BG contaminant, a simulant for BA, rather than basing the design on specific terrorist event scenarios. Many contamination motivations or "background stories" could be described to fit the proposed test events. The test-event characteristics include contaminant concentration, point of dissemination, type of dissemination (only aerosol releases will be performed during the INL-2 Sample Collection Operational Test), and knowledge of the point of dissemination.

Section 2.1 briefly introduces the five test events comprising the experimental design for the INL-2 study. Section 2.2 provides some discussion and guidelines regarding the goal of achieving desirable gradients of contamination concentrations over the test events. Section 2.3 discusses the order of performing the test events.

\subsection{Experimental Design of Test Events}

The experimental design developed for the INL-2 Sample Collection Operational Test includes five test events, the first of which is an Operational Readiness Inspection (ORI). Table 2.1 shows the contamination characteristics for each of the proposed test events. The purpose of the ORI is to provide a complete run that can be used to make any necessary adjustments before the remaining four test events. If the ORI run is completed without any issues, it is possible that its data will be analyzed along with the data from the other four test events. The five test events will each consist of

1. a separate contamination on one of the two floors of the INL building, ${ }^{(a)}$

2. sampling in selected rooms or the complete floor,

3. decontamination, and

4. sampling of the complete floor to determine clearance.

Test Event 1 (the ORI) as well as Test Events 2 and 3 are planned as covert releases in which the response team will not know the room location of the single-source aerosol dissemination. They will only know the floor of the release (first floor for Test Events 1 and 2, second floor for Test Event 3). Test Events 4 and 5 are planned as overt releases in which the response team will know the contaminant release location. In Test Event 4, the release will be in Room 101A on the first floor. In Test Event 5, the release will be in Room 201A on the second floor. The covert test events $(1,2$, and 3) make it possible to assess the relative performance of the sampling approaches under different conditions than the overt test events (4 and 5).

\subsection{Amounts of Contaminant Released and Resulting Gradients}

The five test events in the INL-2 experimental design are intended to provide desirable concentration gradients of contamination across each floor of the building. This will provide a range of contamination conditions (from moderate to low contamination, down to no [or undetectable] contamination). A range

(a) It is assumed that the first and second floors of the INL building will be "sealed" to prevent crosscontamination. Lessons learned from the INL-1 study should enable "sealing" the two floors. 
of contamination conditions will challenge the sampling approaches (judgmental, probabilistic, and CJR) as well as the sampling and analytical methods.

Table 2.1. Test Events of the INL-2 Experimental Design for Contamination-Decontamination Testing of the INL PBF-632 Building

\begin{tabular}{|c|c|c|c|c|c|}
\hline \multirow[b]{2}{*}{$\begin{array}{l}\text { Test } \\
\text { Event }\end{array}$} & \multicolumn{5}{|c|}{ Release } \\
\hline & $\begin{array}{c}\text { Contamination } \\
\text { Scenario }\end{array}$ & $\begin{array}{l}\text { Bldg. } \\
\text { Floor }\end{array}$ & $\begin{array}{c}\text { Building } \\
\text { Room }\end{array}$ & $\begin{array}{l}\text { Offices } \\
\text { Sealed }^{(c)}\end{array}$ & $\begin{array}{c}\text { Initial } \\
\text { Amount }^{(\mathrm{d})}\end{array}$ \\
\hline $1(\mathrm{ORI})^{(\mathrm{a})}$ & Covert Gradient & 1 & Covert $^{(\mathrm{b})}$ & Covert & $\mathrm{A} 1$ \\
\hline 2 & Covert Gradient & 1 & Covert $^{(\mathrm{b})}$ & Covert & $\mathrm{A} 2$ \\
\hline 3 & Covert Gradient & 2 & Covert $^{(\mathrm{b})}$ & Covert & A3 \\
\hline 4 & Overt Gradient & 1 & $101 \mathrm{~A}^{(\mathrm{e})}$ & $105 \& 107$ & A4 \\
\hline 5 & Overt Gradient & 2 & $201 \mathrm{~A}^{(\mathrm{e})}$ & $205-208$ & A5 \\
\hline
\end{tabular}

(a) ORI = Operational Readiness Inspection.

(b) Release location has not yet been selected and thus was unknown in choosing the sampling design (both judgmental and probabilistic samples). The release location will also be unknown to the sampling teams.

(c) The indicated offices should have their doors closed and sealed, and any vents in the rooms covered and sealed before the contaminant release. These measures are intended to provide rooms that have no or undetectable contamination. See Section 4 for more discussion.

(d) The initial amounts of contaminant released will be assessed and adjusted for Test Events 2 to 5 based on results of previous test events.

(e) These release locations were chosen based on tracer pre-tests performed at the INL PBF-632 building, which showed that releases from these rooms would give desirable gradients under the pre-test conditions.

An important factor affecting the contamination gradient obtained is the amount of contaminant that is released. Too high of an amount may result in easy detection of contamination in every room on a floor. Too low of an amount may result in too many rooms on a floor being lightly contaminated or not contaminated at all.

At least one test event should have a gradient with contaminant concentrations ranging from moderate to no/undetectable contamination. This gradient should include rooms with low concentrations (between moderate and no/undetectable contamination) that have low false negative rates (FNRs) ${ }^{(a)}$ (e.g., 10\%). At least one other test event should have a gradient resulting from a lower amount released so that rooms have concentrations ranging from low to no/undetectable contamination, including very low concentrations that have higher FNRs (e.g., 30 to 50\%). Test events with at least one each of these types of contamination gradient would provide an excellent basis for assessing the performance of sampling approaches (judgmental, probabilistic, and CJR), sampling methods, sample extraction methods, and analytical methods.

(a) The FNRs are assumed to include false negatives resulting from failure to detect contamination due to sampling method and extraction recovery inefficiencies, sample transportation/aging issues, and analytical uncertainties. 
Tracer studies in the INL PBF-632 building were completed to aid in selecting the initial contaminant amount and the rooms in which the contaminant will be released. The results are discussed subsequently at the points where they were factored into the experimental and sampling design. The ORI (Test Event 1) will also be used to determine the contaminant amount and dissemination factors necessary to create the desired gradients. Dissemination factors may include 1) time from dissemination until response, 2) heating, ventilation, and air conditioning (HVAC) being on or off, and 3) the contaminant release location. The experimental design allows for adjustments to be made to the contaminant amount (Table 2.1) or to dissemination factors after each event, based on what is learned from previous events.

\subsection{Order of Test Events}

The order of test events shown in Table 2.1 is proposed for use during the INL-2 Sample Collection Operational Test. This order will allow using the results of Test Events 1 to 3 to choose the amounts of contaminant to release in Test Events 4 and 5 so as to obtain concentration gradients ranging from moderate to uncontaminated and low to uncontaminated. The sampling designs for the overt events (Test Events 4 and 5) include sampling rooms with a clearance objective during the characterization phase, as discussed subsequently. Hence, it is important for Test Events 4 and 5 to choose the amount of contaminant released and take other measures (such as closing/sealing doors and sealing vents in rooms selected for clearance) to maximize the chance of having the specified rooms be uncontaminated or have undetectable contamination. It would be possible to intersperse the two overt test events among the covert test events, but then this would not allow using the information from previous covert test events to select the "best" amount of contaminant to release to achieve the desired gradients for the objectives of the overt test events. One such objective is to demonstrate the ability to clear an uncontaminated area of a building during the characterization phase of sampling. 


\subsection{Experimental Factors}

The experimental factors are the variables that will be varied or held constant during the experiment. The experiment is designed to determine whether changes to the levels (i.e., values or settings) of the factors that will be varied affect the detection (absence/presence) or the amount (number of colony forming units, CFUs) of the contaminant. One objective of the INL-2 Sample Collection Operational Test is to examine the relative performance of the sampling approaches (judgmental, probabilistic, CJR) when contamination is likely. Characteristics of the test events are allowed to vary so that the relative performance of the sampling approaches can be assessed over a range of conditions. Other factors not varied in the test events should ideally be held as constant as possible.

After contamination, QC, RMC, judgmental, and probabilistic sampling will occur in each room or floor where sampling is planned. In rooms that are expected to have higher contamination (in the overt test events), fewer judgmental and probabilistic samples will be taken. Up to five judgmental samples per room will be taken in rooms where contamination is probable, based on input from experienced samplers concerning rooms of the size in the INL PBF-632 building.

It is of interest to compare the CJR and probabilistic sampling approaches "after decontamination," as well as "after contamination" in rooms that may not be contaminated because of the building airflow patterns and specifics of given test events. The CJR sampling approach, which combines judgmental and probabilistic (random) samples, is an option available in Visual Sampling Plan 5.0 (VSP) software (Matzke et al. 2007). The CJR sampling approach allows for an $\mathrm{X} \% / Y \%$ clearance statement to be made that would be stronger than the clearance statement that could be made from probabilistic sampling alone. This comparison will focus on the advantages of adding judgmental samples to probabilistic samples.

To best study the sampling approaches, the experimental factors should be identified and their roles in the experiment defined as well as possible. Table 3.1 lists the experimental factors and places them into one of four categories (factors controlled during the experiment, factors not controlled but measured, factors fixed during the experiment, and factors used to create the gradient). The Table 3.1 entries in each of these four categories are discussed in Sections 3.1 to 3.4.

\subsection{Factors Controlled During the Experiment}

The main factors that are varied in the experimental design are 1) the sampling approach (judgmental, probabilistic, and CJR), 2) the floor of the INL PBF-632 building on which the testing will occur, and 3 ) the type of sampling (covert or overt). Another factor that is varied in the experimental design is the sample area (size). For the majority of samples, the sample area will be constant as specified in the procedure for each sampling method (wipe, swab, vacuum). However, selected judgmental samples will be collected in a "composite" fashion in which larger areas or areas in different locations are sampled. For example, a composite wipe sample could involve wiping the standard area in two or three locations. Other factors that will be controlled during the experiment (which are related to creating a concentration gradient of the contaminant) are discussed in Section 3.4. 
Table 3.1. Experimental Factors in the INL-2 Experimental Design for Contamination-Decontamination Testing of the INL PBF-632 Building

\begin{tabular}{|c|c|c|c|}
\hline $\begin{array}{l}\text { Factors Controlled } \\
\text { During the Experiment }\end{array}$ & $\begin{array}{c}\text { Factors Not } \\
\text { Controlled, but } \\
\text { Measured/Recorded }\end{array}$ & $\begin{array}{c}\text { Factors Fixed During } \\
\text { the Experiment }\end{array}$ & $\begin{array}{c}\text { Factors Used to Create } \\
\text { the Gradient }\end{array}$ \\
\hline $\begin{array}{l}\text { - Sampling approach } \\
\text { - Floor of the building } \\
\text { - Type of sampling } \\
\text { (covert or overt) } \\
\text { - Sampling team } \\
\text { collecting samples } \\
\text { - Fixed-area (size) and } \\
\text { composite samples } \\
\text { - Order samples are } \\
\text { collected in a room }\end{array}$ & $\begin{array}{ll}\text { - } & \text { Temperature } \\
\text { - } & \text { Humidity } \\
\text { - } & \text { Furniture } \\
\text { configuration }\end{array}$ & $\begin{array}{l}\text { - } \begin{array}{l}\text { Contaminant release } \\
\text { method (aerosol) }\end{array} \\
\text { - Sample collection } \\
\text { method for a given } \\
\text { sampling surface } \\
\text { - Sample area (size) } \\
\text { - Sample analytical } \\
\text { method } \\
\text { - Decontamination } \\
\text { method }\end{array}$ & $\begin{array}{l}\text { - } \begin{array}{l}\text { Contaminant } \\
\text { concentration }\end{array} \\
\text { - Length of HVAC } \\
\text { operation after } \\
\text { contaminant release } \\
\text { - Location of } \\
\text { contaminant release } \\
\text { - Sealing of doors } \\
\text { and/or vents }\end{array}$ \\
\hline
\end{tabular}

Another factor that must be controlled is the sampling team. It is important that the judgmental samples are not collected by one sampling team while the probabilistic samples are collected by another sampling team. The same is true for QC and RMC samples. The location of each QC, RMC, judgmental, and probabilistic sample in each of the pre-determined rooms or floors should be selected and included in a test matrix (see Appendix B) to aid the sampling teams in collecting the samples. Only the sample locations should be given to the teams collecting the samples so that they would be "blind" as to whether any given sample is a judgmental or probabilistic sample. This would minimize any bias that could be caused by the teams collecting samples. The specific test matrix (see Appendix B) corresponding to the experimental and sampling design will need to identify the sampling team that is assigned to collect each sample. That way, the sampled rooms can be balanced across the number of sampling teams collecting samples so that any systematic or random differences between sample collectors are spread over the collected samples in a controlled manner. The sampler ID should be recorded with the data so that 1) any systematic or random differences in teams that collected the samples can be assessed and 2) it can be verified that such differences do not impact the comparisons of sampling approaches.

Finally, the order in which the sampling team should collect samples within each room must be controlled. Having the sampling team collect the judgmental samples first, the probabilistic samples next, and finally the RMC and QC samples (or any permutation of these) should be avoided. From a statistical standpoint, it would be ideal to collect all samples (QC, RMC, judgmental, and probabilistic) within a room in a random order. Doing so would protect against confounding the effects of any uncontrolled variables that may change over time with the effects of factors of interest (i.e., probabilistic versus judgmental sampling). However, it is recognized that randomizing the order of all QC, RMC, judgmental, and probabilistic samples in a room is not feasible because of time constraints and the need to minimize movement within a room that might redistribute or transfer contamination from one location to another. Thus, it is recommended that a "sampling path" be determined for each room that minimizes unnecessary movements within the room, but still allows for sufficient intermingling of the order in which QC, RMC, judgmental, and probabilistic samples are collected. All samples that will be taken in a 
room should be listed in the test matrix (see Appendix B) in the order they are to be collected so that this factor is controlled.

\subsection{Factors Not Controlled but Measured or Recorded}

Temperature and humidity should remain constant during the sampling as much as possible. The temperature and humidity should be recorded at selected locations on each floor of the building a few times a day during every day of testing.

One consistent furniture configuration should be used in each room if possible. This could possibly be a chair and desk with a monitor placed on the desk. The chair should be out from under the desk so that the BG contaminant can settle on its whole surface. If there is room, a table, a filing cabinet, or other furniture should also be placed in each room. This would increase the chance that probabilistic samples would select sampling positions with non-porous surfaces. Otherwise, the majority of probabilistic samples may be dominated by vacuum samples of the floors (which are mostly carpeted in the INL PBF632 building). If it is not possible to use a single furniture configuration in every room, the number of configurations should be limited to two. In that case, the furniture configuration would need to become a controlled factor (the first column of Table 3.1, as discussed in Section 3.1). The two configurations would need to be assigned so as not to confound the effects of this factor with other factors of interest (e.g., the contamination gradient).

The furniture configurations planned for use in each office on the first and second floors of the INL PBF-632 building are shown in Figure 3.1 and Figure 3.2, respectively. The furniture configuration changes from office to office, depending mainly on the size and layout of each office. It is not clear to what extent different furniture configurations may affect the dissemination of contaminant within an office or to what effect it may affect results of data analyses after INL-2 is completed.

\subsection{Factors Fixed During the Experiment}

Table 3.1 identifies certain factors that will either be held fixed (constant) during the experiment or determined by other factors. These are discussed in the following paragraphs.

The contaminant-release method will be the same for all test events, namely, an aerosol release from a single point (location) on a floor of the INL building. Other contaminant-release methods were discussed and even proposed in early drafts of the experimental design. One such release method was to contaminate only smaller areas (so-called "hot spots") of varying size in selected rooms, which would pose a much different situation for comparing judgmental and probabilistic samples (see Section 6.1 for more discussion of this). However, it was decided for this real-world contamination exercise to limit the contaminant-release method to an aerosol release from a single location (point release). 


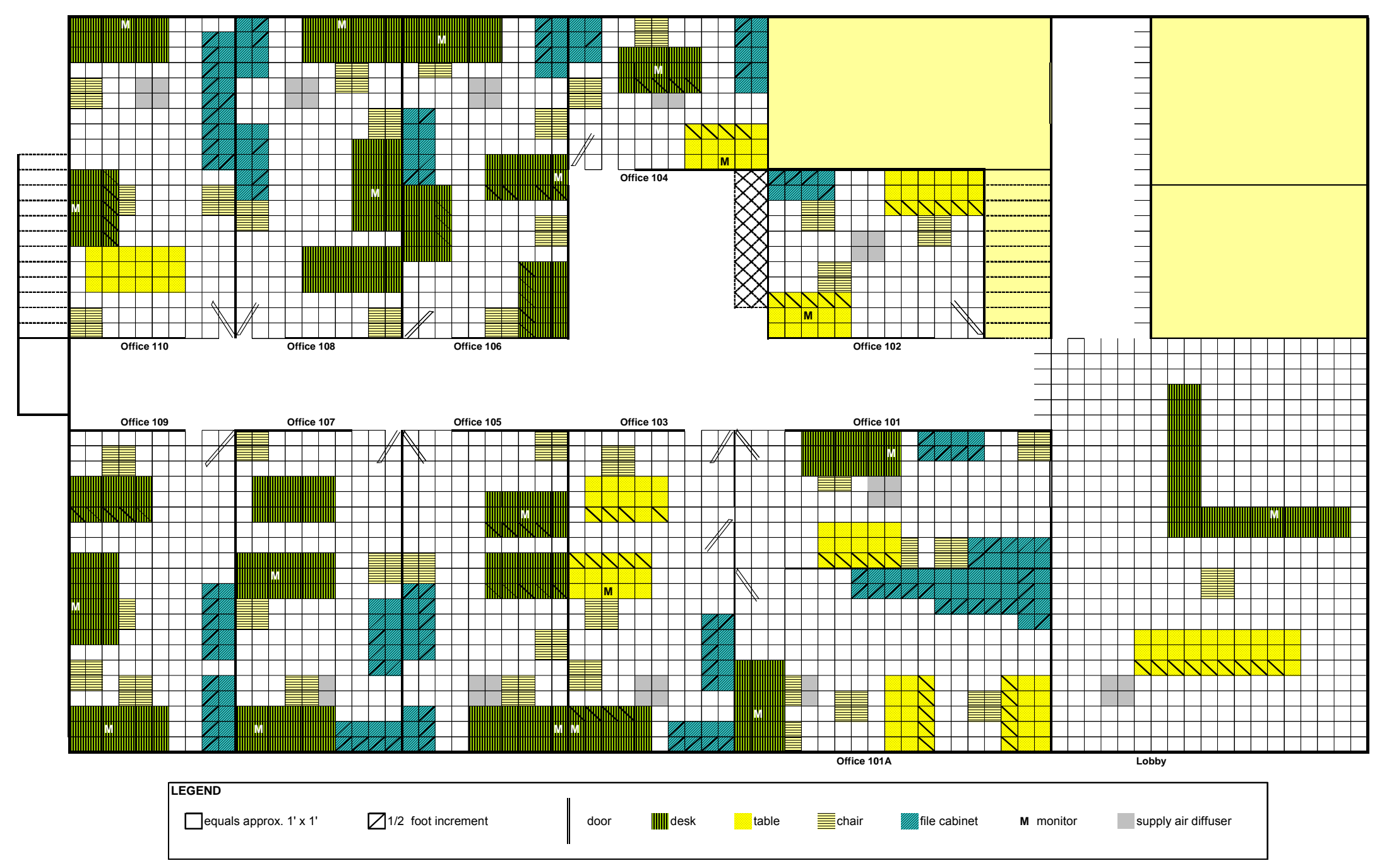

Figure 3.1. Furniture Configuration for the First Floor of the INL PGF-632 Building 


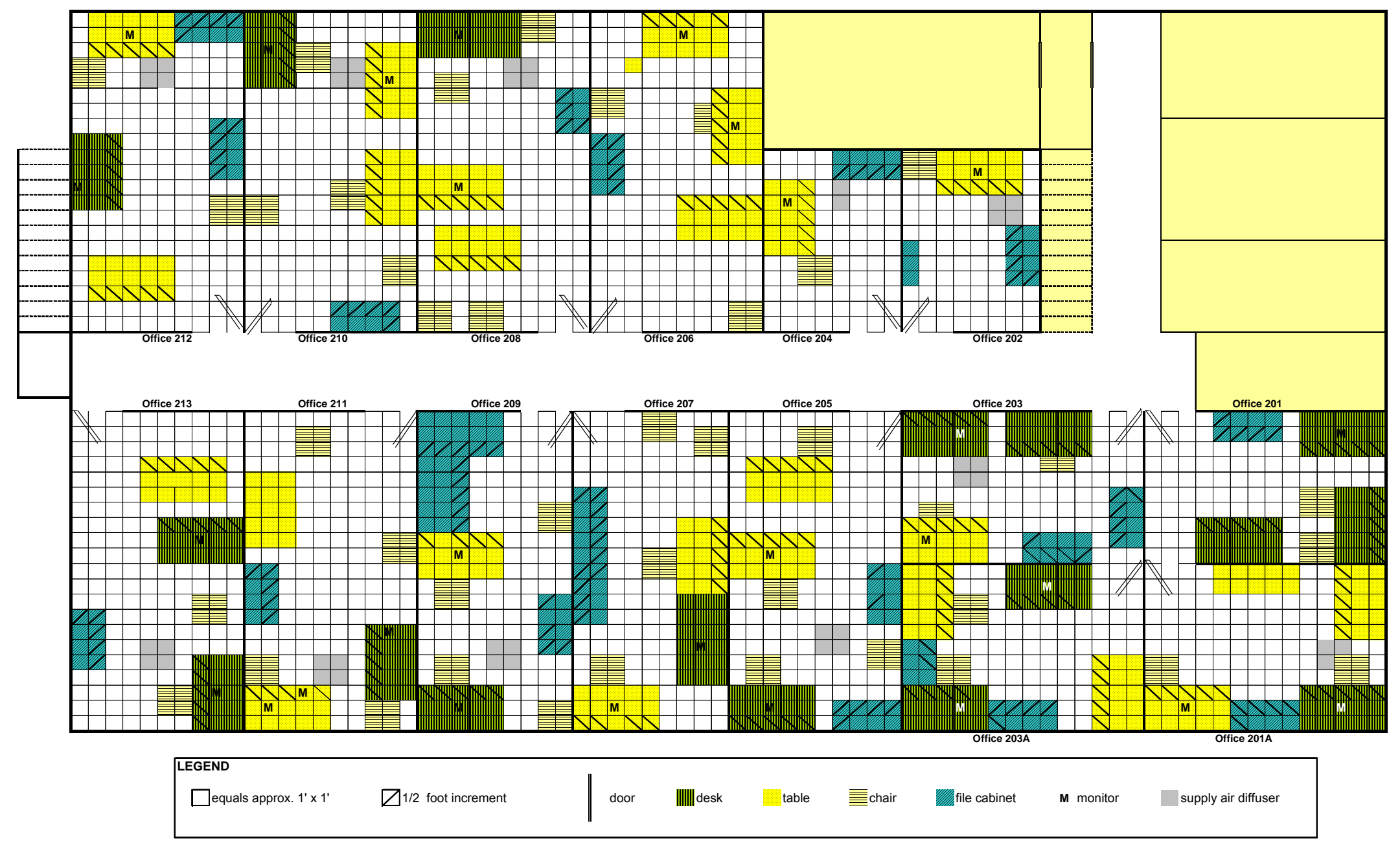

Figure 3.2. Furniture Configuration for the Second Floor of the INL PGF-632 Building 
The sample-collection method (swab, wipe, or vacuum) will be chosen according to the sampling surface that corresponds to each location to be sampled. The appropriate collection method will be applied to the appropriate sampling surface. The test plan should define which collection method should be applied for each of the possible surfaces. The specific test matrix (see Appendix B) for each room should specify the method to be used for each sample (whether judgmental or probabilistic) according to the nature of the surface to be sampled. This will require selecting the locations of judgmental samples in advance so that the sampling method as well as sampling order (see Section 3.1) can be included in the specific test matrix for each room. However, if it is decided to have the sampling team select the locations of judgmental samples at the time they enter a room, there will need to be a system in place to document the specific locations where judgmental samples were collected. This approach would also require the sampling team to be responsible for selecting the intermingling of judgmental and probabilistic samples and documenting the order of sample collection. This latter approach, although possibly more realistic, is far more complicated for the sampling team and could impact the ability to compare judgmental and probabilistic samples.

For probabilistic sampling, it has been assumed that samples will be collected from horizontal surfaces only. Horizontal positions of probabilistic samples selected by the VSP software (Matzke et al. 2007) may allow for the choice of the sample location. For example, a horizontal position might correspond to the floor, a table, or a vent in the ceiling. The specific sample location for a given horizontal sample position will need to be determined and included in the specific test matrix (see Appendix B) for each room. VSP allows for sampling from all surfaces of a room instead of just horizontal surfaces, but that increases the surface area of each room and floor of the building. That in turn increases the number of samples needed to detect contamination or clear a decontaminated floor. However, sampling from horizontal surfaces is the typical practice for BA/BG contamination released as an aerosol. Hence, in constructing the experimental and sampling design for the INL-2 Sample Collection Operational Test, it was assumed that only horizontal surfaces would be sampled.

It is important to note that the size (or area) of each sample should be held constant (per the procedure for each sampling method), independent of whether it is a judgmental or probabilistic sample. If the sampling team determines that a larger area should be sampled with a given sampling method for judgmental samples, then multiple samples should be taken to sample the larger area (rather than collecting a single sample from the larger area). This restriction is removed for some judgmental samples that will be collected using a composite sampling approach.

Culture has been determined to be the only analytical method that will be applied to every sample. It is possible that a few RV-PCR analyses will be made, but it was decided that this would not be factored into the experimental and sampling design. Hence, the choice of samples to be analyzed by RV-PCR is not addressed in this document. It is also assumed that the extraction method will be fixed and performed according to a set procedure for each sampling method, regardless of whether a given sample-collection method is used to collect a judgmental or probabilistic sample. The extraction method also should not change over the gradient of contamination because changes in the extraction method could negate differences due to the contamination gradient.

It is expected that the decontamination method will be aggressive (i.e., the concentration of $\mathrm{ClO}_{2}$ gas will be sufficient to easily decontaminate contaminated areas). Because contamination will be occurring after all but the last decontamination, it is important to make sure that the decontamination is sufficient so 
that there is no residual contamination that could become an uncontrolled factor that affects testing results.

\subsection{Factors Used to Create the Gradient}

The location of contaminant release, the amount of contaminant released, and the HVAC system will be used to create a gradient of the contaminant across a floor of the INL building. Another factor that can be used to create a gradient is whether rooms are "sealed." This could involve anything from closing the door of a room, sealing around a door, or sealing vents in the room.

Modeling and pre-testing work should be used to determine the amount of time the HVAC should remain on after contaminant release to achieve the desired concentration gradient. If the desired concentration gradient is not achieved in Test Event 1 (the ORI), then adjustments could be made in subsequent test events to the amount of contaminant released while holding constant the post-release running time of the HVAC system. However, the amount of time the HVAC system is run after contaminant release, along with the contaminant amount and within-room location of the contaminant release ${ }^{(a)}$ could be used to improve or vary the concentration gradient.

(a) The room of the INL PBF-632 building floor in which the contaminant will be released is specified as part of each test event. However, if the location of the release within the specified room (e.g., proximity to return air vents) affects the dissemination, the location of release within a room could be modified. 


\subsection{Required Numbers of Samples}

The numbers of samples required to achieve desired statistical detection and clearance statements depends on the sampling goal. This goal is formulated using 1) information that is known about an event and 2) the objectives that must be achieved when responding to the event. In an area where contamination is expected, sampling is performed to confirm/detect that contamination is present. In an area that may not be contaminated initially or after decontamination, sampling can be performed to clear the area. The appropriate numbers of samples for the characterization and clearance situations are discussed in Sections 4.1 and 4.2. Individual room calculations are based on a typical room for the INL PBF-632 building (Room 108), while calculations for a single floor are based on the first floor (considering it as a "typical" floor). Calculations associated with clearing two rooms together are based on typical "full size" offices in INL PBF-632.

The calculations in this section for a single floor (represented by the first floor) of the INL PBF-632 building consider only the rooms that will be sampled as part of the INL-2 study. These include the Lobby and Offices 101,101A, 102, 103, 104, 105, 106, 107, 108, 109, and 110. The hallway is not included because it will be sampled separately per agreement with one of the sampling teams. Also, hallway samples would consist of only vacuum samples of carpet, and a better of balance of sample types was desired. Because resources were not sufficient to sample all rooms on a floor, it was decided not to sample the men's and women's restrooms and the mechanical room.

Section 4.1 discusses the methods used to calculate the number of samples needed to detect contamination in a possibly contaminated area. Section 4.2 discusses the methods used to calculate the number of samples needed to clear an uncontaminated or decontaminated area.

\subsection{Characterization of Contamination in a Possibly Contaminated Area}

There are many variables that affect the number of probabilistic samples that should be taken in a room or on a floor to detect contamination in a possibly contaminated area. These variables include the 1) percent confidence of detecting contamination, 2) size of the contaminated area (assumed in this case to be circular, quantified by its diameter $)^{(a)}$ one wishes to be able to detect with high confidence, and 3) FNR. ${ }^{(b)}$ More samples are required to have a higher confidence, detect a smaller diameter of

(a) Statistical formulas for calculating numbers of samples required to detect a contaminated area with specified confidence exist for circular or elliptical contamination shapes using square, rectangular, and triangular contamination shapes (Sego and Wilson 2007; Gilbert 1987, Chapter 10). The formula for a circular contaminated area is used most frequently in practice and thus was the basis for calculations used to develop the experimental design for the INL-2 study.

(b) The false-negative rate is specified as the percentage of times a contaminated sample is erroneously declared to be "uncontaminated." False negatives can occur because of inefficiencies in (1) recovery of the contaminant by sampling, (2) extraction of the contaminant from samples, (3) sample transportation or aging issues, and (4) the analytical method. However, if the concentration of contaminant is high enough, the FNR can be zero (or near zero) despite sampling-recovery inefficiencies, extraction inefficiencies, sample transportation/aging issues, and analytical uncertainties. 
contamination, or when the FNR is higher. Given that the INL-2 study will have smaller amounts of contaminant released than the INL-1 study, it is not clear what sizes of contaminated areas may result. Similarly, there is not much information on the expected FNR. For this reason, the numbers of samples were calculated for confidence levels ranging from $50 \%$ to $95 \%$, contaminated areas ranging from 1 foot to 10 feet in diameter, and FNRs ranging from $0 \%$ to $50 \%$. Sample sizes were calculated using triangular grid patterns where samples are spread out in a relatively uniform manner. This implies that no two samples are bunched together, and there is no large unsampled portion of the room or floor (Gilbert et al. 2002, Matzke et al. 2007). Results of these calculations are provided in subsequent figures and tables for 95\% confidence. The results for the smaller diameters of contaminated areas are not presented because they correspond to unrealistically large numbers of samples. Appendix A contains additional figures displaying the numbers of samples calculated. These figures display realistic numbers of samples for all combinations of contaminated areas (from 1 foot to 10 feet in diameter), FNRs ( $0 \%$ to $50 \%$ ), and confidence $(50 \%, 75 \%, 90 \%$, and $95 \%$ ) for a typical room and for a single floor.

Figure 4.1 summarizes the calculations for the number of probabilistic samples required to sample a typical room and detect contamination with $95 \%$ confidence when the diameter of a circular, contaminated area and the FNR are varied. This plot shows that 20 samples provide $95 \%$ confidence for detecting a circular, contaminated area of 6 feet in diameter with an FNR of 30\%. If a smaller FNR of about $15 \%$ is assumed, then 20 samples are required to achieve $95 \%$ confidence for detecting a circular, contaminated area with a 5-foot diameter.

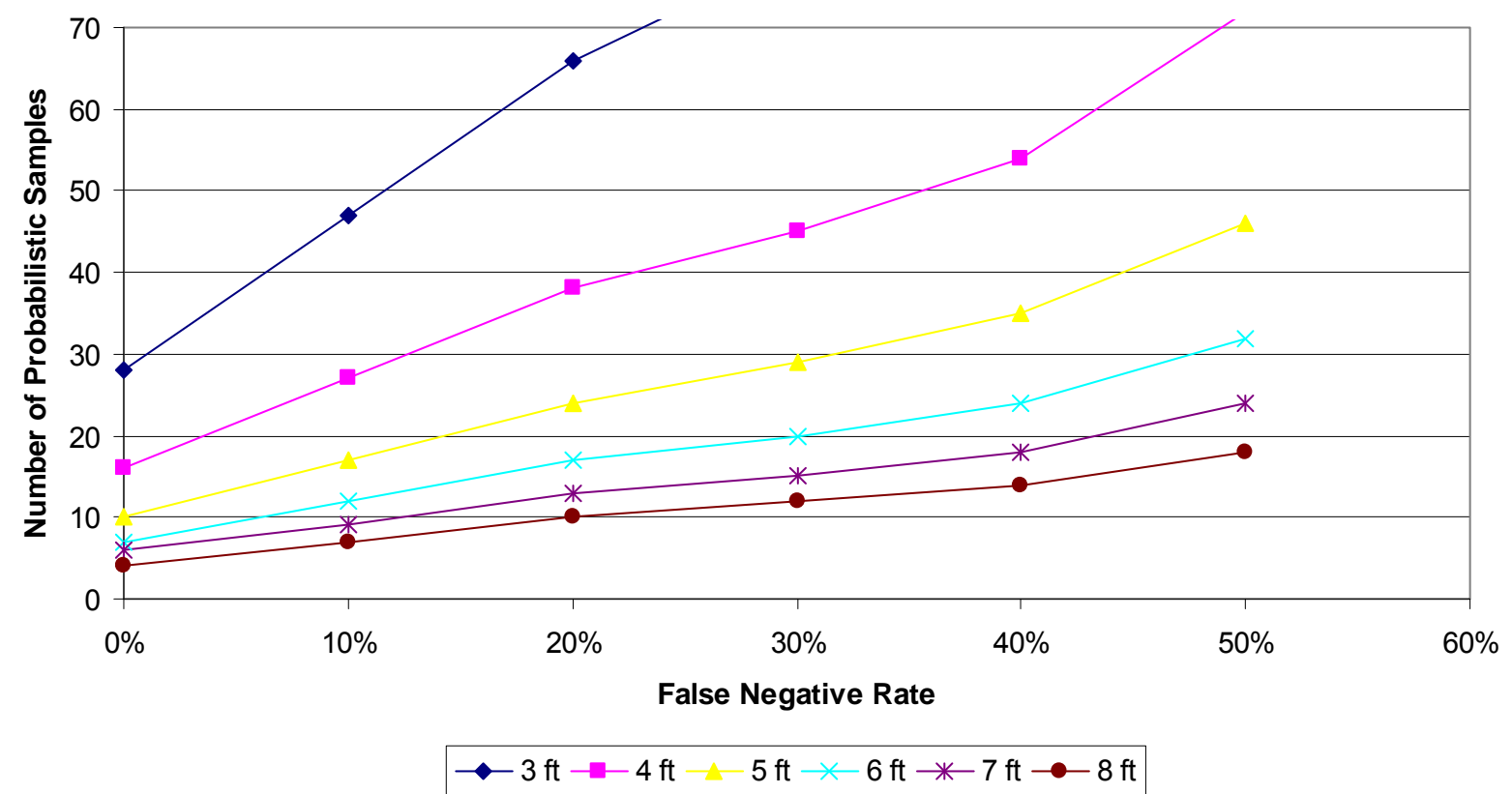

Figure 4.1. Number of Probabilistic Samples Required to Detect with 95\% Confidence a Circular Contaminated Area of a Given Diameter (represented by the colored lines) within a Typical Room of the INL PBF-632 Building

Figure 4.2 summarizes these calculations for the number of samples required to sample a single floor and detect contamination with $95 \%$ confidence when the contamination diameter and the FNR are varied. This plot shows that 200 samples provide $95 \%$ confidence for detecting a 7 -foot contamination diameter 
with an FNR of about $28 \%$. If a smaller FNR of about $15 \%$ is assumed, then 200 samples are required to achieve $95 \%$ confidence for detecting a 6 -foot contamination diameter.

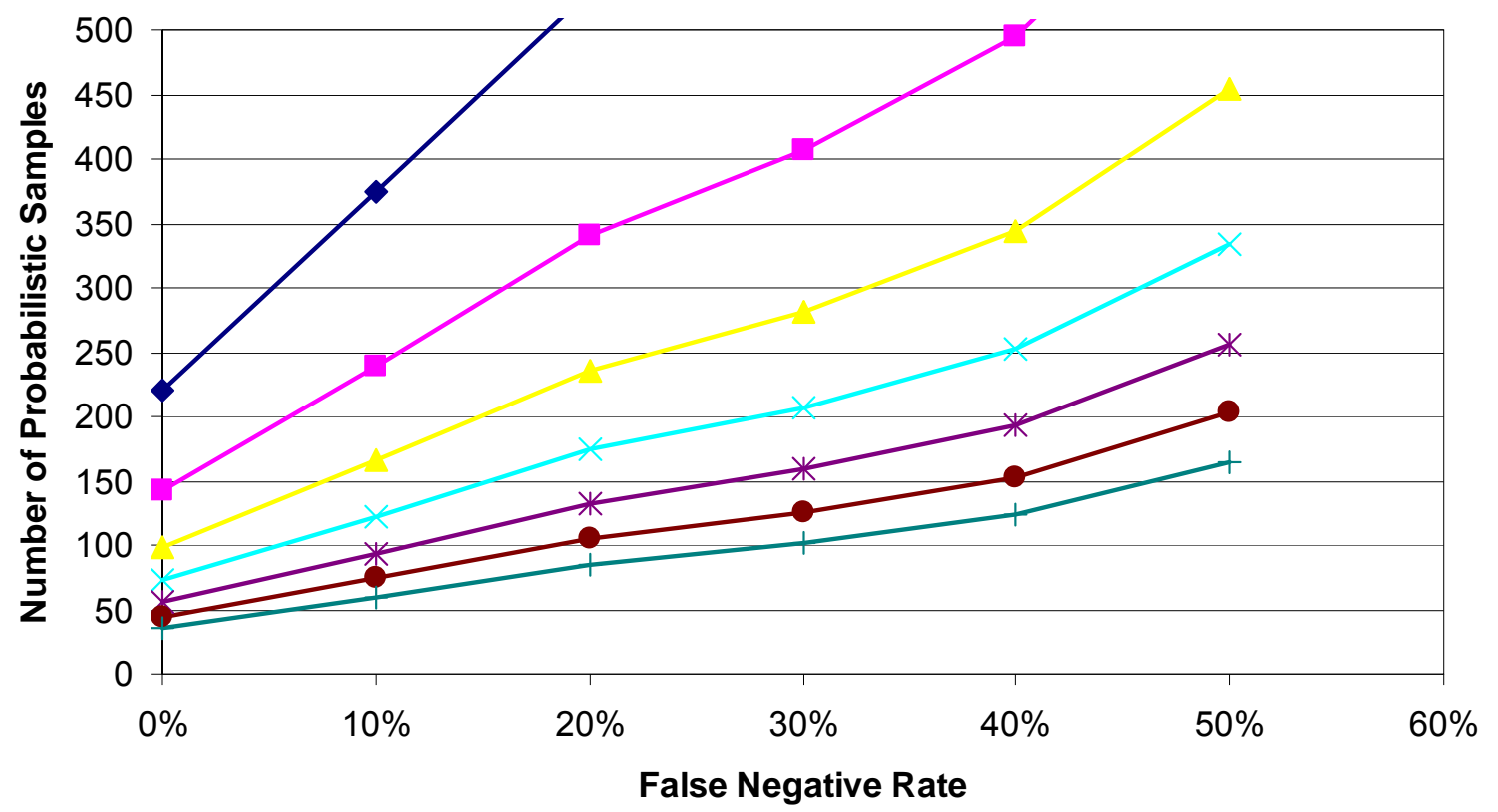

$\neg-4 \mathrm{ft} \rightarrow-5 \mathrm{ft}-6 \mathrm{ft} \leftarrow 7 \mathrm{ft} *-8 \mathrm{ft} \rightarrow 9 \mathrm{ft}+10 \mathrm{ft}$

Figure 4.2. Number of Probabilistic Samples Required to Detect with $95 \%$ Confidence a Circular Contaminated Area of a Given Diameter (represented by the colored lines) within a Single Floor of the INL PBF-632 Building

Figure 4.1 and Figure 4.2 are intended to show how the numbers of probabilistic samples increase as the FNR increases and size of contaminated area to be detected decreases. In practice, response teams should first identify the FNR appropriate for the sampling, transportation, extraction, and analytical methods to be used and the level of contamination that may be present. They should also identify the area of contamination (e.g., circular diameter) to be detected with specified high confidence (e.g., 95\%). Then the number of probabilistic samples required to meet those detection goals can be determined. Sometimes in practice there is a tendency to first determine how many samples are possible (based on time, budget, etc.) and then select values of FNR and area of contamination to yield that number of samples. This is generally considered to be a misuse of the statistical approach.

Table 4.1 lists statistical statements ${ }^{(a)}$ given the number of probabilistic samples and holding constant two of the three variables (contamination diameter and FNR) used to calculate the numbers of samples. In each set of statistical statements, $95 \%$ confidence was used. In the first column of statistical statements, the FNR was set at $10 \%$ so that the size of the contaminated area could be calculated. In the second column of statistical statements, the diameter of the circular, contaminated area was set at 10 feet

(a) A statistical statement indicates the confidence, false-negative rate, and size of contaminated area to be detected that are associated with a given number of samples. 
so that the FNR could be calculated. These calculations were made to quantify what is gained by increasing the number of probabilistic samples.

Table 4.1. Statistical Statements Given the Number of Probabilistic Samples Per Room and Per Floor for Characterizing the INL PBF-632 Building

\begin{tabular}{|c|c|c|c|}
\hline & $\begin{array}{c}\text { \# of } \\
\text { Probabilistic } \\
\text { Samples } \\
\end{array}$ & Statistical Statement $1^{(a)}$ & Statistical Statement $2^{(b)}$ \\
\hline \multicolumn{4}{|c|}{ Per Room } \\
\hline & 3 & $95 \%$ conf $/ 11.8 \mathrm{ft}$ diameter $/ 10 \%$ FNR & $95 \%$ conf $/ 10 \mathrm{ft}$ diameter $/ 0 \%$ FNR \\
\hline & 6 & $95 \%$ conf $/ 8.3 \mathrm{ft}$ diameter $/ 10 \%$ FNR & $95 \%$ conf $/ 10 \mathrm{ft}$ diameter $/ 14.2 \%$ FNR \\
\hline & 7 & $95 \%$ conf $/ 7.7 \mathrm{ft}$ diameter $/ 10 \%$ FNR & $95 \%$ conf $/ 10 \mathrm{ft}$ diameter $/ 20.9 \%$ FNR \\
\hline & 9 & $95 \%$ conf $/ 6.8 \mathrm{ft}$ diameter $/ 10 \%$ FNR & $95 \%$ conf $/ 10 \mathrm{ft}$ diameter $/ 36.8 \%$ FNR \\
\hline & 12 & $95 \%$ conf $/ 5.9 \mathrm{ft}$ diameter $/ 10 \%$ FNR & $95 \%$ conf $/ 10 \mathrm{ft}$ diameter $/ 49 \%$ FNR \\
\hline & 17 & $95 \%$ conf $/ 4.9 \mathrm{ft}$ diameter $/ 10 \%$ FNR & $95 \%$ conf $/ 10 \mathrm{ft}$ diameter $/>50 \%$ FNR \\
\hline \multicolumn{4}{|c|}{ Per Floor } \\
\hline & 65 & $95 \%$ conf $/ 9.6 \mathrm{ft}$ diameter $10 \%$ FNR & $95 \%$ conf $/ 10 \mathrm{ft}$ diameter $/ 11.5 \%$ FNR \\
\hline & 82 & $95 \%$ conf $/ 8.6 \mathrm{ft}$ diameter $/ 10 \%$ FNR & $95 \%$ conf $/ 10 \mathrm{ft}$ diameter $/ 18.1 \%$ FNR \\
\hline & 101 & $95 \%$ conf $/ 7.7 \mathrm{ft}$ diameter $/ 10 \%$ FNR & $95 \%$ conf $/ 10 \mathrm{ft}$ diameter $/ 29.3 \%$ FNR \\
\hline \multicolumn{4}{|c|}{$\begin{array}{l}\text { (a) Statistical Statement } 1 \text { lists the calculated circular diameter of the contamination that can be detected, given } \\
\text { the number of probabilistic samples, } 95 \% \text { confidence, and } 10 \% \text { FNR. } \\
\text { (b) Statistical Statement } 2 \text { lists the calculated FNR, given the number of probabilistic samples, } 95 \% \text { confidence }\end{array}$} \\
\hline (b) & \multicolumn{3}{|c|}{ and detecting a 10 -foot-diameter area of contamination. } \\
\hline
\end{tabular}

There are other assumptions that were not allowed to vary because of limitations in the VSP software (Matzke et al. 2007). VSP performs probabilistic sampling using a grid approach and assumes an equal probability of contamination within each grid cell. With the exception of CJR sampling designs, VSP does not (at this time) allow for different areas of the sampling grid to have different probabilities of detectable contamination. Another assumption not included in the calculations is the sample area (i.e., the physical area that is swabbed, wiped, or vacuumed for a single sample). VSP is able to factor in the sample area when $0 \%$ FNR is assumed (a value of $1 \mathrm{ft}^{2}$ was used for the work in this report, based on input from experts on the VSPWG). However, VSP does not yet have the capability to vary the sample area and FNR for a grid-sampling approach. Further, the VSP capability to address the sample area assumes that the area is the same for every sample. Thus, VSP does not currently have the capability to account for the smaller area sampled by a swab versus the larger areas sampled by a wipe or vacuum. When the FNR is greater than zero, VSP assumes point sampling (i.e., samples cover a negligible area). This results in conservative estimates for the numbers of samples, meaning that the statistical statements are actually better than stated for point samples. On the other hand, the number of samples is conservative (i.e., larger than what would otherwise be needed) by basing calculations on point samples rather than actual areas covered by samples.

\subsection{Clearance of a Non-Contaminated or Decontaminated Area}

In a situation where decontamination has occurred, or in an area of the INL PBF-632 building expected not to have been contaminated, sampling may be performed to clear the area (i.e., declare that there is no detectable contamination). When sampling an area for clearance, probabilistic samples are 
typically used because they allow making an X\%/Y\% clearance statement (see Section 1.2 ). The CJR sampling approach that combines judgmental and probabilistic samples (Sego et al. 2007) also provides for making an $\mathrm{X} \% / \mathrm{Y} \%$ clearance statement. The CJR sampling approach is implemented in the VSP Version 5 software (Matzke et al. 2007). Both options (probabilistic samples only and the CJR sampling approach) will be examined in this study. Samples were placed using an adaptive fill algorithm (Gilbert et al. 2002; Matzke et al. 2007) to spread out the probabilistic samples.

There are many parameters that affect the number of probabilistic samples taken using the CJR sampling approach to clear an area or a floor of the INL PBF-632 building that has been decontaminated or is expected to be uncontaminated. These parameters include 1) the percent confidence $(\mathrm{X} \%)$ desired, 2 ) the minimum percent ( $\mathrm{Y} \%$ ) of the room or floor that can be stated to not contain detectable contamination, ${ }^{(a)} 3$ ) the number of judgmental samples taken, 4) how much more likely it is that a judgmental sample location contains detectable contamination than a probabilistic sample location, and 5) the expected a priori probability that a judgmental sample will detect contamination. The clearance statement only holds true if none of the samples (judgmental or probabilistic) indicate the presence of contamination. More probabilistic samples are necessary to achieve higher values of $\mathrm{X}$ and/or Y.

An important assumption of the mathematical model used in the CJR approach is that the decision area can be divided into areas of higher and lower risk (the high risk area and low risk areas need not be contiguous). The higher risk areas have a higher likelihood of being contaminated than the lower risk areas. The CJR model assumes that all of the high risk areas are sampled judgmentally. In essence, the judgmental sample locations define the high risk areas in the sampling design. Consequently, fewer probabilistic samples are necessary when more judgmental samples are taken and/or when locations with judgmental samples are more likely to contain detectable contamination. Fewer probabilistic samples are also necessary as the a priori probability that a judgmental sample will detect contamination decreases. FNRs have not yet been implemented into the CJR sampling approach of the VSP software, so they were not considered for these calculations. For this reason, the $\mathrm{X} \% / \mathrm{Y} \%$ clearance statement that can be made using the CJR approach in VSP is defined as " $\mathrm{X} \%$ confidence that at least $\mathrm{Y} \%$ of the area does not contain detectable contamination."

Figure 4.3 summarizes the number of probabilistic samples required to sample an area consisting of two typical rooms in the INL PBF-632 building using the CJR sampling approach. This figure assumes a $95 \%$ confidence level and the likelihood that a judgmental sample location is three times $(3 \times)$ more likely to contain detectable contamination than a probabilistic sample location. The number of judgmental samples, the percentage of the two rooms that does not contain detectable contamination, and the $a$ priori probability that a judgmental sample will detect contamination $(10 \%$ or $30 \%)$ were allowed to vary.

Figure 4.3 shows that given 12 negative judgmental samples (i.e., ones that do not detect contamination), 143 negative probabilistic samples would be necessary to have $95 \%$ confidence that at least $99 \%$ of the area in the two rooms does not contain detectable contamination. This result is obtained when the $a$ priori probability that a judgmental sample will detect contamination is $10 \%$.

(a) It would require $100 \%$ sampling of an area and a zero false-negative rate to state with $100 \%$ confidence that $100 \%$ of the area is not contaminated. With less than $100 \%$ sampling and possibly a false-negative rate higher than zero, an $\mathrm{X} \% / \mathrm{Y} \%$ clearance statement must necessarily have $\mathrm{X}<100$ and $\mathrm{Y}<100$. 


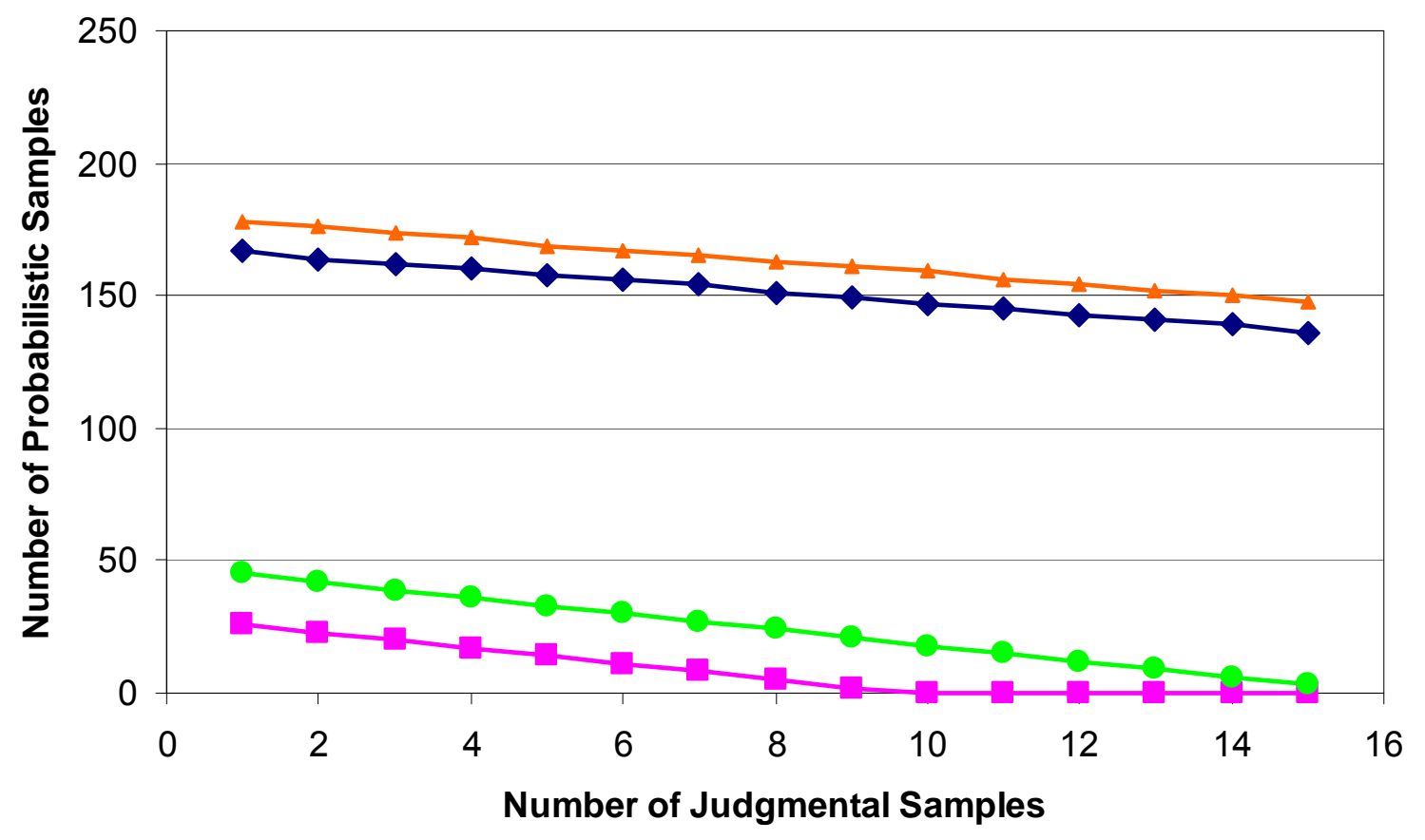

-99\% clean / $10 \%-95 \%$ clean $/ 10 \% \multimap-99 \%$ clean $/ 30 \%-95 \%$ clean $/ 30 \%$

Figure 4.3. Number of Negative Probabilistic Samples Required to be 95\% Confident that 95\% or 99\% of Two Rooms in the INL PBF-632 Building Do Not Contain Detectable Contamination Given Various Numbers of Negative Judgmental Samples. Colored lines represent the percentage of the two rooms (considered together) not containing detectable contamination and the $a$ priori probability that a judgmental sample will detect contamination.

Figure 4.4 summarizes the number of probabilistic samples necessary to make a $99 \% / 97 \%$ clearance statement about a single floor in the INL PBF-632 building when using the CJR sampling approach. Three parameters were allowed to vary: 1) the number of judgmental samples, 2) the $a$ priori probability that a judgmental sample will detect contamination $(10 \%$ or $30 \%)$, and 3$)$ the likelihood that a judgmental sample location contains detectable contamination as compared to a probabilistic sample location $(1 \times=$ judgmental location just as likely as probabilistic or $3 \times=$ judgmental location is three times as likely as probabilistic location, etc.). Figure 4.4 shows that with 20 negative judgmental samples, 124 negative probabilistic samples would be required to have $99 \%$ confidence that $97 \%$ of the floor does not contain detectable contamination. This result is obtained when (i) there is a $30 \%$ a priori probability that a judgmental sample will detect contamination and (ii) a judgmental sample location is just as likely $(1 \times)$ to contain detectable contamination as a probabilistic sample location.

Figure 4.3 and Figure 4.4 show the numbers of judgmental and probabilistic samples needed with the CJR approach to clear either $95 \%$ or $99 \%$ of the area in two rooms (Figure 4.3 ) or a whole floor (Figure 4.4) with $95 \%$ confidence. Results for the cases of $10 \%$ and $30 \%$ a priori probability that a judgmental sample will detect contamination are shown. Caution is needed in interpreting and using these figures. As discussed previously in this section, the number of judgmental samples should correspond only to locations that have a higher risk of contamination. It would be a misuse of the CJR 
approach to arbitrarily pick a larger number of judgmental samples in order to reduce the number of probabilistic samples.

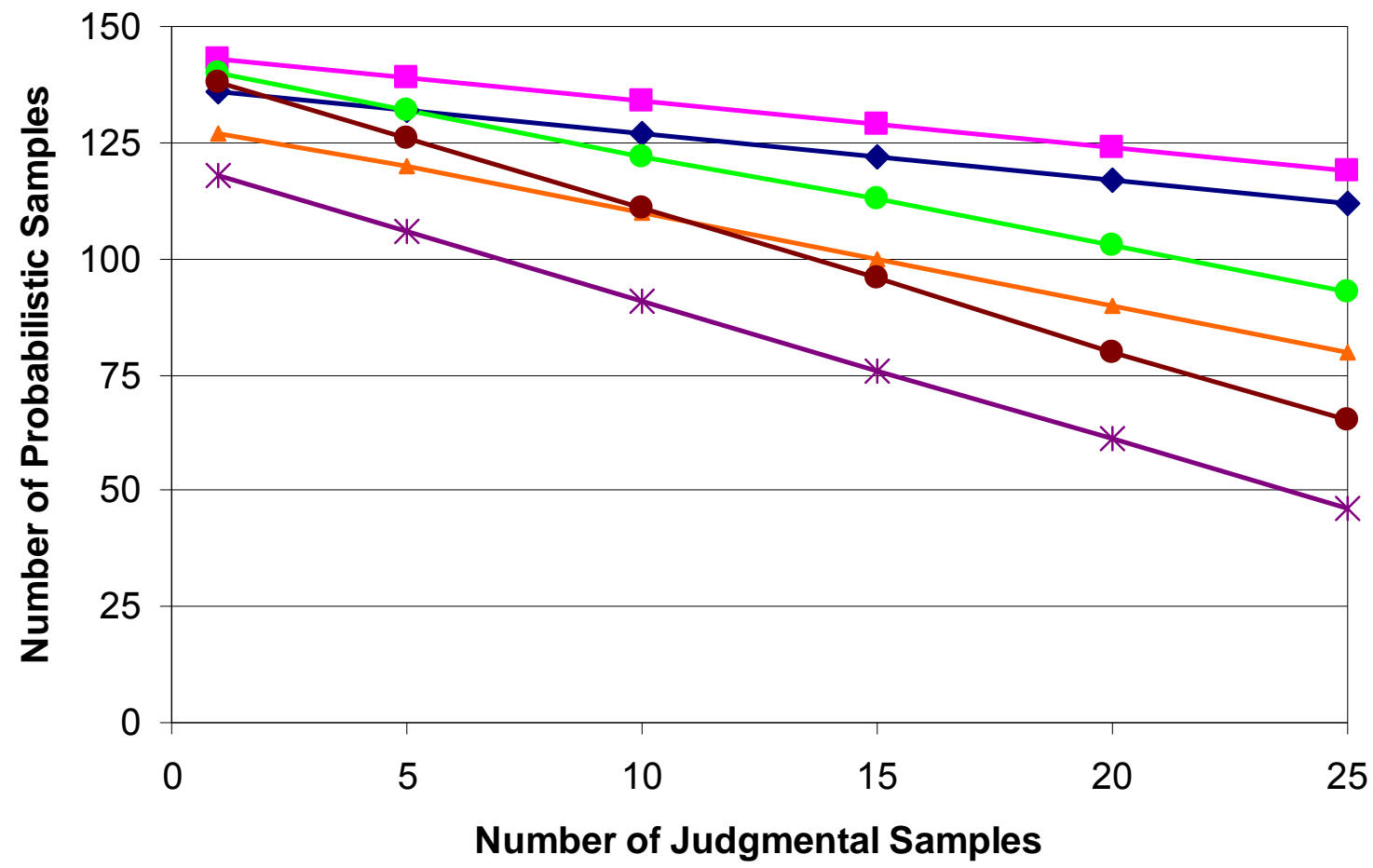

Figure 4.4. Number of Negative Probabilistic Samples Required to be $99 \%$ Confident that at Least $97 \%$ of a Typical Floor in the INL PBF-632 Building Does Not Contain Detectable Contamination Given Various Numbers of Negative Judgmental Samples. Colored lines represent the $a$ priori probability that a judgmental sample will detect contamination and the likelihood of a judgmental sample location containing detectable contamination relative to a probabilistic sample location. Note that the " $10 \% / 1 \times$ " and " $30 \% / 3 \times$ " lines are nearly identical.

Figure 4.5 summarizes the number of negative probabilistic samples required to make an $\mathrm{X} \% / \mathrm{Y} \%$ clearance statement about two typical rooms (considered together) in the INL PBF-632 building using only probabilistic samples. The percent confidence $(\mathrm{X} \%)$ and the minimum percent of the room not containing detectable contamination ( $\mathrm{Y} \%$ ) were allowed to vary. If 42 probabilistic samples all came back negative (the same number in the previous example for Figure 4.2), then there would 95\% confidence that at least $93 \%$ (approximately) of the room does not contain detectable contamination. Thus, the 12 judgmental samples in the example associated with Figure 4.3, combined with the 42 probabilistic samples, increased the percentage of the room that can be declared not to contain detectable contamination from $93 \%$ to $99 \%$. Although not illustrated in this report, it is also possible to calculate the reduction in percentage confidence $(\mathrm{X} \%$ ) associated with $\mathrm{Y}=99 \%$ by only using probabilistic samples instead of the Bayesian combination of judgmental and probabilistic samples used in the CJR approach. 


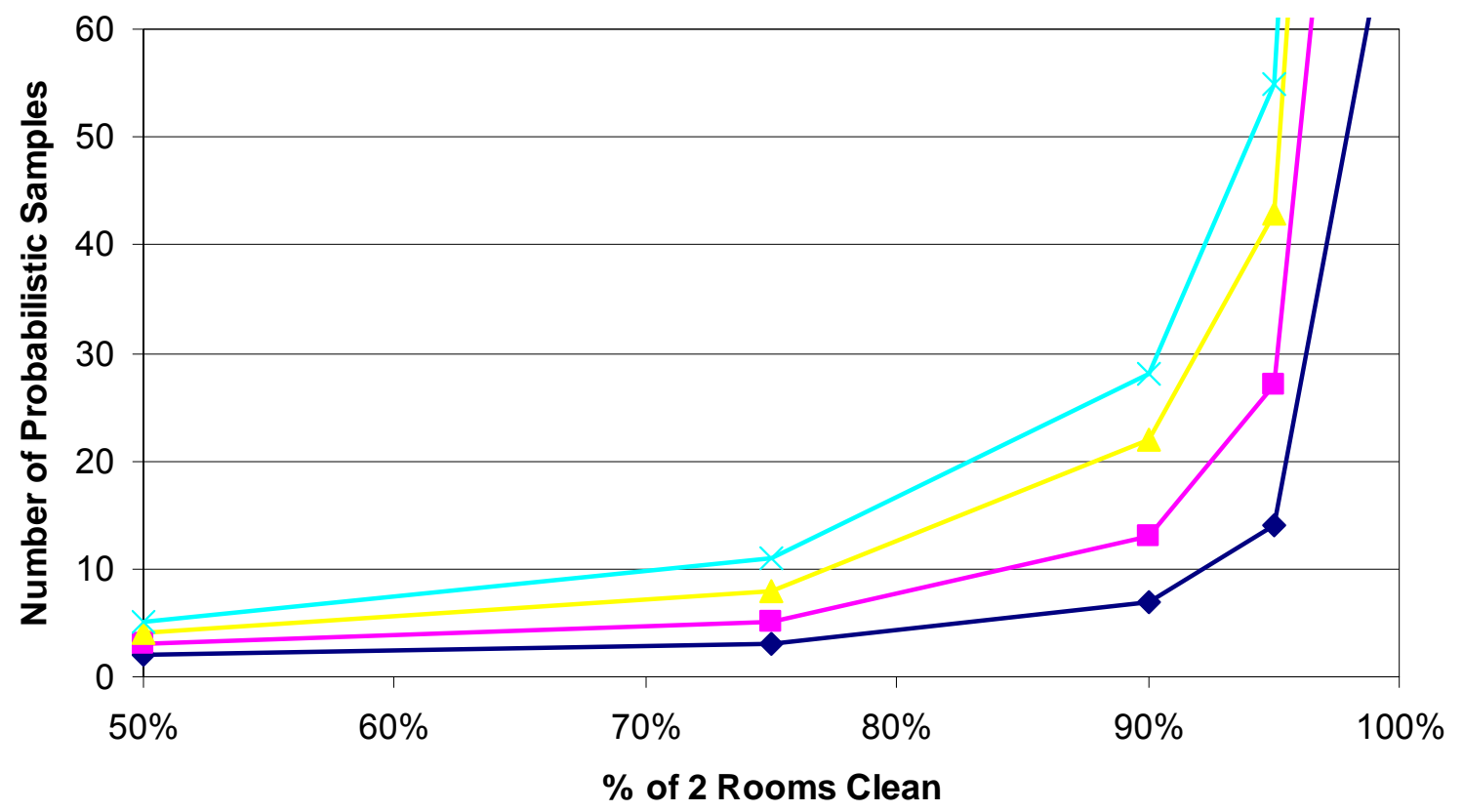

$-50 \%$ Confident $-75 \%$ Confident $\leftarrow-90 \%$ Confident $\leftarrow 95 \%$ Confident

Figure 4.5. Number of Probabilistic Samples Required to Determine if a Given Percentage of Two Typical Rooms in the INL PBF-632 Building Does Not Contain Detectable Contamination (x-axis) with a Given Level of Confidence (color lines)

Figure 4.6 summarizes the number of probabilistic samples required to make an $\mathrm{X} \% / \mathrm{Y} \%$ clearance statement about a single floor in the INL PBF-632 building using the only probabilistic samples. The percent confidence $(\mathrm{X} \%)$ and the percent of the room that does not contain detectable contamination (Y\%) were allowed to vary. This plot shows that if 119 probabilistic samples were taken and found to be negative (the same number as in the example above for Figure 4.4), then there would be $95 \%$ confidence that at least $96 \%$ of the floor does not contain detectable contamination. Although not illustrated, it is also possible to calculate the $\mathrm{X} \%$ confidence associated with $\mathrm{Y}=99 \%$ for a given number of probabilistic samples compared to also having a given number of judgmental samples in the CJR sampling approach. 


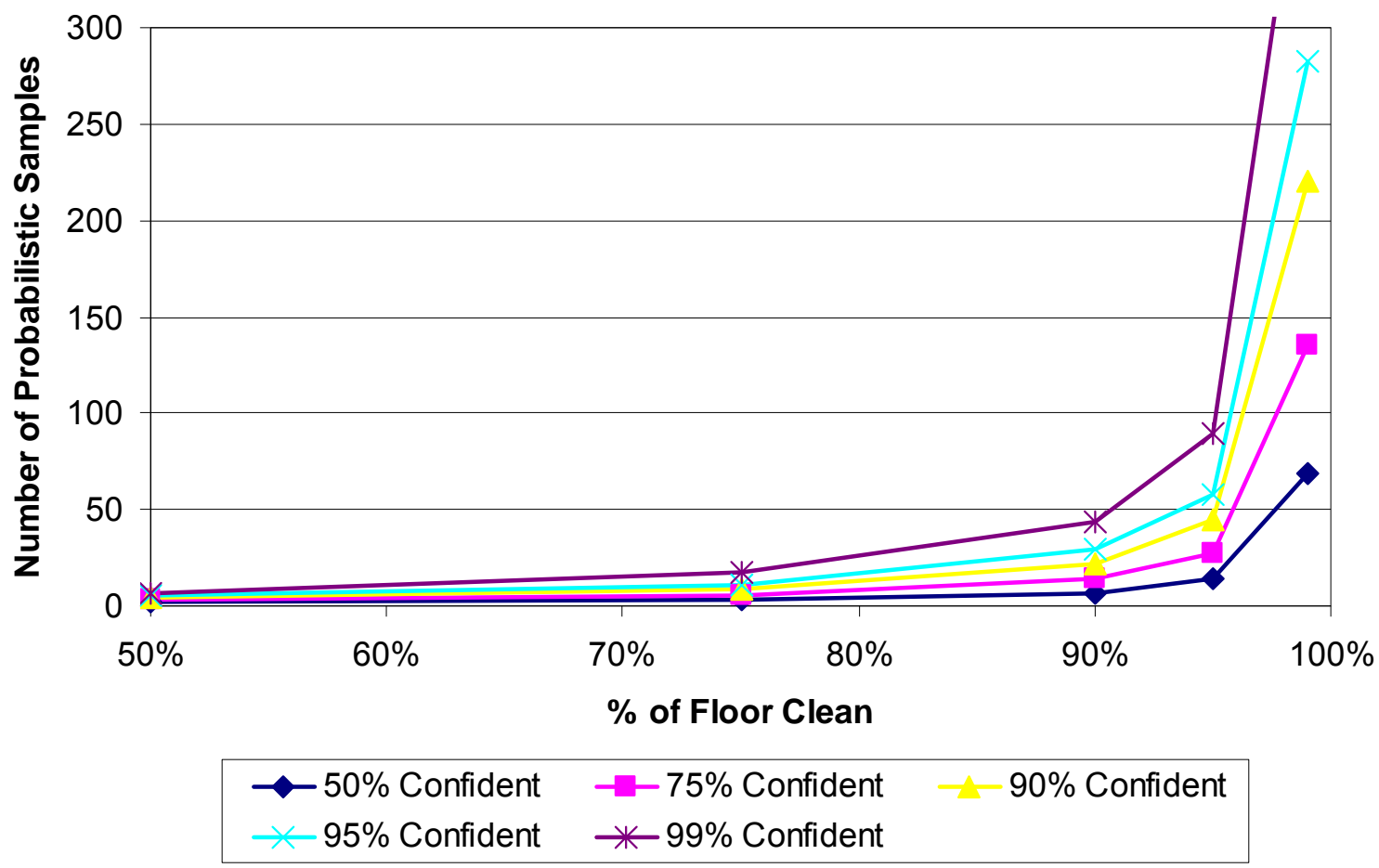

Figure 4.6. Number of Probabilistic Samples Required to Determine if a Given Percentage of a Typical Floor in the INL PBF-632 Building Does Not Contain Detectable Contamination (x-axis) with a Given Level of Confidence (color lines)

Figure 4.3 through Figure 4.6 were used to determine numbers of judgmental and probabilistic samples for determining clearance of a floor or a set of two rooms in the INL-2 Sample Collection Operational Test. Table 4.2 lists statistical statements for the Bayesian sampling approach given these numbers of judgmental and probabilistic samples and assuming that two of the three other variables are held constant. In each set of statistical statements, $95 \%$ or $99 \%$ confidence and a sample area of $1 \mathrm{ft}^{2}$ were used. In the first column of statistical statements, the likelihood that a judgmental sample location contains detectable contamination relative to a probabilistic sample location was set to $3 \times$, and the $a$ priori probability that a judgmental sample will detect contamination was set to $30 \%$, so that the percent of the room not containing detectable contamination could be calculated. In the second column of statistical statements, the likelihood that a judgmental sample location contains detectable contamination relative to a probabilistic sample location was set to be equivalent $(1 \times)$, and the a priori probability that a judgmental sample will detect contamination was set to $30 \%$, so that the percent of the rooms/floor not containing detectable contamination could be calculated. The third column did not use the CJR sampling approach, but instead relied on a compliance sampling methodology that uses probabilistic sampling only (Bowen and Bennett 1988). It did not rely on assumptions about the a priori probability that a judgmental sample will detect contamination nor the relationship between the likelihood of detectable contamination existing in the judgmental and probabilistic sample locations. The statistical statement of the third column lists the percent of the rooms/floor that does not contain detectable contamination, given the number of negative probabilistic samples and desired $95 \%$ or $99 \%$ confidence. 
Table 4.2. Statistical Statements Given the Number of Probabilistic and Judgmental Samples for Clearance of a Decontaminated or Non-Contaminated Area in the INL PBF-632 Building

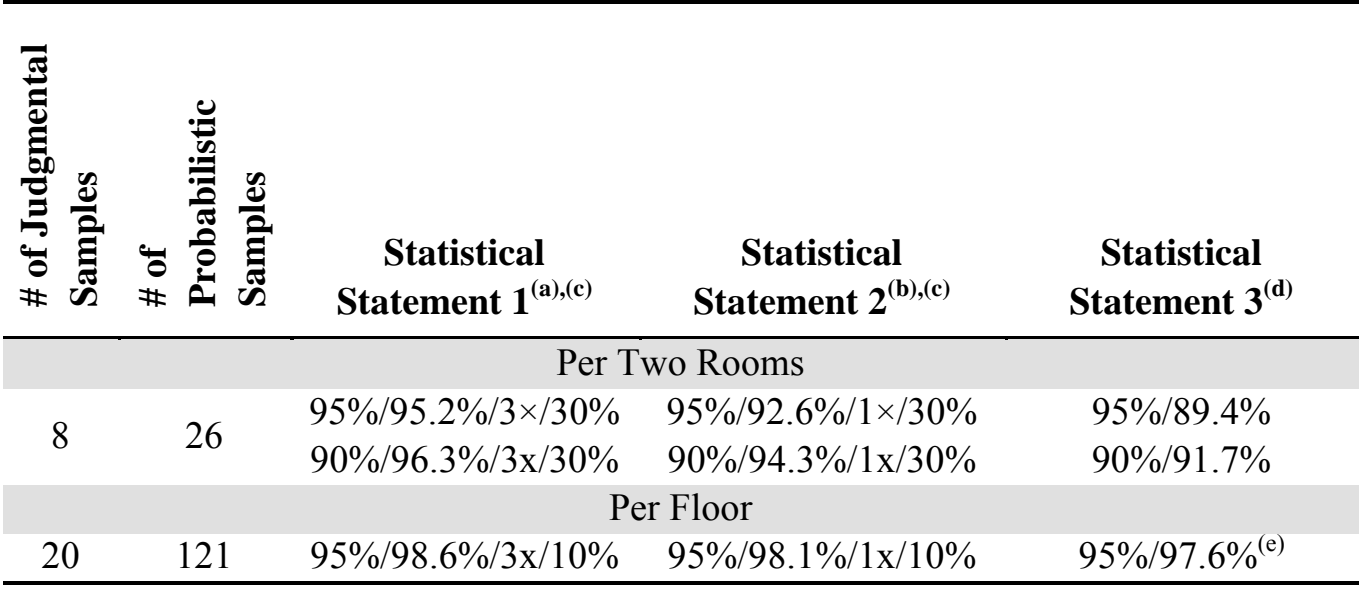

(a) Statistical Statement 1 is listed as the percent confidence/percent of an area that does not contain a detectable contaminated/multiplier that indicates a judgmental sample location is $3 \times$ more likely to contain detectable contamination than a probabilistic sample location/a priori probability that a judgmental sample will detect contamination.

(b) Statistical Statement 2 is listed as the percent confidence/percent of an area that does not contain detectable contamination/multiplier that indicates a judgmental sample location is $1 \times$ more (equally) likely to contain detectable contamination than a probabilistic sample location/a priori probability that a judgmental sample will detect contamination.

(c) When decontamination has occurred (per floor), then the a priori probability was set to $10 \%$. When decontamination had not occurred (per two rooms), then the a priori probability was set to $30 \%$.

(d) Statistical Statement 3 is listed as the percent confidence/percent of an area that does not contain detectable contamination using only probabilistic sampling.

(e) The "percent cleared" value of $97.6 \%$ is not much different than the corresponding values in Statistical Statements 1 and 2 for CJR sampling. This is because of the 95\% confidence required, the $10 \%$ chance that a judgmental sample is contaminated, and the number of judgmental samples being smaller relative to the number of probabilistic samples (than in the "two rooms" case).

There are other assumptions that are not allowed to vary when sampling for clearance because of limitations in the VSP software (Matzke et al. 2007). With the exception of CJR sampling designs, VSP does not (at this time) allow for different areas of the sampling grid to have different a priori probabilities that a judgmental sample will detect contamination. VSP also does not yet account for the FNR in a grid sampling approach. 


\subsection{Experimental and Sampling Design}

The experimental and sampling design for the INL-2 Sample Collection Operational Test is described in this section. The rationales concerning characterization and clearance sampling are explained in Sections 5.1 and 5.2, respectively. Test Event 1 (the ORI) and Test Event 2 are described in Section 5.3, while Test Events 3, 4, and 5 are described in Sections 5.4 to 5.6, respectively. The sampling design for the numbers of samples to be collected is presented for each test event in Sections 5.3 to 5.6. The total numbers of samples for the characterization and clearance phases are summarized in Section 5.7. Additional details about the experimental and sampling design are discussed in Section 5.8.

\subsection{Guidance for Characterization and Clearance Sampling Designs}

Section 5.1.1 presents the guidelines provided by the VSPWG on the maximum number of samples that could be taken during the characterization and clearance phases of the five test events in the INL-2 study. Section 5.1 .2 briefly summarizes the VSPWG guidance on composite sampling.

\subsubsection{Guidelines on the Maximum Numbers of Samples for Characterization and Clearance}

Generally, the VSPWG was interested in collecting close to the maximum number of samples feasible for the characterization and clearance phases of Test Events 1 to 5. Maximizing (within operational limitations) the numbers of samples would provide for sampling most (if not all) rooms and also possibly provide for over-sampling. Over-sampling (more sampling than required by defensible bases for selecting the number of judgmental and probabilistic samples) provides for the ability to better characterize building contamination patterns. Over-sampling also allows performing after-the-fact assessments of how sampling plans using fewer samples would have performed.

The VSPWG provided the following guidelines to help determine the numbers of samples to be collected during the characterization and clearance phases

- There will be four sampling teams working simultaneously during each of the characterization and clearance phases.

- The characterization sampling must be completed within a 6-hour period, including a break after 3 hours. The clearance sampling must be completed within a 4-hour period, including a break after 2 hours. These time limits include time to get into and out of protective gear.

- For the characterization phase, three RMC samples will be taken in each room that will be sampled. For the clearance phase, no RMC samples will be taken.

- It takes an average of 6 minutes per sample per sampling team. RMC samples will take less time, vacuum samples more time.

- It is recommended that a single sampling team should work in an individual room without being interrupted by taking a break.

Based on this guidance, the VSPWG specified the following maximum numbers of samples. 
- Maximum 60 total rooms sampled over the characterization phases of the five test events.

- Maximum 70 total rooms sampled over the clearance phases of the five test events.

- Maximum 260 characterization samples for each of the characterization and clearance phases of each of the five test events.

- During the characterization phase, a maximum of 37 samples per room, with the following maximums for each sample type: Vacuum (15), Wipe (14), Swab (5), and RMC (3).

- Maximum of 19 samples per room, with the following maximums for each sample type: Vacuum (10), Wipe (6), Swab (3), and RMC (0).

Initial planning included five RMCs per sampled room for each of the characterization and clearance phases. However, Mike Walter (JPEO-CBD) and Dino Mattorano (EPA) subsequently decided on three RMCs per room for characterization sampling and no RMCs for clearance sampling. They concluded that three RMCs per room would be sufficient to characterize the extent of contamination during the characterization phase. Further, they concluded that sufficient information is available from the sampling matrices (vacuum, wipe, swab) to assess the efficacy of fumigation, thus making the clearance RMCs unnecessary. For example, suppose all RMCs were negative for the clearance phase of a test event, but several positive surface samples were found from the other matrices. Contamination would still be suspected either through handling or through residual contamination in the building left from the initial dispersal. The negative RMCs would have no impact on the assessments from that particular clearance phase. Hence, it was decided to eliminate placing RMCs for collection during the clearance phases of the test events.

Because of limitations on the numbers of samples and analyses that can be performed for the INL-2 study, it was decided that certain rooms in the INL PBF-632 building would not be sampled. These included men's and women's restrooms plus mechanical rooms on both the first and second floors, as well as two storage rooms on the second floor.

\subsubsection{Limited Investigation of Composite Sampling}

Finally, the VSPWG wanted to investigate using a composite-sampling method to collect judgment samples in at least one room per characterization phase for each of the test events. In the INL-1 study, the area sampled by each sampling method (wipe, swab, vacuum) was the same for all samples collected by each method, regardless of the samples being judgmental or probabilistic samples. Hence, multiple judgmental samples of a fixed area were required to sample a larger area, if desired. However, in practice, judgmental samples are often collected in a composite fashion (e.g., by wiping several areas with the same wipe). It was decided to investigate this way of collecting judgmental samples for limited portions of the INL-2 study.

As discussed subsequently, we decided to perform composite judgmental sampling in two rooms per test event. This provides for evaluating composite judgmental sampling in rooms having expected lower and higher contaminant concentrations. In all other rooms, the sample area will be the same size whether the sample is probabilistic or judgmental. Thus, in all other rooms, multiple judgmental samples will be necessary to sample a larger area if so desired. There should be enough planned numbers of judgmental samples to allow for multiple samples when needed. 


\subsection{Rationales for Characterization and Clearance Sampling}

Sections 5.2.1 and 5.2.2 discuss the rationales for how the numbers of samples were determined for characterization and clearance sampling, respectively.

\subsubsection{Characterization Sampling Rationale}

For sampling with the goal of characterization, the resulting numbers of samples are based on three quantities: 1) percent confidence, 2) size of the contaminated area (assumed to be circular and quantified by the diameter, in feet) one wishes to be able to detect with high confidence, and 3) the FNR. For INL-2 sampling designs, the percent confidence was consistently set at $95 \%$. Specifying values for any two of 1) contamination size, 2) FNR, and 3) number of samples permits calculating the third quantity. In each sampling case, two statistical statements were made. The first statement involved specifying the size (diameter) of a circular contaminated area with $\mathrm{FNR}=10 \%$ and then calculating the required number of samples. For overt tests, the second statement involved choosing a consistent contaminated area size (10-ft diameter) and calculating the FNR for the number of samples calculated corresponding to the first statistical statement. For covert tests, the second statement involved choosing a consistent FNR $(\mathrm{FNR}=30 \%)$ and calculating the contaminated area size for the number of samples calculated corresponding to the first statistical statement.

Each of these statistical statements allows the opportunity to see what advantage is gained when increasing the numbers of samples. The advantages include the ability to detect a smaller contaminated area and/or being able to detect contamination when the FNR is higher. Because it is not known at this time 1) how much of each room in the INL PBF-632 building will be contaminated after BG contaminant dissemination and 2) how the FNR will vary with contamination level, it is informative to consider what statistical statements is provided by each number of samples.

The numbers of samples to be taken after contamination in the INL-2 study are presented in Sections 5.3 to 5.6 and are summarized in Section 5.7. The numbers of characterization samples given in Sections 5.3 to 5.6 allow making $95 \%$ confidence statements about detecting contamination in circular areas ranging from $6 \mathrm{ft}$ to $10 \mathrm{ft}$ in diameter for a room or one complete floor of the INL PBF-632 building and have FNRs ranging from $10 \%$ to over $50 \%$.

\subsubsection{Clearance Sampling Rationale}

For sampling with the goal of clearance, the resulting numbers of samples are based on four quantities: 1) percent confidence, 2) percent of a room or floor of the INL PBF-632 building that does not contain detectable contamination, 3) a priori probability that a judgmental will detect contamination, and 4) likelihood that a judgmental sample location contains detectable contamination relative to a probabilistic sample location. For this experimental and sampling design, the percent confidence was consistently set at $95 \%$ for two typical rooms and $99 \%$ for the whole floor, and the a priori probability that a judgmental sample will detect contamination was set to $30 \%$. Specifying values for any two of 1 ) percent of area containing detectable contamination, 2) likelihood that a judgmental sample location contains detectable contamination relative to a probabilistic sample location, or 3) number of samples (judgmental and probabilistic) permits calculating the third quantity. In each sampling case, two statistical statements were made. Each statement lists the percentage of the room or floor not containing detectable contamination, given that a judgmental sample location was either $1 \times$ or $3 \times$ more likely to contain detectable contamination as a probabilistic sample location. 
The numbers of clearance samples given in the following sections allow making clearance statements of the form " $\mathrm{X} \%$ confidence that at least $\mathrm{Y} \%$ of an area does not contain detectable contamination" with $\mathrm{X}=95 \%$ or $99 \%$ and $\mathrm{Y}=96 \%$ or $97 \%$. The tables also show that increasing the likelihood that a judgmental sample location contains detectable contamination from $1 \times$ to $3 \times$ relative to a probabilistic sample location will increase $\mathrm{Y}$ by $1 \%$. To appreciate these increases, it may be more appropriate to consider them in terms of the percentage of the area containing detectable contamination (i.e., $100 \%-$ $\mathrm{Y} \%$ ). If the percentage not containing detectable contamination increases from $96 \%$ to $97 \%$, then this is actually a $25 \%$ decrease in the percentage containing detectable contamination (from $4 \%$ to $3 \%$ ). The change is more dramatic when expressed in terms of the percentage of an area or floor that may contain detectable contamination.

The numbers of samples to be taken after decontamination are presented in Sections 5.3 to 5.6 and are summarized in Section 5.7. Because the decontamination process is expected to be the same after each test event and achieve thorough decontamination, the same numbers of post-decontamination samples are recommended for each test event.

\subsection{Test Events 1 and 2}

Test Events 1 and 2 involve covert releases on the first floor of the INL PBF-632 building, with unspecified locations for the release of the contaminant. The sampling designs for Test Events 1 and 2 are identical. Test Event 1 is the ORI, and it is not known ahead of time whether the results from that test event will be able to be included in the data analysis. Hence, the sampling design for Test Event 2 is the same as for Test Event 1.

The purpose of the ORI (Test Event 1) is to provide an opportunity for any issues that might arise (e.g., concerning the dissemination, contamination gradient, sampling, and decontamination) to be addressed before the remaining test events. Following the ORI, adjustments should be made to the process so that the subsequent test events will result in desirable contamination gradients, as described in Section 2.2. If the data from the ORI are deemed useful, they may be included in the data analyses.

If it is discovered in Test Event 1 that the amount of contaminant released is too high or too low to yield a desirable gradient (e.g., from moderate/low down to no/undetectable contamination), then the amount of contaminant released in Test Event 2 should be changed accordingly. If a moderate-tono/undetectable range of contamination is achieved in Test Event 1, it is recommended that a lower amount of contaminant be released in Test Event 2 to achieve a low-to-no/undetectable contaminant range. This should provide more rooms with very-low concentrations of contaminant, which are needed to assess the performance of the sampling approaches, sampling methods, and analytical methods when the false negative rate is higher.

Table 5.1 summarizes the numbers of samples of each type (QC, RMC, judgmental, and probabilistic) to be taken after contamination and after decontamination during Test Events 1 and 2. Figure 5.1 and Figure 5.2 give visual displays of the sample locations after contamination and after decontamination, respectively, using the sampling design for Test Events 1 and 2. Figure 5.2 also includes Test Event 4, which is discussed subsequently in Section 5.5. It is assumed that the locations and order (see the last paragraph of Section 3.1) of all samples to be collected in a given room will be entered into a test matrix (see Appendix B) that will provide specific directions for the sampling teams. 
Table 5.1. Numbers of Samples for INL-2 Test Events 1 and 2 on the First Floor of the INL PBF-632 Building. These events involve covert releases.

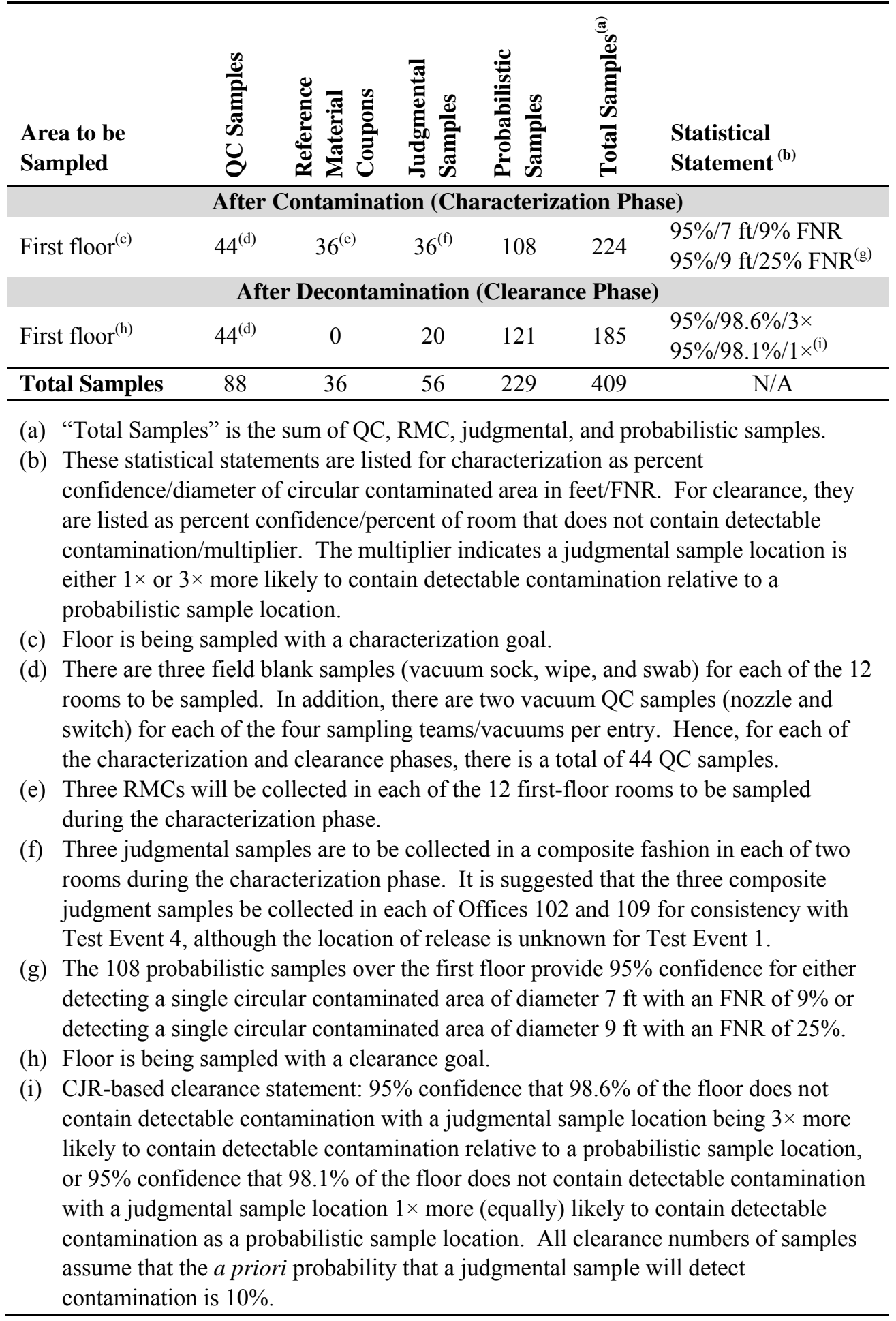




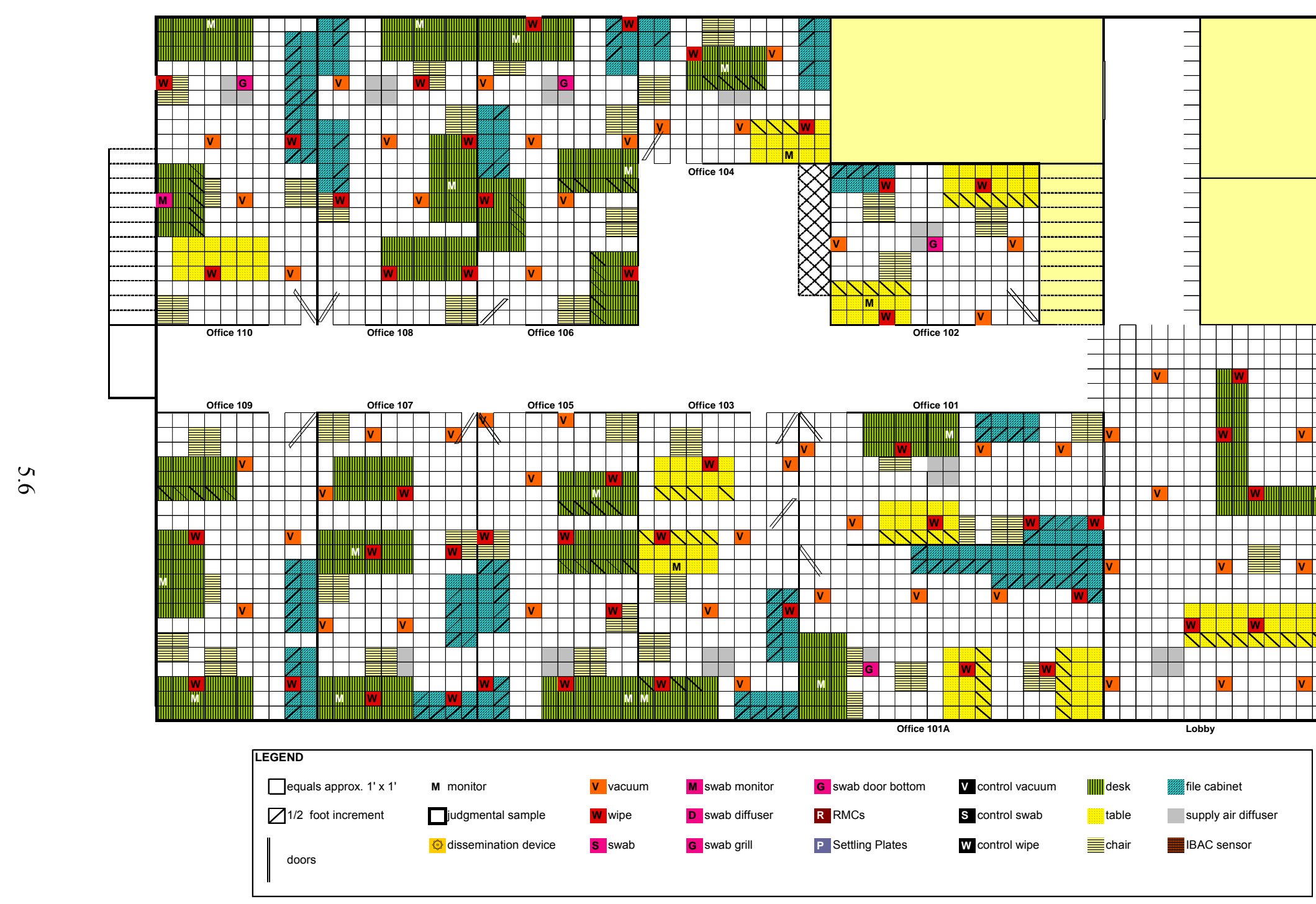

Figure 5.1. Map of Probabilistic Sample Locations and Types for Characterization Sampling of the First Floor of the INL Building During INL-2 Test Events 1 and 2 


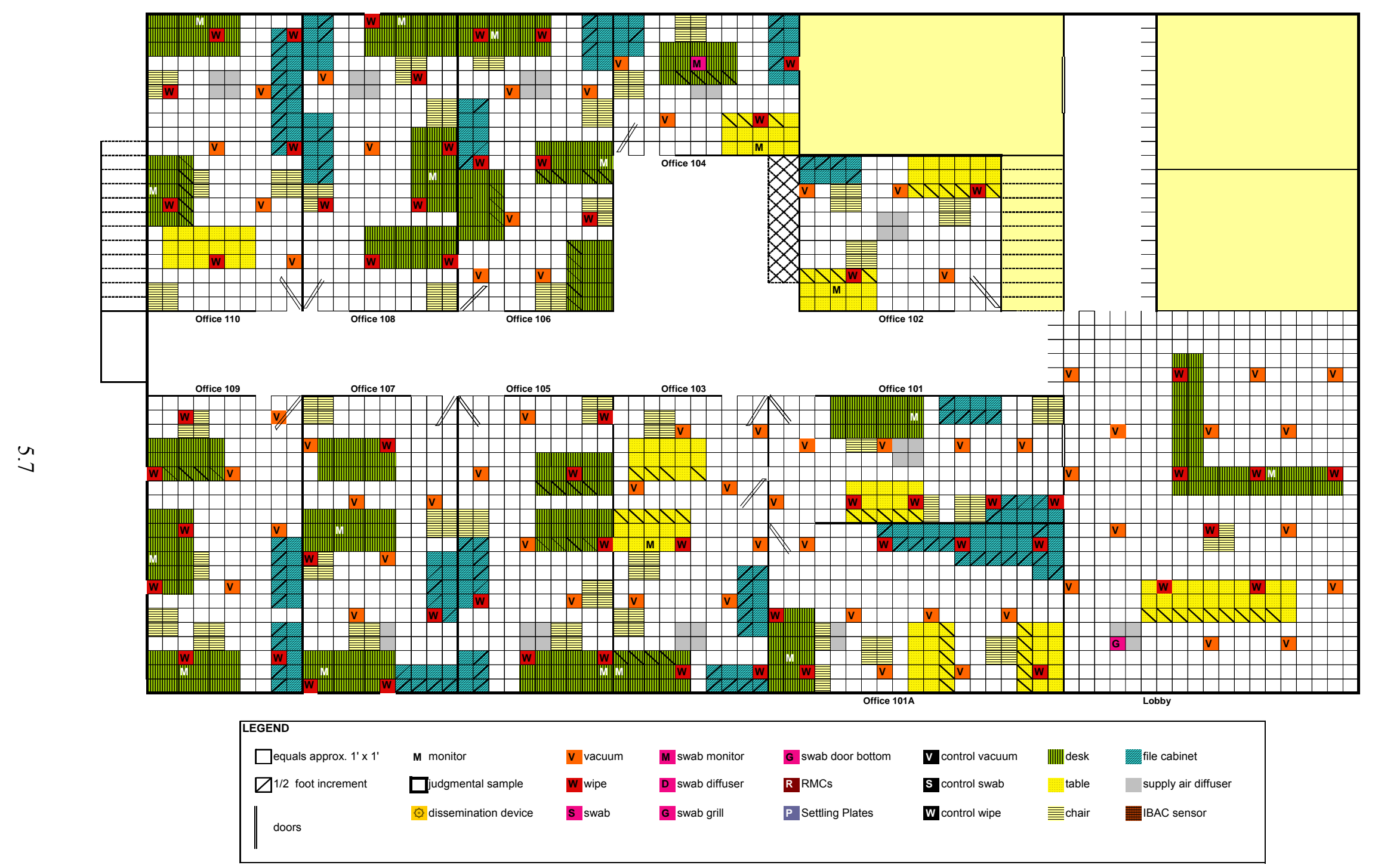

Figure 5.2. Map of Probabilistic Sample Locations and Types for Clearance Sampling of the First Floor of the INL Building During INL-2 Test Events 1, 2, and 4 
The characterization phase of sampling in Test Events 1 and 2 includes 44 QC samples, 36 RMC samples, 36 judgmental samples, and 108 probabilistic samples. Two examples of the statistical statements about detecting contamination that are supported by the 108 probabilistic samples are shown in the last column of Table 5.1. The 36 judgmental samples is an average of three per the 12 rooms on the first floor. In two rooms, three judgmental samples should be collected in a composite fashion (as opposed to the fixed-area fashion of collecting other judgmental samples). For each of Test Events 1 and 2, it is recommended that three composite judgment samples be collected in each of Offices 102 and 109 for consistency with Test Event 4, although the location of release is unknown for Test Events 1 and 2.

The clearance phase of sampling in Test Events 1 and 2 includes 44 QC samples, 0 RMC samples, 20 judgmental samples, and 121 probabilistic samples. Note that the numbers of judgmental and probabilistic samples per floor after decontamination are the same for all five test events. Two examples of $\mathrm{X} \% / \mathrm{Y} \%$ clearance statements supported by these numbers of judgmental and probabilistic samples are shown in the last column of Table 5.1.

\subsection{Test Event 3}

Test Event 3 involves a covert release on the second floor of the INL PBF-632 building, with an unspecified location for release of the contaminant. The sampling design for Test Event 3 is very close to that for Test Events 1 and 2, with the small difference a result of using the second floor of the building.

Table 5.2 summarizes the numbers of samples of each type (QC, RMC, judgmental, and probabilistic) to be taken after contamination and after decontamination during Test Event 3. Figure 5.3 and Figure 5.4 give visual displays of the locations of probabilistic samples after contamination and after decontamination, respectively, using the sampling design for Test Event 3. Figure 5.4 also includes Test Event 5, which is discussed subsequently in Section 5.6. The locations of QC, RMC, and judgmental samples will be determined subsequently by relevant experts and hence are not shown in Figure 5.3 and Figure 5.4. It is assumed that the locations and order (see the last paragraph of Section 3.1) of all samples to be collected in a given room will be entered into a test matrix (see Appendix B) that will provide specific directions for the sampling teams.

The characterization phase of sampling in Test Event 3 includes 53 QC samples, 45 RMC samples, 45 judgmental samples, and 105 probabilistic samples. Two examples of the statistical statements about detecting contamination that are supported by the 105 probabilistic samples are shown in the last column of Table 5.2. The 45 judgmental samples is an average of three per each of the 15 rooms on the second floor. In two rooms, three judgmental samples should be collected in a composite fashion (as opposed to the fixed-area fashion of collecting other judgmental samples). For Test Event 3, it is recommended that three composite judgment samples be collected in each of Offices 201 and 213 for consistency with Test Event 5, although the location of release is unknown for Test Event 3.

The clearance phase of sampling in Test Event 3 includes 53 QC samples, 0 RMC samples, 20 judgmental samples, and 121 probabilistic samples. Note that the numbers of judgmental and probabilistic samples per floor after decontamination are the same for all five test events. Two examples of $\mathrm{X} \% / \mathrm{Y} \%$ clearance statements supported by these numbers of judgmental and probabilistic samples are shown in the last column of Table 5.2. 
Table 5.2. Numbers of Samples for INL-2 Test Event 3 on the Second Floor of the INL PBF-632 Building. This event involves a covert release.

\begin{tabular}{|c|c|c|c|c|c|c|}
\hline Area to be Sampled & 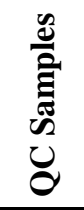 & 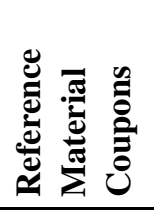 & 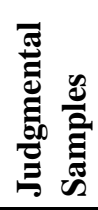 & 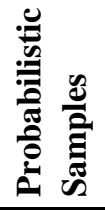 & 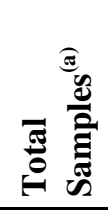 & Statistical Statement ${ }^{(b)}$ \\
\hline \multicolumn{7}{|c|}{ After Contamination (Characterization Phase) } \\
\hline Second floor ${ }^{(c)}$ & $53^{(\mathrm{d})}$ & $45^{(\mathrm{e})}$ & $45^{(\mathrm{f})}$ & 105 & 248 & $\begin{array}{l}95 \% / 7 \mathrm{ft} / 9 \% \mathrm{FNR} \\
95 \% / 9 \mathrm{ft} / 25 \% \mathrm{FNR}^{(\mathrm{g})}\end{array}$ \\
\hline \multicolumn{7}{|c|}{ After Decontamination (Clearance Phase) } \\
\hline Second floor ${ }^{(\mathrm{h})}$ & $53^{(\mathrm{d})}$ & 0 & 20 & 121 & 194 & $\begin{array}{l}95 \% / 98.6 \% / 3 \times \\
95 \% / 98.1 \% / 1 \times^{(i)}\end{array}$ \\
\hline Total Samples & 106 & 45 & 65 & 226 & 442 & $\mathrm{~N} / \mathrm{A}$ \\
\hline
\end{tabular}

(a) "Total Samples" is the sum of QC, RMC, judgmental, and probabilistic samples.

(b) These statistical statements are listed for characterization as percent confidence/diameter of circular contaminated area in feet/FNR. For clearance, they are listed as percent confidence/percent of room that does not contain detectable contamination/multiplier. The multiplier indicates a judgmental sample location is either $1 \times$ or $3 \times$ more likely to contain detectable contamination relative to a probabilistic sample location.

(c) The floor is being sampled with a characterization goal.

(d) There are three field blank samples (vacuum sock, wipe, and swab) for each of the 15 rooms (see Section 4.0) to be sampled. In addition, there are two vacuum QC samples (nozzle and switch) for each of the four sampling teams/vacuums per entry. Hence, for each of the characterization and clearance phases, there is a total of $53 \mathrm{QC}$ samples.

(e) Three RMCs will be collected in each of the 15 second-floor rooms to be sampled during the characterization phase.

(f) Three judgmental samples are to be collected in a composite fashion in each of two rooms during the character-ization phase. It is suggested that the three composite judgment samples be collected in each of Offices 201 and 213 for consistency with Test Event 5, although the location of release is unknown for Test Event 3.

(g) The 105 probabilistic samples over the second floor provide $95 \%$ confidence for either detecting a single circular contaminated area of diameter $7 \mathrm{ft}$ with an FNR of $9 \%$ or detecting a single circular contaminated area of diameter $9 \mathrm{ft}$ with an FNR of $25 \%$.

(h) The floor is being sampled with a clearance goal.

(i) CJR-based clearance statement: $95 \%$ confidence that $98.6 \%$ of the floor does not contain detectable contamination with a judgmental sample location being $3 \times$ more likely to contain detectable contamination relative to a probabilistic sample location, or $95 \%$ confidence that $98.1 \%$ of the floor does not contain detectable contamination with a judgmental sample location $1 \times$ more (equally) likely to contain detectable contamination as a probabilistic sample location. All clearance numbers of samples assume that the a priori probability that a judgmental sample will detect contamination is $10 \%$ after decontamination 


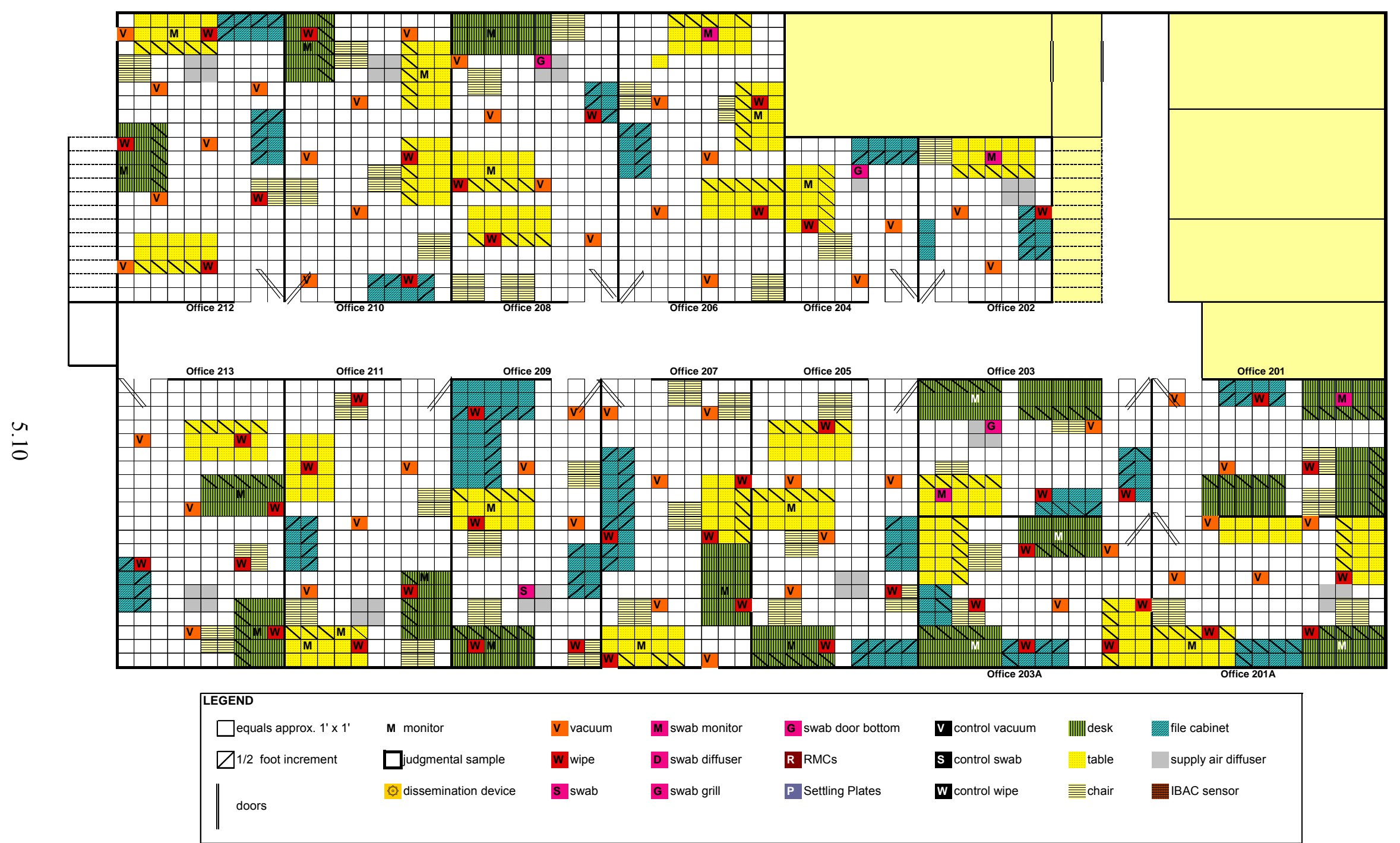

Figure 5.3. Map of Probabilistic Sample Locations and Types for Characterization Sampling of the Second Floor of the INL Building During INL-2 Test Event 3 


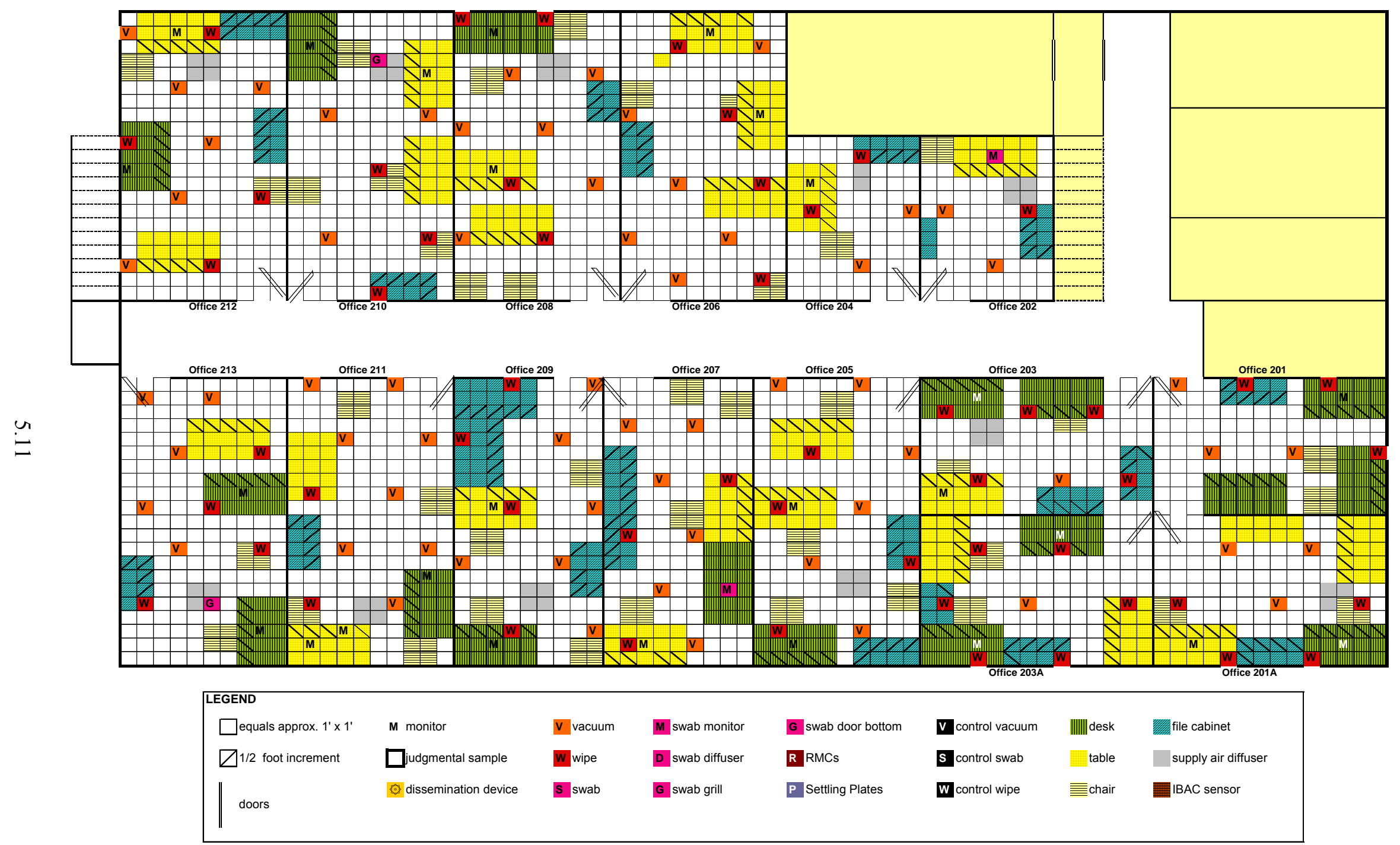

Figure 5.4. Map of Probabilistic Sample Locations and Types for Clearance Sampling of the Second Floor of the INL Building During INL-2 Test Events 3 and 5 


\subsection{Test Event 4}

Test Event 4 involves an overt release on the first floor of the INL PBF-632 building, with Office 101A specified as the location for release of the contaminant. Office 101A was selected as the release location based on the results of pre-test tracer releases and measurements in the INL building. Specifically, the conditions of releases \#5 and \#7 from that work show that Offices 105 to 108 will be very lowly contaminated or uncontaminated.

Table 5.3 summarizes the numbers of samples of each type (QC, RMC, judgmental, and probabilistic) to be taken after contamination and after decontamination during Test Event 4 . Table 5.3 shows the numbers of samples by room (after contamination) and floor (after decontamination). Figure 5.5 and Figure 5.2 give visual displays of the locations of probabilistic samples after contamination and after decontamination, respectively, using the sampling design for Test Event 4. The locations of QC, RMC, and judgmental samples will be determined subsequently by relevant experts and hence are not shown in Figure 5.5 and Figure 5.2. It is assumed that the locations and order (see the last paragraph of Section 3.1) of all samples to be collected in a given room will be entered into a test matrix (see Appendix B) that will provide specific directions for the sampling teams.

Additional discussion about the numbers of samples in Table 5.3 for Test Event 4 is given in the following bullets.

- Only 10 of the 12 offices on the first floor were selected for sampling after contamination because of limitations discussed in Section 5.1.1. The offices to be sampled include: 101, 102, 103, 104, 105, 106, 107, 108, 109, and 110. All 12 rooms (including the Lobby and Office 101A) will be sampled after decontamination.

- Eight vacuum QC samples (2 for each of the four sampling teams) will be collected after contamination and after decontamination. Three QC samples will be collected in each room sampled after contamination and after decontamination.

- Offices 101 and 102 close to the contaminant release point (Office 101A) were each assigned 7 probabilistic samples. Fewer probabilistic samples were assigned because it was assumed that contamination will be more easily detected in those offices. The 7 probabilistic samples provide 95\% confidence of detecting a contaminated area 1) 8 feet in diameter with 10\% FNR or 2) 10 feet in diameter with $29 \%$ FNR. Office 101 was assigned 4 single-increment judgmental samples while Office 102 was assigned 3 composite judgmental samples.

- Offices 103, 104, 109, and 110 were assigned 12 probabilistic samples because they are farther away from the contaminant release location (Office 101A). The 12 probabilistic samples provide $95 \%$ confidence of detecting a contaminated area 1) 6-feet in diameter with $10 \%$ FNR, or 2) 10 feet in diameter with 49\% FNR. Offices 103, 104, and 110 were assigned 5 single-increment judgmental samples, while Office 109 was assigned 3 composite judgmental samples. 
Table 5.3. Numbers of Samples for INL-2 Test Event 4 on the First Floor of the INL PBF-632 Building. This event involves an overt release from Office 101A.

\begin{tabular}{|c|c|c|c|c|c|c|}
\hline Area to be Sampled & 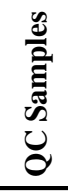 & 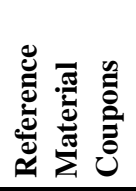 & 预 & 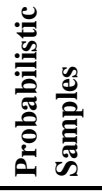 & 预 & Statistical Statement $^{(\mathbf{b})}$ \\
\hline \multicolumn{7}{|c|}{ After Contamination (Characterization Phase) } \\
\hline Team Vacuum QC Samples & 8 & $\mathrm{NA}^{(\mathrm{c})}$ & NA & NA & 8 & $\mathrm{~N} / \mathrm{A}$ \\
\hline Office $101^{(\mathrm{d})}$ & 3 & 3 & 4 & 7 & 17 & $\begin{array}{l}95 \% / 8 \mathrm{ft} / 10 \% \mathrm{FNR} \\
95 \% / 10 \mathrm{ft} / 29 \% \mathrm{FNR}^{(\mathrm{e})}\end{array}$ \\
\hline Office $102^{(\mathrm{d})}$ & 3 & 3 & $3^{(\mathrm{f})}$ & 7 & 16 & $\begin{array}{l}95 \% / 8 \mathrm{ft} / 10 \% \text { FNR } \\
95 \% / 10 \mathrm{ft} / 29 \% \text { FNR }\end{array}$ \\
\hline Office $103^{(\mathrm{d})}$ & 3 & 3 & 5 & 12 & 23 & $\begin{array}{l}95 \% / 6 \mathrm{ft} / 10 \% \text { FNR } \\
95 \% / 10 \mathrm{ft} / 49 \% \text { FNR }\end{array}$ \\
\hline Office $104^{(d)}$ & 3 & 3 & 5 & 12 & 23 & $\begin{array}{l}95 \% / 6 \mathrm{ft} / 10 \% \text { FNR } \\
95 \% / 10 \mathrm{ft} / 49 \% \text { FNR }\end{array}$ \\
\hline Office $109^{(\mathrm{d})}$ & 3 & 3 & $3^{(\mathrm{f})}$ & 12 & 21 & $\begin{array}{l}95 \% / 6 \mathrm{ft} / 10 \% \text { FNR } \\
95 \% / 10 \mathrm{ft} / 49 \% \text { FNR }\end{array}$ \\
\hline Office $110^{(\mathrm{d})}$ & 3 & 3 & 5 & 12 & 23 & $\begin{array}{l}95 \% / 6 \mathrm{ft} / 10 \% \text { FNR } \\
95 \% / 10 \mathrm{ft} / 49 \% \text { FNR }\end{array}$ \\
\hline Office $105 \& 107^{(\mathrm{g})}$ & 6 & 6 & 8 & 26 & 46 & $\begin{array}{l}90 \% / 96.3 \% / 3 x \\
90 \% / 94.3 \% / 1 x\end{array}$ \\
\hline Offices $106 \& 108^{(\mathrm{g})}$ & 6 & 6 & 8 & 26 & 46 & $\begin{array}{l}90 \% / 96.3 \% / 3 x \\
90 \% / 94.3 \% / 1 x\end{array}$ \\
\hline \# Contamination Samples & 38 & $30^{(\mathrm{h})}$ & 41 & 114 & 223 & N/A \\
\hline \multicolumn{7}{|c|}{ After Decontamination (Clearance Phase) } \\
\hline Team Vacuum QC Samples & 8 & NA & NA & NA & 8 & $\mathrm{~N} / \mathrm{A}$ \\
\hline First floor ${ }^{(i)}$ & $36^{(\mathrm{j})}$ & 0 & 20 & 121 & 177 & $\begin{array}{l}95 \% / 98.6 \% / 3 \times \\
95 \% / 98.1 \% / 1 \times^{(\mathrm{k})}\end{array}$ \\
\hline Total Samples & 82 & 30 & 61 & 235 & 408 & $\mathrm{~N} / \mathrm{A}$ \\
\hline
\end{tabular}

(a) "Total Samples" is the sum of QC, RMC, judgmental, and probabilistic samples.

(b) These statistical statements are listed for characterization as percent confidence/diameter of circular contaminated area in feet/FNR. For clearance, they are listed as percent confidence/percent of room that does not contain detectable contamination/multiplier. The multiplier indicates a judgmental sample location is either $1 \times$ or $3 \times$ more likely to contain detectable contamination relative to a probabilistic sample location.

(c) NA = not applicable.

(d) Room is being sampled with a characterization goal.

(e) Characterization statement: $95 \%$ confidence of detecting a single circular contaminated area of diameter $8 \mathrm{ft}$ with an FNR of $10 \%$ or detecting a single circular contaminated area of diameter $10 \mathrm{ft}$ with an FNR of $29 \%$.

(f) These judgmental samples are to be collected in a composite fashion.

(g) The area (two adjacent rooms) is being sampled with a clearance goal, assuming a $30 \%$ a priori probability that a judgmental sample will detect contamination.

(h) Three RMCs will be collected for each of the 10 first-floor rooms to be sampled during the characterization phase.

(i) The floor is being sampled with a clearance goal.

(j) There are three field blank samples (vacuum sock, wipe, and swab) for each of the 12 rooms to be sampled for clearance.

(k) CJR-based clearance statement: $95 \%$ confidence that either $98.6 \%$ of the floor does not contain detectable contamination with a judgmental sample location being $3 \times$ more likely to contain detectable contamination relative to a probabilistic sample location, or $95 \%$ confidence that $98.1 \%$ of the floor does not contain detectable contamination with a judgmental sample location $1 \times$ more (equally) likely to contain detectable contamination as a probabilistic sample location. All clearance numbers of samples assume the a priori probability that a judgmental sample will detect contamination is $10 \%$ after decontamination. 


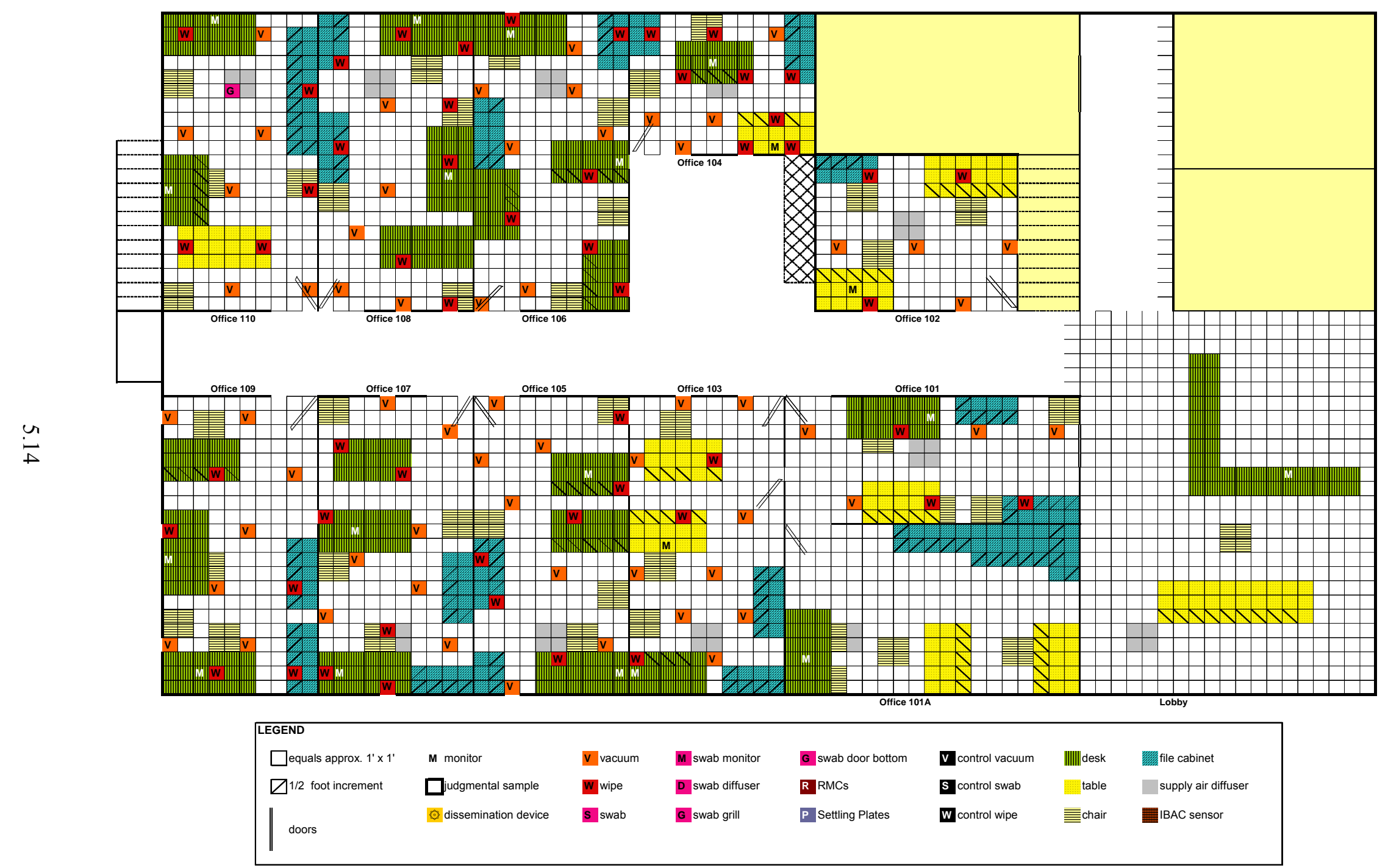

Figure 5.5. Map of Probabilistic Sample Locations and Types for Characterization Sampling of the First Floor of the INL Building During INL-2 Test Event 4 
- Preliminary tracer studies indicated that releasing the contaminant from Office 101A may result in very low or no or contamination in Offices 105, 106, 107, and 108. Hence, pairs of offices $(105 / 107$ and 106/108) were selected for clearance sampling using the CJR sampling approach. Eight judgmental samples (single increment) and 26 probabilistic samples were selected. Provided all of the samples are negative (i.e., no detectable contamination), these numbers of samples provide $90 \%$ confidence that at least $96.3 \%$ of the area in a pair of offices does not contain detectable contamination. This is if a judgmental sample location is $3 \times$ more likely to contain detectable contamination than a probabilistic sample location. Instead, if a judgmental sample is $1 \times$ more (equally) likely to contain detectable contamination, a 90\%/94.3\% clearance statement can be made.

- Per the discussion in Section 5.1.1, three RMC samples were assigned to be taken in each of the 10 offices sampled during the characterization phase, and 2) no RMC samples were assigned to be taken during the clearance phase.

In the "after contamination" sampling design of Table 5.4, Offices 105 and 107 as well as 106 and 108 were paired to provide two opportunities for the CJR sampling approach to clear a portion of the floor during the characterization sampling phase. It was not clear from the preliminary tracer study results, but apparently no office doors were closed during the tracer studies. It is recommended that the doors of Offices 105 and 107 be closed and sealed, and vents into those rooms be covered/sealed, to increase the chances of having no (or undetectable) contamination in those rooms. The doors and vents of Offices 106 and 108 can remain open, provided that is how they were during the tracer studies.

Offices 102 and 109 were specified for performing composite judgmental sampling. Based on pretest tracer studies performed in the INL building, Office 102 is expected to have a moderate contaminant concentration, while Office 109 is expected to have a lower concentration. Rooms nearby to these with similar contaminant concentrations (e.g., possibly Offices 104 and 110) where single-increment judgmental sampling will be performed can serve to compare the performance of single-increment and composite judgmental sampling.

The clearance phase of sampling in Test Event 4 includes 8 team-vacuum QC samples, 36 QC samples, 0 RMC samples, 20 judgmental samples, and 121 probabilistic samples. Note that the numbers of judgmental and probabilistic samples per floor after decontamination are the same for all five test events. Two examples of $\mathrm{X} \% / \mathrm{Y} \%$ clearance statements supported by these numbers of judgmental and probabilistic samples are shown in the last column of Table 5.3.

\subsection{Test Event 5}

Test Event 5 involves an overt release on the second floor of the INL PBF-632 building, with Office 201A specified as the location for release of the contaminant. Office 201A was selected as the release location based on the results of pre-test tracer releases and measurements in the INL building. Specifically, the conditions of releases \#9, \#10, and \#11 from that work involved closing the doors of Offices 205, 206, and 207 with the release from Office 201A. The results from the tracer study show that Offices 205 to 207 will be very lowly contaminated, if not uncontaminated. 
Table 5.4 summarizes the numbers of samples of each type (QC, RMC, judgmental, and probabilistic) to be taken after contamination and after decontamination during Test Event 5. Table 5.4 shows the numbers of samples by room (after contamination) and floor (after decontamination). Figure 5.6 and Figure 5.4 give visual displays of the locations of probabilistic samples after contamination and after decontamination, respectively, using the sampling design for Test Event 5. The locations of QC, RMC, and judgmental samples will be determined subsequently by relevant experts, and hence are not shown in Figure 5.6 and Figure 5.4. It is assumed that the locations and order (see the last paragraph of Section 3.1) of all samples to be collected in a given room will be entered into a test matrix (see Appendix B) that will provide specific directions for the sampling teams.

Additional discussion about the numbers of samples in Table 5.4 for Test Event 5 is given in the following bullets.

- Only 10 of the 15 offices on the second floor were selected for sampling after contamination because of limitations discussed in Section 5.1.1. The offices to be sampled include 201, 202, 205, 206, 207, 208, 209, 210, 212, and 213. All 15 offices (including 201A, 203, 203 A, 204, and 211) will be sampled after decontamination.

- Eight vacuum QC samples (2 for each of the four sampling teams) will be collected after contamination and after decontamination. In each room sampled after contamination and after decontamination, 3 QC samples will be collected.

- Offices 201 and 202, which are close to the contaminant release point (Office 201A), were each assigned 7 probabilistic samples. Fewer probabilistic samples were assigned because it was assumed that contamination will be more easily detected in those offices. The 7 probabilistic samples provide $95 \%$ confidence of detecting a contaminated area 1) 8 feet in diameter with $10 \%$ FNR, or 2) 10 feet in diameter with 29\% FNR. Office 202 was assigned 4 single-increment judgmental samples, while Office 201 was assigned 3 composite judgmental samples.

- Offices 209, 210, 212, and 213 were assigned 12 probabilistic samples because they are farther away from the contaminant release location (Office 201A). The 12 probabilistic samples provide $95 \%$ confidence of detecting a contaminated area 1) 6 feet in diameter with $10 \%$ FNR, or 2) 10 feet in diameter with $49 \%$ FNR. Offices 209,210 , and 213 were assigned 5 singleincrement judgmental samples, while Office 213 was assigned 3 composite judgmental samples.

- Preliminary tracer studies indicated that releasing the contaminant from Office 201A may result in very low or no or contamination in Offices 205, 206, 207, and 208. Hence, pairs of offices (205/207 and 206/208) were selected for clearance sampling using the CJR approach. Eight judgmental samples (single increment) and 26 probabilistic samples were selected. Provided all of the samples are negative (i.e., no detectable contamination), these numbers of samples provide $90 \%$ confidence that $96.3 \%$ of the area in a pair of offices does not contain detectable contamination. This is if a judgmental sample location is $3 \times$ more likely to contain detectable contamination than a probabilistic sample location. If, instead, a judgmental sample is $1 \times$ more (equally) likely to contain detectable contamination, a 90\%/94.3\% clearance statement can be made.

- Per the discussion in Section 5.1.1, three RMC samples were assigned to be taken in each of the 10 offices sampled during the characterization phase and no RMC samples were assigned to be taken during the clearance phase. 
Table 5.4. Numbers of Samples for INL-2 Test Event 5 on the Second Floor of the INL PBF-632 Building. This event involves an overt release from Office 201A.

\begin{tabular}{|c|c|c|c|c|c|c|}
\hline Area to be Sampled & 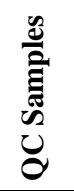 & 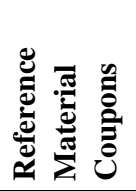 & 预 & 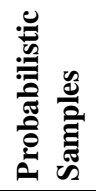 & 苞 总 & Statistical Statement $^{(\mathbf{b})}$ \\
\hline \multicolumn{7}{|c|}{ After Contamination (Characterization Phase) } \\
\hline Team Vacuum QC Samples & 8 & $\mathrm{NA}^{(\mathrm{c})}$ & NA & NA & 8 & $\mathrm{~N} / \mathrm{A}$ \\
\hline Office $201^{(\mathrm{d})}$ & 3 & 3 & $3^{(\mathrm{e})}$ & 7 & 16 & $\begin{array}{l}95 \% / 8 \mathrm{ft} / 10 \% \mathrm{FNR} \\
95 \% / 10 \mathrm{ft} / 29 \% \mathrm{FNR}^{(\mathrm{f})}\end{array}$ \\
\hline Office $202^{(\mathrm{d})}$ & 3 & 3 & 4 & 7 & 17 & $\begin{array}{l}95 \% / 8 \mathrm{ft} / 10 \% \text { FNR } \\
95 \% / 10 \mathrm{ft} / 29 \% \text { FNR }\end{array}$ \\
\hline Office $209^{(\mathrm{d})}$ & 3 & 3 & 5 & 12 & 23 & $\begin{array}{l}95 \% / 6 \mathrm{ft} / 10 \% \text { FNR } \\
95 \% / 10 \mathrm{ft} / 49 \% \text { FNR }\end{array}$ \\
\hline Office $210^{(\mathrm{d})}$ & 3 & 3 & 5 & 12 & 23 & $\begin{array}{l}95 \% / 6 \mathrm{ft} / 10 \% \text { FNR } \\
95 \% / 10 \mathrm{ft} / 49 \% \text { FNR }\end{array}$ \\
\hline Office $212^{(\mathrm{d})}$ & 3 & 3 & 5 & 12 & 23 & $\begin{array}{l}95 \% / 6 \mathrm{ft} / 10 \% \text { FNR } \\
95 \% / 10 \mathrm{ft} / 49 \% \text { FNR }\end{array}$ \\
\hline Office $213^{(\mathrm{d})}$ & 3 & 3 & $3^{(\mathrm{e})}$ & 12 & 21 & $\begin{array}{l}95 \% / 6 \mathrm{ft} / 10 \% \mathrm{FNR} \\
95 \% / 10 \mathrm{ft} / 49 \% \mathrm{FNR}\end{array}$ \\
\hline Office $205 \& 207^{(\mathrm{g})}$ & 6 & 6 & 8 & 26 & 46 & $\begin{array}{l}90 \% / 96.3 \% / 3 x \\
90 \% / 94.3 \% / 1 x\end{array}$ \\
\hline Offices $206 \& 208^{(\mathrm{g})}$ & 6 & 6 & 8 & 26 & 46 & $\begin{array}{l}90 \% / 96.3 \% / 3 \mathrm{x} \\
90 \% / 94.3 \% / 1 \mathrm{x}\end{array}$ \\
\hline \# Contamination Samples & 38 & $30^{(\mathrm{h})}$ & 41 & 114 & 223 & $\mathrm{~N} / \mathrm{A}$ \\
\hline \multicolumn{7}{|c|}{ After Decontamination (Clearance Phase) } \\
\hline Team Vacuum QC Samples & 8 & NA & NA & NA & 8 & $\mathrm{~N} / \mathrm{A}$ \\
\hline Second floor ${ }^{(i)}$ & $45^{(\mathrm{j})}$ & 0 & 20 & 121 & 186 & $\begin{array}{l}95 \% / 98.6 \% / 3 \times \\
95 \% / 98.1 \% / 1 \times^{(\mathrm{k})}\end{array}$ \\
\hline Total Samples & 91 & 30 & 61 & 235 & 417 & $\mathrm{~N} / \mathrm{A}$ \\
\hline
\end{tabular}

(a) "Total Samples" is the sum of QC, RMC, judgmental, and probabilistic samples.

(b) These statistical statements are listed for characterization as percent confidence/diameter of circular contaminated area in feet/FNR. For clearance, they are listed as percent confidence/percent of room that does not contain detectable contamination/multiplier. The multiplier indicates a judgmental sample location is either $1 \times$ or $3 \times$ more likely to contain detectable contamination relative to a probabilistic sample location.

(c) $\mathrm{NA}=$ not applicable.

(d) The room is being sampled with a characterization goal.

(e) These judgmental samples are to be collected in a composite fashion.

(f) Characterization statement: 95\% confidence of detecting a single circular contaminated area of diameter $8 \mathrm{ft}$ with an FNR of $10 \%$ or detecting a single circular contaminated area of diameter $10 \mathrm{ft}$ with an FNR of $29 \%$.

(g) The area (two adjacent rooms) is being sampled with a clearance goal, assuming a 30\% a priori probability that a judgmental sample will detect contamination.

(h) Three RMCs will be collected for each of the 10 second-floor rooms to be sampled during the characterization phase.

(i) The floor is being sampled with a clearance goal.

(j) There are three field blank samples (vacuum sock, wipe, and swab) for each of the 15 rooms to be sampled for clearance.

(k) CJR-based clearance statement: $95 \%$ confidence that either $98.6 \%$ of the floor does not contain detectable contamination with a judgmental sample location being $3 \times$ more likely to contain detectable contamination relative to a probabilistic sample location, or $95 \%$ confidence that $98.1 \%$ of the floor does not contain detectable contamination with a judgmental sample location $1 \times$ more (equally) likely to contain detectable contamination as a probabilistic sample location. All clearance numbers of samples assume the a priori probability that a judgmental sample will detect contamination is $10 \%$ after decontamination. 


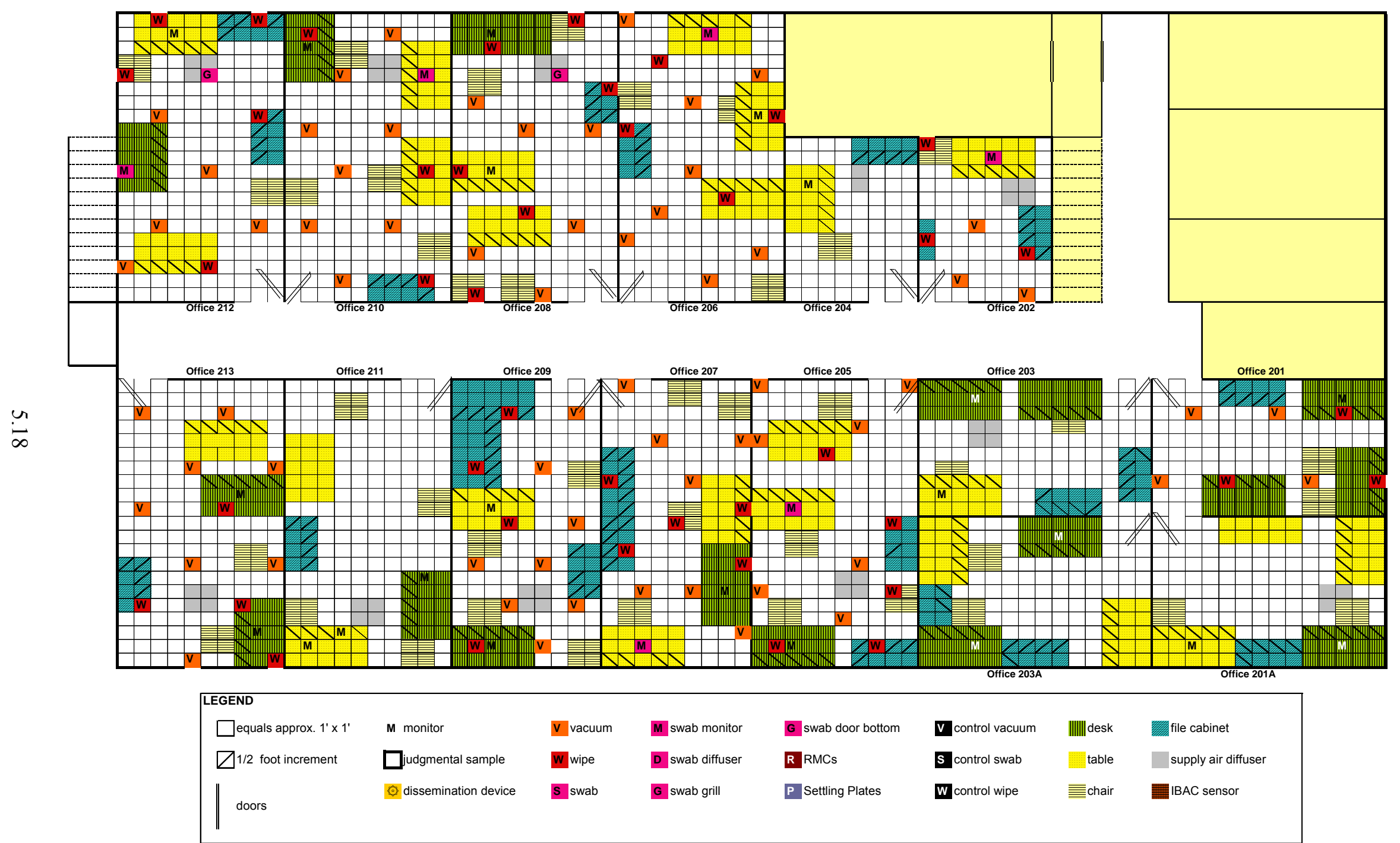

Figure 5.6. Map of Probabilistic Sample Locations and Types for Characterization Sampling of the Second Floor of the INL Building During INL-2 Test Event 5 
In the "after contamination" sampling design of Table 5.4, Offices 205 and 207 as well as 206 and 208 were paired to provide two opportunities for the CJR sampling approach to clear a portion of the floor during the characterization sampling phase. It is recommended that the door of Office 208 be closed and sealed in addition to the doors of Offices 205 to 207. Further, it is recommended that the vents into Offices 205 to 208 be covered and sealed. These measures should increase the chances of having no (or undetectable) contamination in at least one of the two pairs of rooms. If some contaminant still makes its way into one or more of these four rooms despite closing and sealing their doors and vents, the results would still be very useful for evaluating the performance of sampling approaches, sampling methods, and analytical methods in rooms with very low contaminant concentrations.

Offices 201 and 213 were specified for performing composite judgmental sampling. Based on pretest tracer studies performed in the INL building, Office 201 is expected to have a high contaminant concentration, while Office 213 is expected to have a lower concentration. Rooms nearby to these with similar contaminant concentrations (e.g., possibly Offices 202 and 212) where single-increment judgmental sampling will be performed can serve to compare the performance of single-increment and composite judgmental sampling.

The clearance phase of sampling in Test Event 5 includes 8 team-vacuum QC samples, 45 QC samples, 0 RMC samples, 20 judgmental samples, and 121 probabilistic samples. Note that the numbers of judgmental and probabilistic samples per floor after decontamination are the same for all five test events. Two examples of $\mathrm{X} \% / \mathrm{Y} \%$ clearance statements supported by these numbers of judgmental and probabilistic samples are shown in the last column of Table 5.4.

\subsection{Total Number of Samples}

Table 5.5 summarizes the total numbers of samples across all five test events (the ORI and the subsequent four test events). There are a total of 2085 samples, with 1142 samples after contamination (54.8\% of the total) and 943 samples after decontamination (45.2\% of the total). Of the 2085 total number of samples, $455(21.8 \%)$ are QC samples. There are 177 RMC samples planned after contamination, which is $15.5 \%$ of the total number of samples after contamination. 
Table 5.5. Summary of the Numbers of Samples Needed for All INL-2 Test Events in the PBF-632 Building

\begin{tabular}{|c|c|c|c|c|c|c|c|c|c|c|}
\hline \multirow[b]{2}{*}{$\begin{array}{l}\text { Test } \\
\text { Event }\end{array}$} & \multicolumn{5}{|c|}{$\begin{array}{c}\text { After Contamination } \\
\text { (Characterization Phase) }\end{array}$} & \multicolumn{5}{|c|}{$\begin{array}{l}\text { After Decontamination } \\
\text { (Clearance Phase) }\end{array}$} \\
\hline & 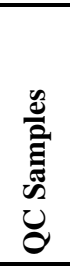 & 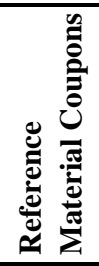 & 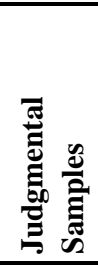 & 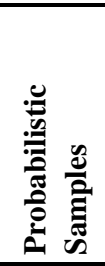 & 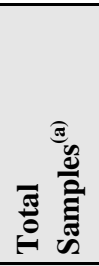 & 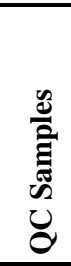 & 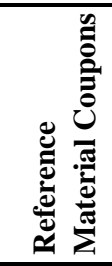 & 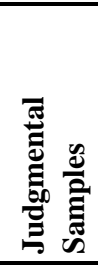 & 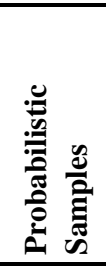 & ๘ \\
\hline Event $1^{(\mathrm{b})}$ & 44 & 36 & 36 & 108 & 224 & 44 & 0 & 20 & 121 & 185 \\
\hline Event 2 & 44 & 36 & 36 & 108 & 224 & 44 & 0 & 20 & 121 & 185 \\
\hline Event 3 & 53 & 45 & 45 & 105 & 248 & 53 & 0 & 20 & 121 & 194 \\
\hline Event 4 & 38 & 30 & 41 & 114 & 223 & 44 & 0 & 20 & 121 & 185 \\
\hline Event 5 & 38 & 30 & 41 & 114 & 223 & 53 & 0 & 20 & 121 & 194 \\
\hline Total & 217 & 177 & 199 & 549 & 1142 & 238 & 0 & 100 & 605 & 943 \\
\hline $\begin{array}{ll}\text { (a) "Total } & \text { sampl } \\
\text { (b) Event }\end{array}$ & & $\begin{array}{l}\text { the } \\
\text { abili } \\
\text { ratio }\end{array}$ & mpl & les, & ence & & & & udg & \\
\hline
\end{tabular}

\subsection{Experimental and Sampling Design Details}

The details of each sample in each test should be stored in a test matrix to clearly specify the nature and location of each sample. It is not possible to complete all of the entries in such a table at this time. Some of this information cannot be filled out until the QC, RMC, and judgmental sample locations are determined, and sampling teams are assigned. However, locations of probabilistic samples are known at this time and are listed in Tables D.1 to D.6 of Appendix D.

A draft layout of a test matrix table can be found in Appendix B. This table represents the samples that would be taken in Office 101 during Test Event 4. Information about each sample could be stored within this table or a similar table or software package. The results from the culture analysis of each sample could also be stored in this table, making it a good source for the data needed to perform the eventual statistical analyses of the data. 


\subsection{Experimental and Sampling Design Limitations}

The scope of the INL-2 Sample Collection Operational Test was limited because of the time and expense required to contaminate, sample, decontaminate, and re-sample a building in an operational environment. Concerns were expressed by the team planning the INL-2 Sample Collection Operational Test that it should not attempt to do too much. This section discusses several ways in which the INL-2 study was limited.

\subsection{Concentration Gradient}

One of the key aspects of the INL-2 Sample Collection Operational Test is the concentration gradient of the contaminant over a floor of the INL PBF-632 building. There is a possibility of three possible outcomes for a given gradient, two of which are undesirable. The ideal outcome is to obtain gradients with contaminant concentrations ranging from moderate to low contamination down to no contamination over a floor of the INL PBF-632 building. The two undesirable outcomes are that the contamination is evenly spread throughout the floor and is easily detectable in each room, or the contamination is confined to only the area of dissemination, and the other rooms are not contaminated. Because the experiment is dependent on obtaining good gradients, it will be important to review at least some of the results (perhaps the RMC samples) from the ORI (Test Event 1) before the second test event is started so adjustments can be made if necessary. Also, it is envisioned that the tracer studies conducted in the INL building before the testing will help define the characteristics necessary for desirable gradients.

\subsection{Aerosol Release}

While the experimental and sampling design for the INL-2 Sample Collection Operational Test was designed to study the performance of probabilistic and judgmental sampling, it is important to remember that only aerosol disseminations are being studied. Therefore, all conclusions made concerning the sampling approaches should state these limitations. For example, one of the main goals of the INL-2 study is to compare the capability of judgmental samples and probabilistic samples to detect contamination. It might be expected that judgmental samples should perform well in detecting an aerosol contaminant dispersed throughout a building via HVAC vents and return air pathways. An early draft of the experimental design contained one test event with localized "hot spot" contamination of smaller areas of varying size in different rooms, potentially in locations that would not naturally be chosen by judgmental samples. Such a contamination scenario would have been more likely to show the advantages of larger numbers of probabilistic samples (compared to typically smaller numbers of judgmental samples) in detecting smaller areas of contamination in less-likely locations. However, this contamination scenario was not included in a test event of the final experimental design because of issues about how to contaminate smaller areas with viable contaminant spores.

\subsection{Probabilistic Sampling of Horizontal Surfaces}

All probabilistic sampling for the experimental and sampling design of the INL-2 Sample Collection Operational Test has been designed to sample only horizontal surfaces. In developing the sampling plans, a decision was made if a sample location has more than one possible horizontal surface. Generally, it was decided to sample the highest vertical point of the sampling area without sampling anything on the ceiling. For example, if the vertical extension of a sample location has the floor, a desktop, and a ceiling 
vent, it will be decided to sample the desktop. Future versions of the VSP software (Matzke et al. 2007) will include the capability to add furniture to the probabilistic sampling area so future experiments could be designed to take advantage of this feature. The VSP software already has the capability to sample from floors, walls, and ceiling of a room or building by "laying out" the room/building and then selecting "horizontal" samples from the "laid out" room/building. However, that capability requires larger numbers of samples to cover the increased surface area, and it was judged sufficient for the INL exercise to sample only horizontal surfaces on which aerosol-disseminated contaminant could settle.

\subsection{Limited Knowledge of Information Required to Calculate Numbers of Samples}

Many assumptions are necessary to calculate the numbers of samples required to make statistical confidence statements for detection and clearance. These assumptions include the size of the contaminated area, the FNR, how much more likely a judgmental sample location is to contain detectable contamination relative to a probabilistic sample location, and the a priori probability that a judgmental sample will detect contamination. A limitation of the experimental and sampling design for the INL-2 Sample Collection Operational Test is that previous research has not fully defined specific values for each of these assumptions. Reasonable ranges for each assumption were created using expertise from subject matter experts. Multiple statistical statements were made with each number of samples considered. These statistical statements look across the expected range of values for each assumption. These investigations were performed to minimize the limitation of not knowing the actual values of quantities involved in the assumptions.

\subsection{Comparing Sample-Collection Methods}

In general, the sample-collection methods to be used in the INL-2 Sample Collection Operational Test (swab, wipe, vacuum) are each used in unique sampling situations such that there is little opportunity to compare results from one sampling method to results from another. In early planning of the experimental and sampling design, the statistical comparison of results obtained from side-by-side wipe and vacuum samples of non-porous surfaces was considered. This testing would have also included side-by-side sampling with the same sampling methods as a way of quantifying the variation in contamination and uncertainty in sampling and analytical processes. However, it was ultimately decided that this sort of investigation was not feasible because of the limitations on the numbers of samples that could be collected and analyzed within the available time for testing at the INL PBF-632 building.

\subsection{Comparing Judgmental and Probabilistic Samples to RMC Samples}

The experimental and sampling design was not constructed to enable direct comparison of results from judgmental and probabilistic samples to those from RMC samples. The settling pattern of the BG contaminant on surfaces in a given room of the INL PBF-632 building is expected to vary considerably within a room and from room to room. Hence, results from RMC samples cannot be directly compared to results from judgmental and probabilistic samples because of the likelihood that locations where RMC samples are collected will be contaminated to different extents than the locations where judgmental and probabilistic samples are collected. However, it is possible to use RMC samples to give a general indication of the extent to which a given room was contaminated and to assess the relative levels of 
contamination from room to room. Thus, the RMC samples will be useful in assessing how well desirable gradients across each floor of the INL PBF-632 building (see Section 2.2) were achieved.

\subsection{Numbers of Test Events and Numbers of Samples}

Because of the period of time available for testing at the INL PBF-632 building, as well as the time and funding available for sample collection and analysis, the number of test events and the total number of samples per test event were limited. These limitations ultimately impact the ability to perform statistical analyses of the test data. However, the limitations on numbers of samples were accommodated by 1) sampling only some rooms during the characterization phase of sampling and 2) assigning fewer samples to be collected from rooms closer to the contaminant release locations (for overt Test Events 4 and 5).

\subsection{Limitations in VSP Software}

Although the VSP software (Matzke et al. 2007) has had additional capabilities added in new versions over its 10-year history, it still has some limitations that impacted the calculation of numbers of samples associated with the experimental and sampling design for the INL-2 Sample Collection Operational Test. The VSP limitations include:

- VSP creates probabilistic sampling plans that are based on the assumption that the probability of contamination is the same for each sample location. Only in CJR sampling designs does VSP provide for different probabilities of detectable contamination for judgmental versus probabilistic samples.

- VSP can only account for the surface area covered by a single sample (i.e., the physical area that is swabbed, wiped, or vacuumed) when a $0 \%$ FNR is assumed. In that case, only one magnitude of surface area is allowed. If a positive FNR is specified, then VSP currently assumes "point samples." Not accounting for differences in surface area sampled is an unrealistic assumption when different sampling methods (such as swab, wipe, and vacuum) are used. Assuming point samples in the FNR $>0$ case leads to larger numbers of samples than would otherwise be needed.

- The CJR sampling approach implemented in VSP for clearing uncontaminated or decontaminated areas currently only addresses the case where FNR $=0$. If the FNR is actually greater than zero, then the numbers of samples calculated for the FNR $=0$ case provide less protection than indicated by $\mathrm{X}$ and/or $\mathrm{Y}$ in a $\mathrm{X} \% / \mathrm{Y} \%$ clearance statement. Not accounting for FNR $>0$ also results in clearance statements of the form " $\mathrm{X} \%$ confidence that at least $\mathrm{Y} \%$ of the area does not contain detectable contamination," rather than the more desirable clearance statement "X\% confidence that at least $\mathrm{Y} \%$ of an area is uncontaminated."

\subsection{Conclusions Regarding Study Limitations}

The limitations identified and described in the preceding sections are not so severe that they compromise the ability to meet the objectives of the INL-2 Sample Collection Operational Test. Rather, they should be considered in the data analyses of the INL-2 study and any future studies. 


\subsection{Summary and Recommendations for Any Future Studies}

Section 7.1 summarizes the work performed to generate the experimental and sampling design presented in this report for the INL-2 Sample Collection Operational Test. Section 7.2 makes recommendations for any future studies that may be conducted.

\subsection{Summary}

This report documents the experimental and sampling design developed for the INL-2 Sample Collection Operational Test.

The VSPWG developed five objectives for the INL-2 study. These objectives are listed in Section 1.2. The primary objectives that influenced developing the experimental and sampling design presented in this report are summarized below.

- Evaluate judgmental and probabilistic sampling for characterization as well as probabilistic and hybrid (judgment and probabilistic) sampling approaches for clearance.

- Conduct these evaluations for gradient contamination (from low or moderate down to absent or not detectable) for different initial concentrations of the contaminant.

- Explore judgment composite sampling approaches to reduce sample numbers.

- Collect baseline data to serve as an indication of the actual levels of simulant contamination in the tests.

The CJR sampling approach is a hybrid approach that combines judgmental and probabilistic (random) samples to make clearance statements of the form " $\mathrm{X} \%$ confidence that at least $\mathrm{Y} \%$ of a room (or floor of the building) does not contain detectable contamination." These are referred to as $\mathrm{X} \% / \mathrm{Y} \%$ clearance statements.

The INL-2 experimental design described in this report includes five test events, the first of which is an ORI. The test events 1) vary the floor of the building on which the contaminant will be released, 2) provide for varying or adjusting the concentration of contaminant released to obtain desired concentration gradients across a floor of the building, and 3) investigate overt as well as covert release of contaminants (i.e., the responders either know or do not know the release point of the contaminant). Desirable contaminant gradients would have contaminant concentrations ranging from moderate to low and down to zero (i.e., not contaminated). Such gradients are desirable because they would provide a range of contamination levels to challenge the sampling, sample extraction, and analytical methods.

Test Event 1 is an Operational Readiness Inspection to confirm that the whole testing process is ready for testing and to make adjustments if needed. Test Events 1, 2, and 3 are covert scenarios in which the locations of contaminant release are not known to the people who selected the specific locations of judgmental and probabilistic samples or to the sampling teams. Test Events 4 and 5 are overt scenarios in which the locations of contaminant release are known to these participants. 
For each of the five test events, the specified floor of the INL PBF-632 building will be contaminated with BG. The BG contaminant will be disseminated from a point-release device located in the room for each test event specified in the experimental design. Then QC, RMC, judgmental, and probabilistic samples will be collected according to the pre-specified sampling plan for each event. Judgmental samples will be selected based on professional judgment and prior information. Probabilistic samples were selected with a random aspect and in sufficient numbers to provide desired confidence for detecting contamination or clearing uncontaminated (or decontaminated) areas. Following sample collection for a given test event, the INL PBF-632 building will be decontaminated using $\mathrm{Cl}_{2} \mathrm{O}$ gas.

For possibly contaminated areas (which may be individual rooms or a whole floor of the INL PBF632 building), the numbers of probabilistic samples were chosen to provide $95 \%$ confidence of detecting contaminated areas of specified sizes. The numbers of judgmental samples were chosen based on guidance from experts in judgmental sampling. For rooms that may be uncontaminated following a contamination event or for whole floors after decontamination, the numbers of judgmental and probabilistic samples were chosen using the CJR sampling approach that combines judgmental and probabilistic samples. The numbers of judgmental and probabilistic samples were chosen to make clearance statements of the form " $\mathrm{X} \%$ confidence that at least $\mathrm{Y} \%$ of the floor does not contain detectable contamination". To clear a pair of rooms, $X=95 \%$ and $Y=92 \%$ or $95 \%$ depending on the values of parameters assumed for the CJR approach. To clear a floor of the building, $\mathrm{X}=99 \%$ and $\mathrm{Y}=96 \%$ or 97\% depending on the parameters assumed for the CJR approach. The experimental and sampling design also provides for making X\%/Y\% clearance statements using only probabilistic samples, where 95\%/89\% was obtained for clearing two rooms and $99 \% / 96 \%$ was obtained for clearing a floor of the building.

For each test event, the numbers of characterization and clearance samples were selected within limits based on operational considerations while still maintaining high confidence for detection and clearance aspects. The sampling design for all five test events specifies a total of 2085 samples, with 1142 after contamination (characterization and clearance) and 943 after decontamination (clearance). These numbers include QC, RMC, judgmental, and probabilistic samples. The experimental and sampling design specified in this report provides a good statistical foundation for achieving the objectives of the INL-2 Sample Collection Operational Test, despite some limitations of the experimental and sampling design.

The limitations of the experimental and sampling design for the INL-2 Sample Collection Test are briefly summarized below (see Section 6 for more detailed discussions).

- $\quad$ Concentration Gradient: All five test events relied on releasing the contaminant as an aerosol from a room at one end of either the first or the second floor of the INL PBF-632 building. Desirable gradients would have the contaminant concentration varying from moderate to low all the way down to uncontaminated. If desirable gradients are not achieved, it would limit the ability to achieve some of the objectives.

- Aerosol Release: Considering only aerosol releases meets the objectives of this particular study, but limits the ability to make conclusions about other types of contaminant releases. In particular, it limits the ability to compare probabilistic and judgmental samples when contamination occurs in "hot spots" (i.e., smaller areas of contamination surrounded by uncontaminated, or very lowly contaminated, areas). 
- $\quad$ Probabilistic Sampling of Horizontal Surfaces: The numbers of probabilistic samples for the INL-2 sampling design were chosen assuming that only horizontal surfaces would be sampled. This reduced the number of samples required to detect contamination or clear an area, which was required to meet limitations on the time and personnel available for sampling. Sampling only horizontal surfaces is a limitation of the study to the extent that non-horizontal surfaces could be contaminated with a different chance than horizontal surfaces. This possibility was deemed unlikely for the aerosol dissemination method to be used.

- $\quad$ Limited Knowledge of Information Required to Calculate Numbers of Samples: Several input parameters are necessary to calculate the numbers of probabilistic samples needed to detect contamination or to clear an uncontaminated (or decontaminated) area. These include the size of the contaminated areas to be detected, the FNR, how much more likely it is that a judgmental sample location contains detectable contamination compared to a probabilistic sample location (required in the CJR sampling approach), and the a priori probability that a judgmental sample will detect contamination. Note that the FNR includes all "inefficiencies" and uncertainties associated with sample collection, sample recovery, sample transportation/aging, and analytical methods. Because good estimates of these input parameters were not available, it was necessary to perform calculations over a range of parameter values judged to be reasonable.

- Comparing Sample Collection Methods: The experimental and sampling design does not provide for statistically comparing sample collection methods (swab, wipe, vacuum). It was considered possible to compare wipe and vacuum methods for non-porous surfaces, but doing so was considered a lower priority given the number of additional samples that would have been required. Collecting some side-by-side samples using the same sampling method was also considered as a way to quantify the combined uncertainties in "nearby sampling," sample extraction, and analytical. This was also considered a lower priority given the additional number of samples that would have been required.

- Comparing Judgmental and Probabilistic Samples to RMC Samples: The experimental and sampling design was not constructed to enable direct comparison of results from judgmental and probabilistic samples to those from RMC samples. Results from RMC samples cannot be directly compared to results from judgmental and probabilistic samples because it is likely that RMC sample locations will be contaminated to different extents than judgmental and probabilistic sample locations. However, it is possible to use RMC samples to obtain a general indication of the extent to which a given room was contaminated and to assess the relative levels of contamination from room to room.

- Numbers of Test Events and Numbers of Samples: Because of the period of time available for testing at the INL PBF-632 building as well as the time and funding available for sample collection and analysis, the number of test events and the total number of samples per test event were limited in the INL-2 study. These limitations ultimately impact the ability to perform statistical analyses of the test data. However, the limitations on numbers of samples were accommodated by 1) sampling only some rooms during the characterization phase of sampling and 2) assigning fewer samples to be collected from rooms closer to the contaminant release locations (for overt Test Events 4 and 5).

- Limitations in VSP Software: The VSP software (Matzke et al. 2007) was well suited for use in calculating numbers of samples for characterization and clearance in the INL-2 Sample Collection Operational Test. However, VSP has some limitations, as follows. 
1) The VSP creates probabilistic sampling designs that are based on the assumption that the probability of contamination is the same for each sample location. The CJR sampling designs in VSP do allow for different probabilities of contamination for judgmental versus probabilistic samples.

2) The VSP does not provide for different sampling methods covering different surface areas, such as occurs with swab, wipe, and vacuum samples.

3) When the FNR is greater than zero, the VSP assumes point samples (with negligible surface area), which yields larger numbers of samples than would otherwise be required.

4) The CJR sampling approach implemented in VSP for clearing uncontaminated or decontaminated areas currently only addresses the case where FNR $=0$. If the FNR is actually greater than zero, then the numbers of samples calculated provide less protection (i.e., $\mathrm{X}$ and/or $\mathrm{Y}$ values) in a $\mathrm{X} \% / \mathrm{Y} \%$ clearance statement. This also results in clearance statements of the form " $\mathrm{X} \%$ confidence that at least $\mathrm{Y} \%$ of the area does not contain detectable contamination," rather than the more desirable statement " $\mathrm{X} \%$ confidence that at least $\mathrm{Y} \%$ of an area is uncontaminated."

It is important to note that these limitations are not so severe that they compromise the ability to meet the objectives of this study. Hence, the experimental design and numbers of QC, RMC, judgmental, and probabilistic samples specified in this report provide a good statistical foundation for achieving the objectives of the INL-2 Sample Collection Operational Test.

\subsection{Recommendations for any Future Studies}

The following specific recommendations are made for any future testing that may be conducted at the INL PBF-632 building or other real-world facilities.

- Other Contamination Scenarios: Other contamination scenarios that may be possible in a realworld environment should be investigated in any future work. For example, "hot-spot" scenarios in which contaminated areas are surrounded by uncontaminated areas should be tested using a range of sizes for contaminated areas. This is a fundamentally different type of contamination scenario than the aerosol release scenario considered in this report. Hot-spot contamination is harder to detect and would more readily show the advantages of probabilistic sampling over judgmental sampling, especially if the hot spots of contamination are located (e.g., placed by a terrorist or disgruntled employee) in places that are not typically sampled by judgmental sampling.

- Contributors to FNR: To address congressional and GAO concerns (see Section 1.1) about making defensible conclusions based on negative results, it is extremely important to have good estimates of FNRs. The FNR is likely to be different for each sample collection, recovery, transportation/aging, and analytical method combination. The FNR will also depend on the level of contamination - the FNR increases as the level of contamination decreases.

- Information to Calculate Numbers of Samples: For any future studies, better estimates are needed for input parameters used in calculating the numbers of samples necessary to satisfy detection and clearance requirements. In addition to the FNR discussed in the previous bullet, other parameters include the size of contaminated areas to be detected, how much more likely a judgmental sample location is to be contaminated than a probabilistic sample location, and the a priori probability 
that a judgmental sample will detect contamination. The last two items are required in the CJR sampling approach that combines judgmental and probabilistic sampling.

In general, it is also recommended that statisticians be involved in planning, experimental and sampling design, and data analyses of future validation work such as is described in the Interagency Strategic Plan. ${ }^{(a)}$ Statistical involvement is critical to planning experimental studies and analyzing the data that result from them. In this way resources are used efficiently, testing and analytical uncertainties are accounted for, and that conclusions can be made with the desired statistical confidence. Statistical planning combined with proper statistical analysis of data leads to defensible conclusions that satisfy the research objectives.

(a) Interagency Strategic Plan for Validation of Environmental Sampling Methods Used in Detection and Cleanup of B. Anthracis Contamination in Facilities, June 29, 2007. 


\subsection{References}

Bowen MW and CA Bennett. 1988. Statistical Methods for Nuclear Material Management. NUREG/CR-4604, U.S. Nuclear Regulatory Commission, Washington, DC.

Government Accountability Office (GAO). 2005a. Anthrax Detection: Agencies Need to Validate Sampling Activities in Order to Increase Confidence in Negative Results (Report to the Chairman, Subcommittee on National Security, Emerging Threats, and International Relations, House Committee on Government Reform, House of Representatives). GAO-05-251, U.S. Government Accountability Office, Washington, DC, March 2005.

Government Accountability Office (GAO). 2005b. Anthrax Detection: Agencies Need to Validate Sampling Activities in Order to Increase Confidence in Negative Results, (Testimony before the Chairman, Subcommittee on National Security, Emerging Threats, and International Relations, House Committee on Government Reform, House of Representatives). GAO-05-493T, U.S. Government Accountability Office, Washington, DC, April 2005.

Gelman A, JB Carlin, HS Stern, and DB Rubin. 2003. Bayesian Data Analysis, Second Edition. Chapman \& Hall/CRC, New York, NY.

Gilbert RO. 1987. Statistical Methods for Environmental Pollution Monitoring. Van Nostrand Reinhold, New York, NY.

Gilbert RO, JE Wilson, RF O'Brien, DK Carlson, DJ Bates, BA Pulsipher, and CA McKinstry. 2002. Version 2.0 Visual Sample Plan (VSP): Models and Code Verification. PNNL-13991, Pacific Northwest National Laboratory, Richland, WA. Available at: http://vsp.pnl.gov/docs/pnnl13991.pdf. Accessed 01-13-09.

Hahn GJ and WQ Meeker. 1991. Statistical Intervals, A Guide to Practitioners. John Wiley \& Sons, Inc., New York, NY.

Matzke BD, JE Wilson, LL Nuffer, ST Dowson, RO Gilbert, NL Hassig, JE Hathaway, CJ Murray, LH Sego, BA Pulsipher, B Roberts, and S McKenna. 2007. Visual Sample Plan Version 5.0 User's Guide. PNNL-16939, Pacific Northwest National Laboratory, Richland, WA. Available at:

http://vsp.pnl.gov/docs/pnnl16939.pdf. Accessed 01-13-09.

Sego LH and JE Wilson. 2007. Accounting for False Negatives in Hotspot Detection. PNNL16812, Pacific Northwest National Laboratory, Richland, WA.

Sego LH, KK Anderson, BD Matzke, WK Sieber, S Shulman, J Bennett, M Gillen, JE Wilson, and BA Pulsipher. 2007. An Environmental Sampling Model for Combining Judgment and Randomly Placed Samples. PNNL-16636, Pacific Northwest National Laboratory, Richland, WA. 


\section{Appendix A: Numbers of Probabilistic Samples}

Figures A.1 through A.12 display the numbers of probabilistic samples calculated for confidence levels ranging from $50 \%$ to $95 \%$, circular contaminated areas ranging from 1 foot to 10 feet in diameter, and false-negative rates ranging from $0 \%$ to $50 \%$. Only combinations of these factors that result in 100 or less samples for a typical room in the INL PBF-632 building or 500 or less samples for a single floor are displayed. Odd-numbered figures display numbers of samples for a typical room, while even-numbered figures display numbers of samples for a single floor. 


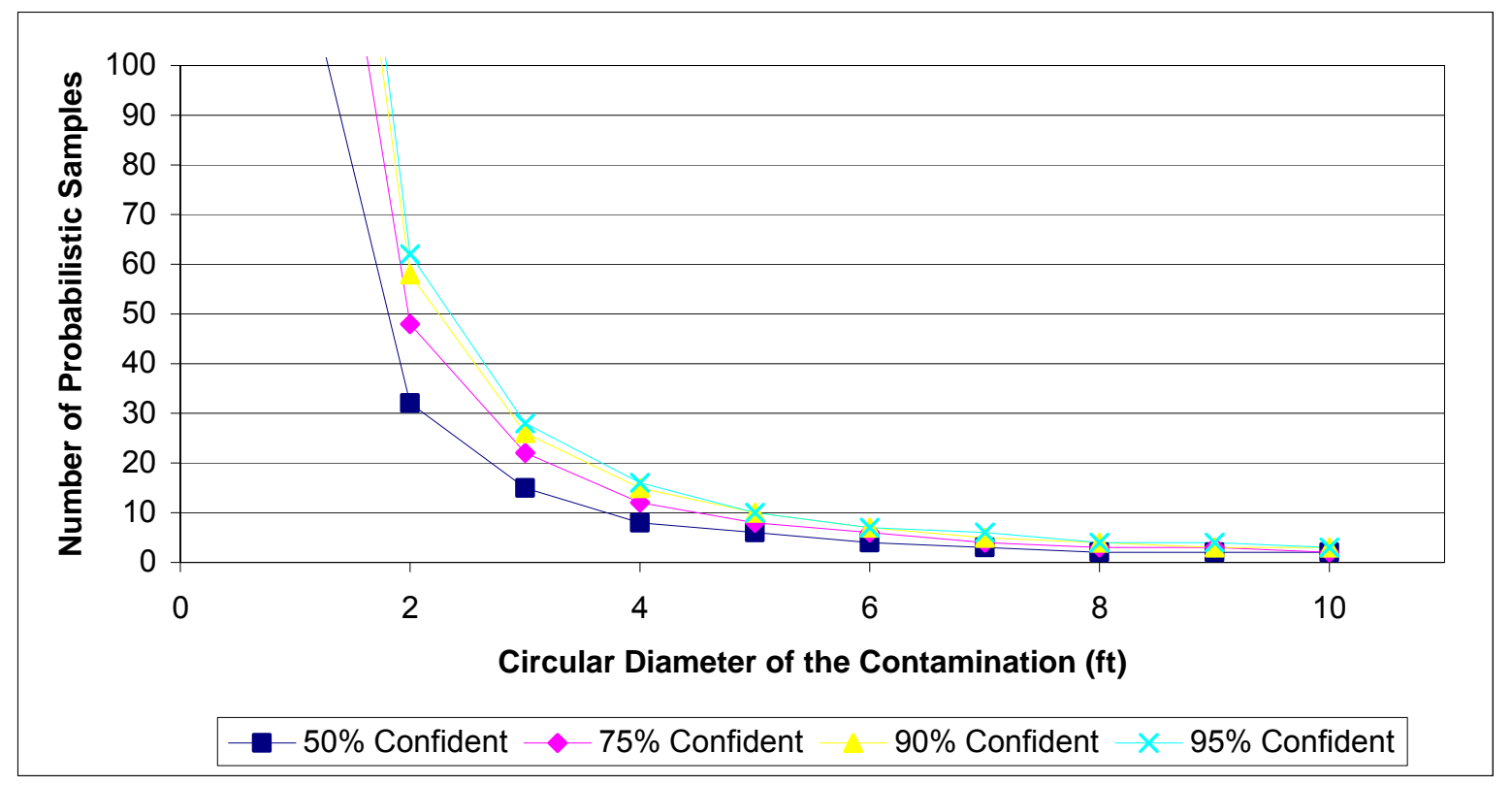

Figure A.1. Number of Probabilistic Samples Required to Detect with $0 \%$ False Negative Rate a Circular Contaminated Area of a Given Diameter with a Given Confidence (represented by the colored lines) within a Typical Room of the INL PBF-632 Building

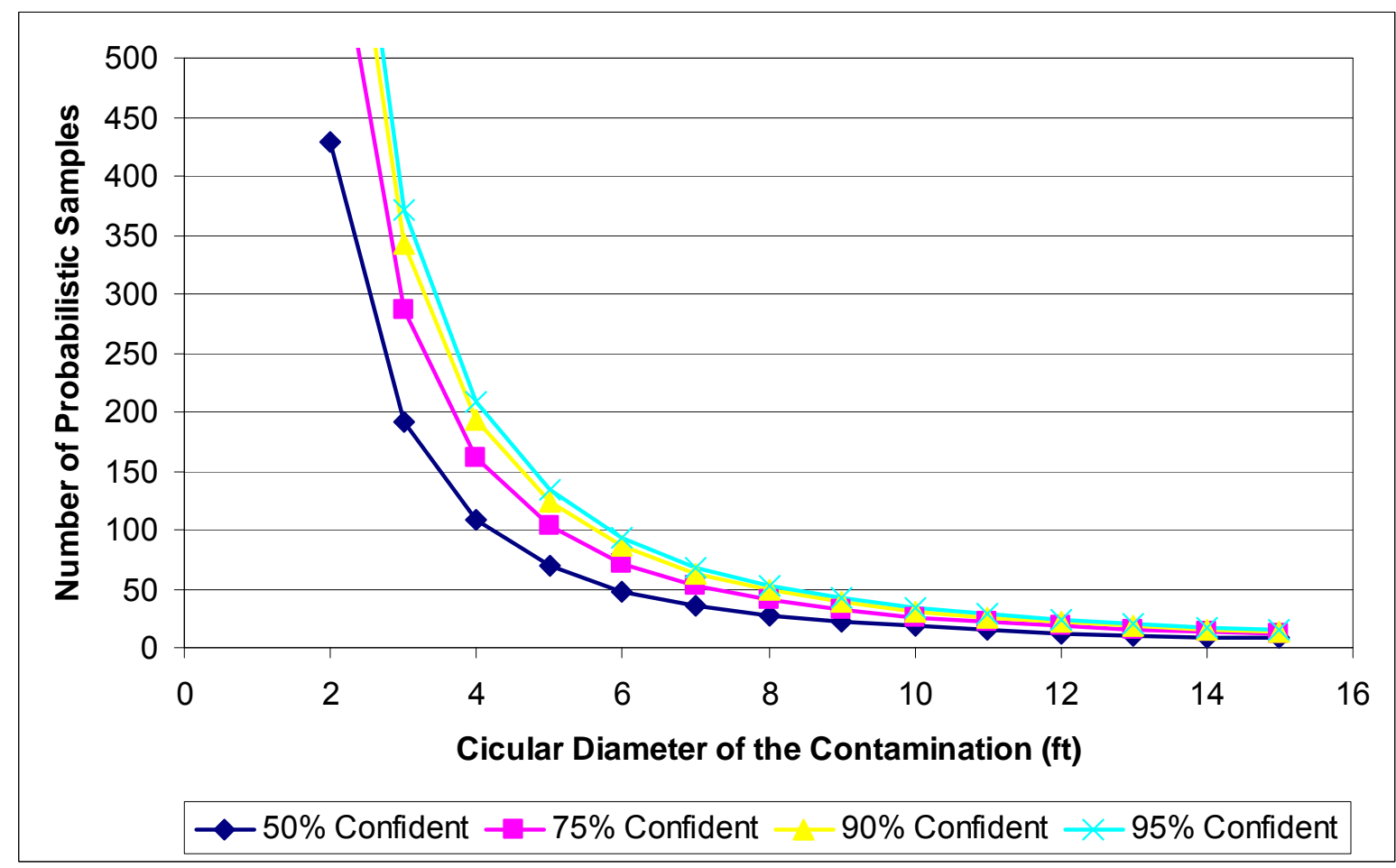

Figure A.2. Number of Probabilistic Samples Required to Detect with $0 \%$ False Negative Rate a Circular Contaminated Area of a Given Diameter with a Given Confidence (represented by the colored lines) within a Single Floor of the INL PBF-632 Building 


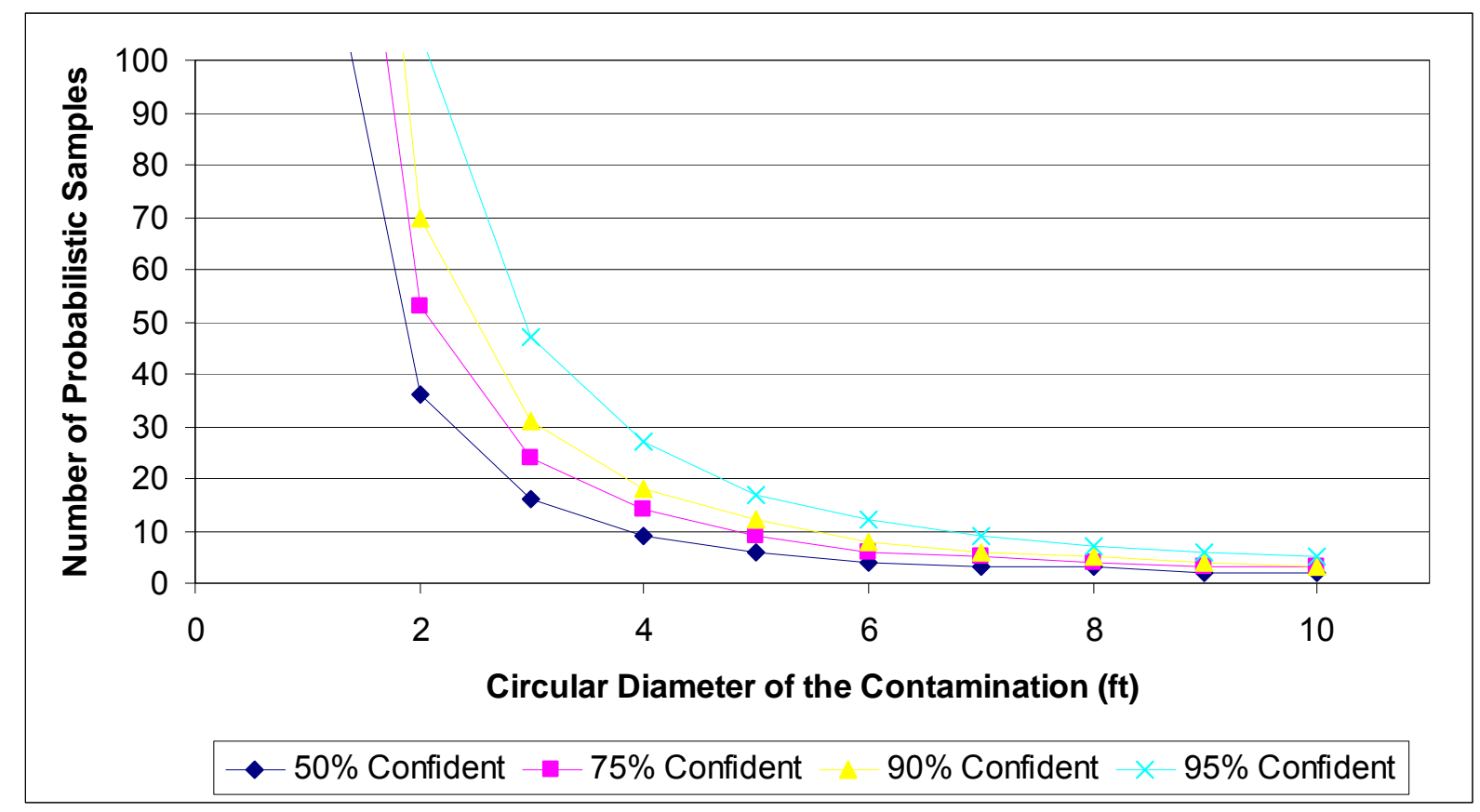

Figure A.3. Number of Probabilistic Samples Required to Detect with 10\% False Negative Rate a Circular Contaminated Area of a Given Diameter with a Given Confidence (represented by the colored lines) within a Typical Room of the INL PBF-632 Building

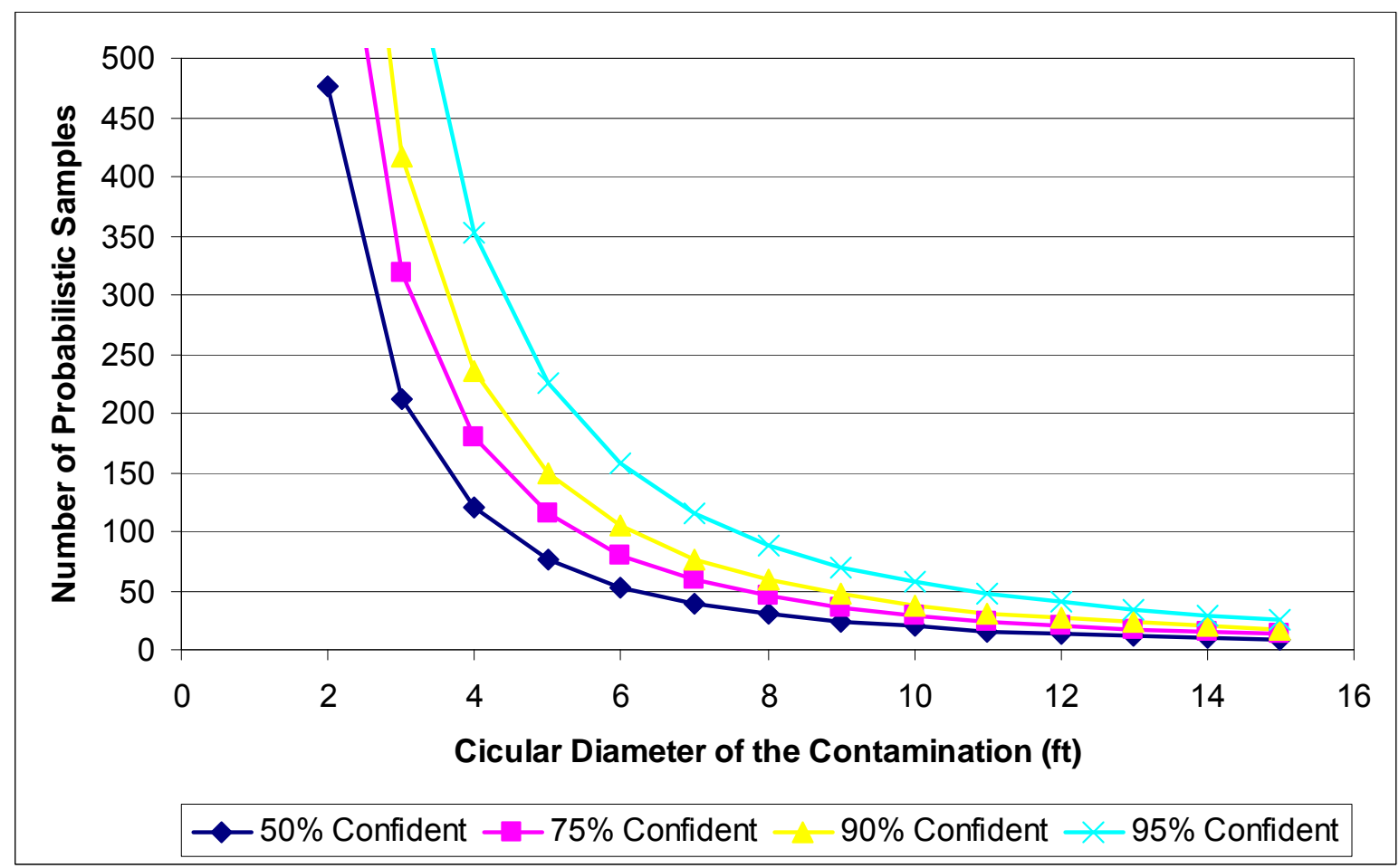

Figure A.4. Number of Probabilistic Samples Required to Detect with 10\% False Negative Rate a Circular Contaminated Area of a Given Diameter with a Given Confidence (represented by the colored lines) within a Single Floor of the INL PBF-632 Building 


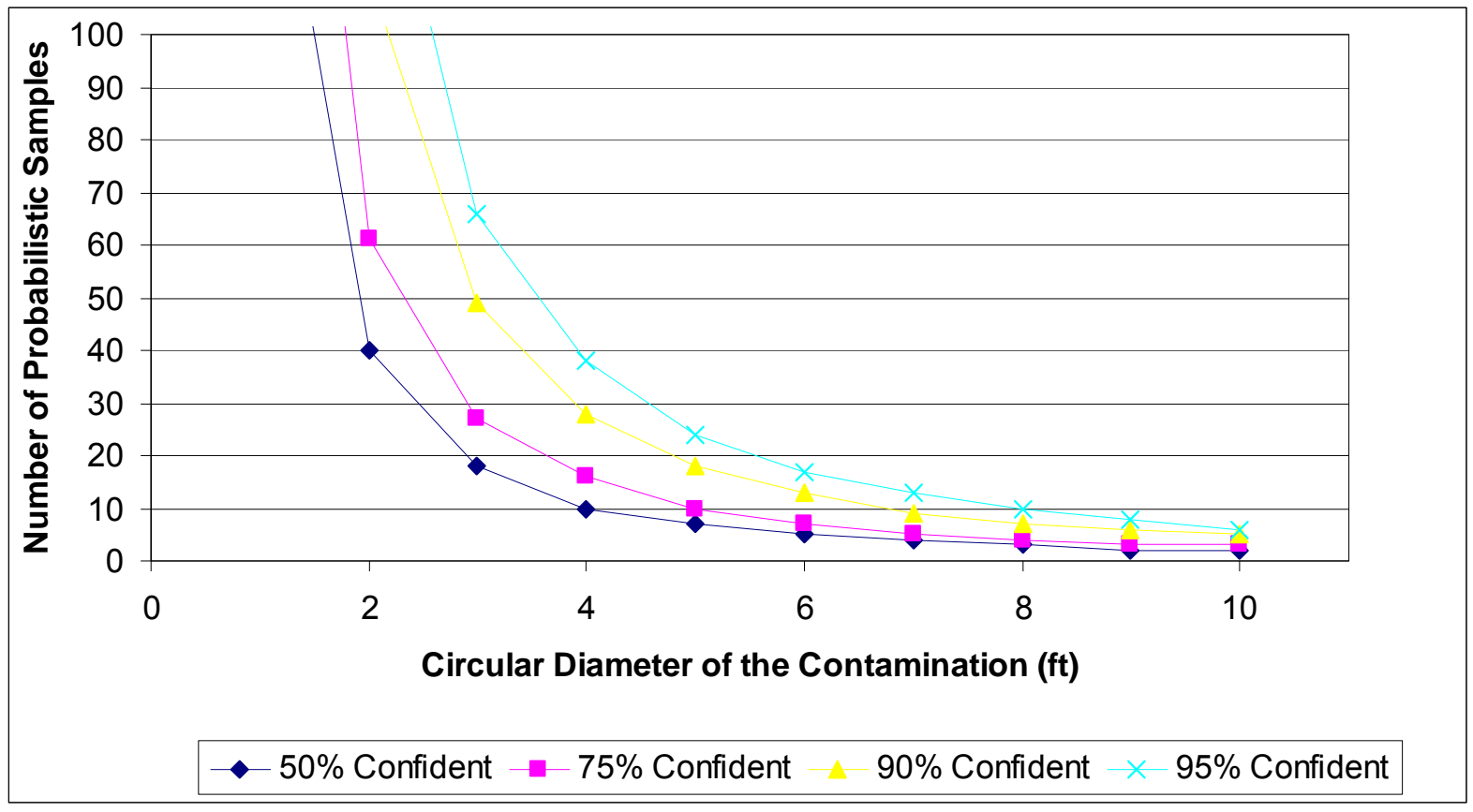

Figure A.5. Number of Probabilistic Samples Required to Detect with 20\% False Negative Rate a Circular Contaminated Area of a Given Diameter with a Given Confidence (represented by the colored lines) within a Typical Room of the INL PBF-632 Building

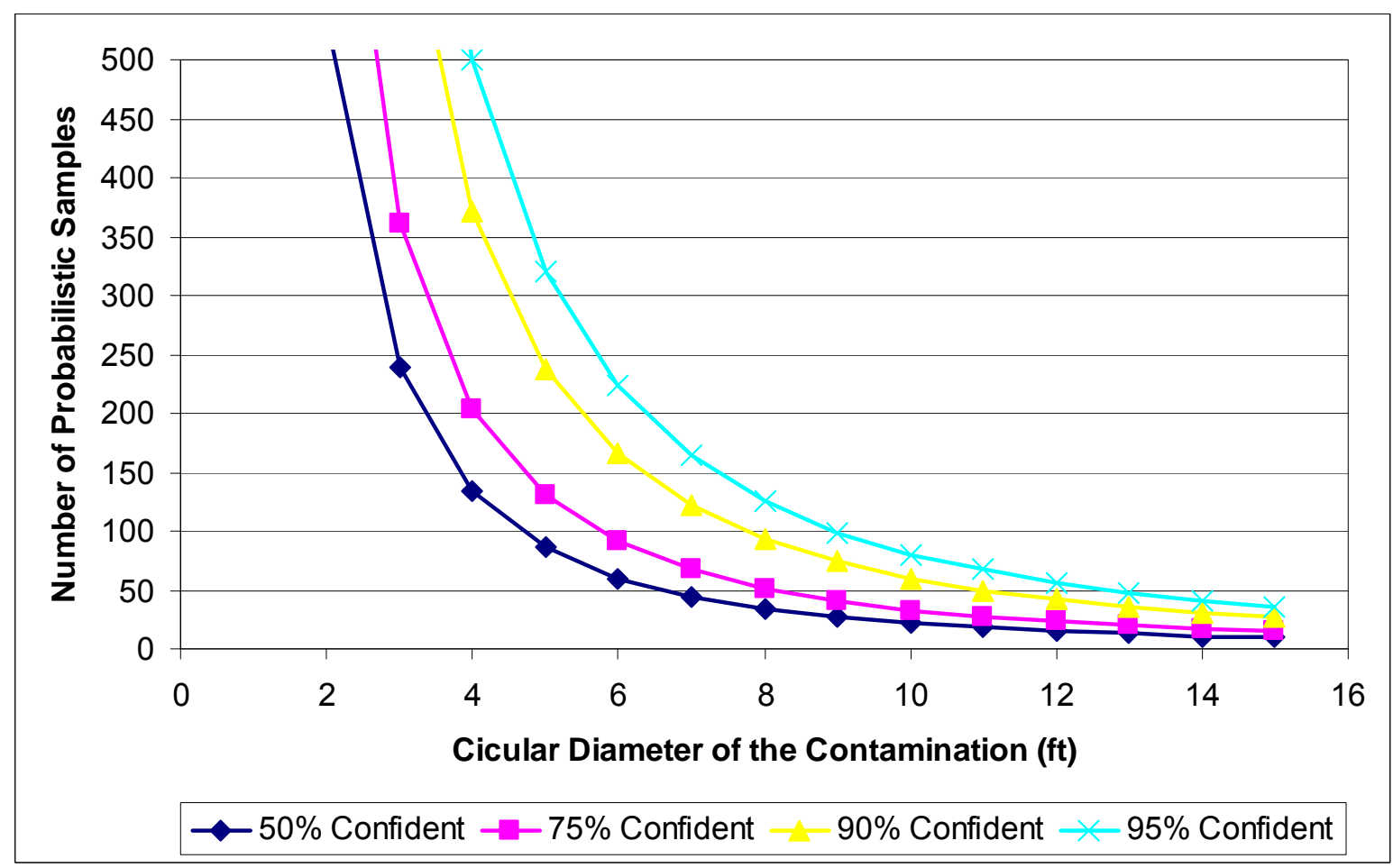

Figure A.6. Number of Probabilistic Samples Required to Detect with 20\% False Negative Rate a Circular Contaminated Area of a Given Diameter with a Given Confidence (represented by the colored lines) within a Single Floor of the INL PBF-632 Building 


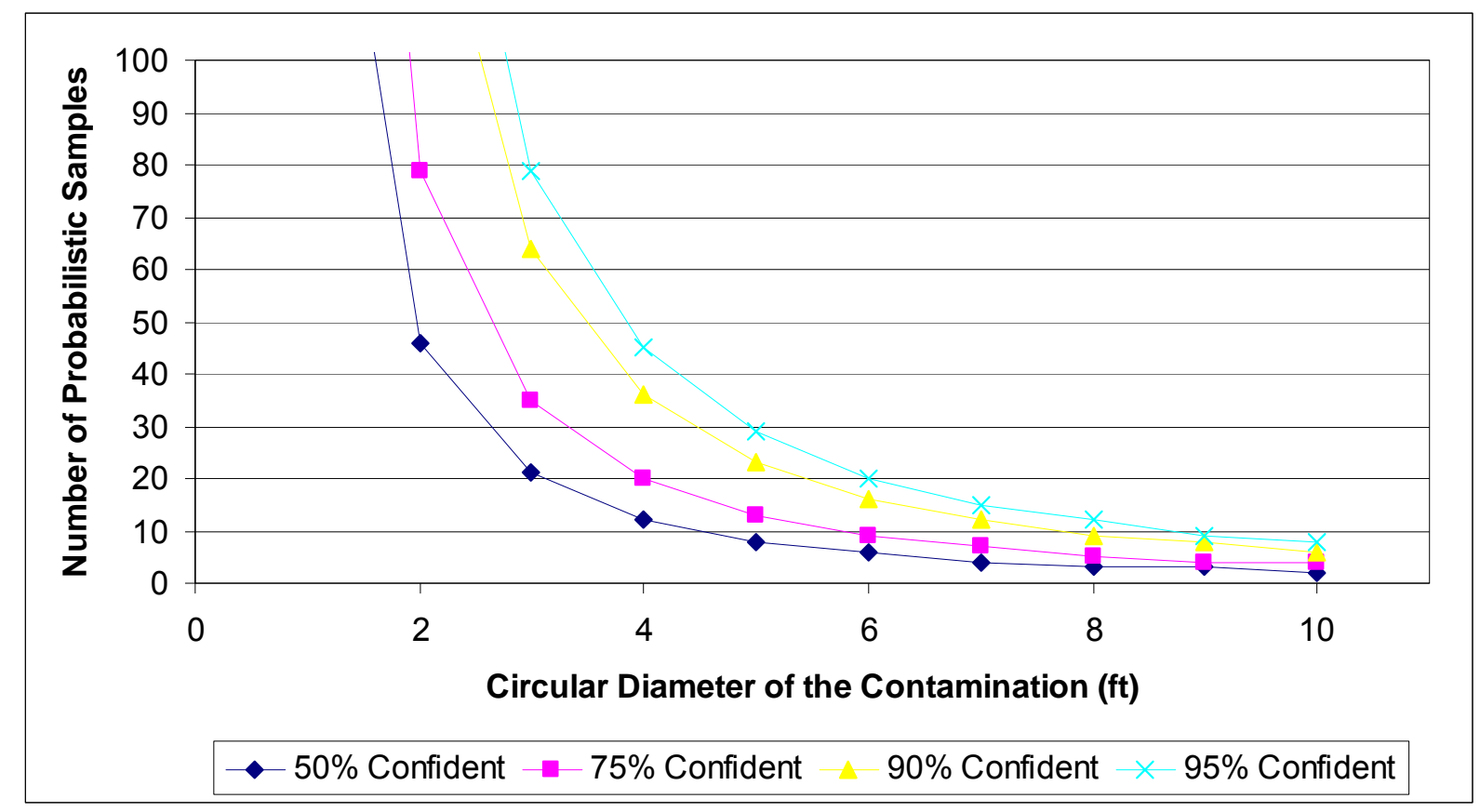

Figure A.7. Number of Probabilistic Samples Required to Detect with 30\% False Negative Rate a Circular Contaminated Area of a Given Diameter with a Given Confidence (represented by the colored lines) within a Typical Room of the INL PBF-632 Building

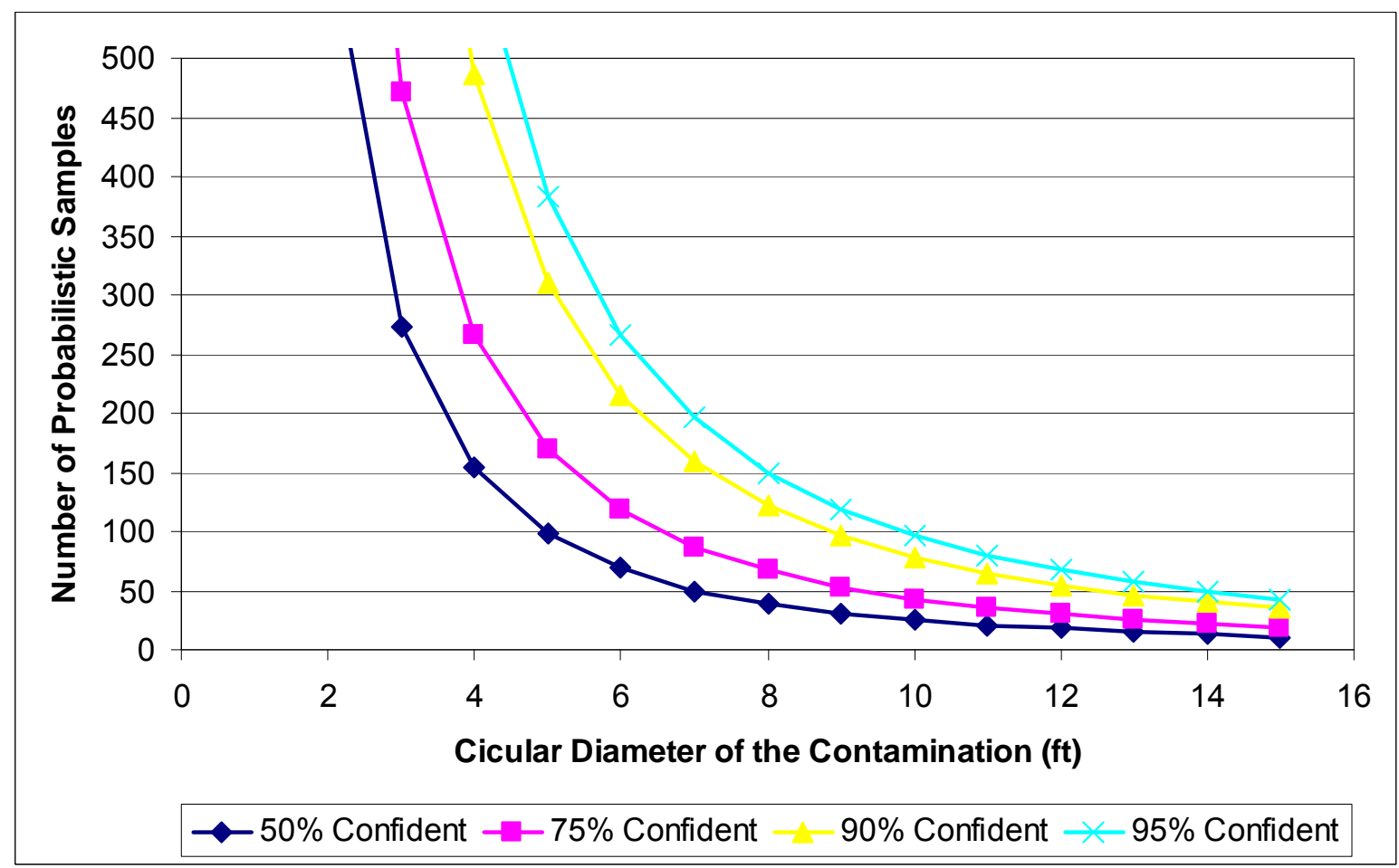

Figure A.8. Number of Probabilistic Samples Required to Detect with 30\% False Negative Rate a Circular Contaminated Area of a Given Diameter with a Given Confidence (represented by the colored lines) within a Single Floor of the INL PBF-632 Building 


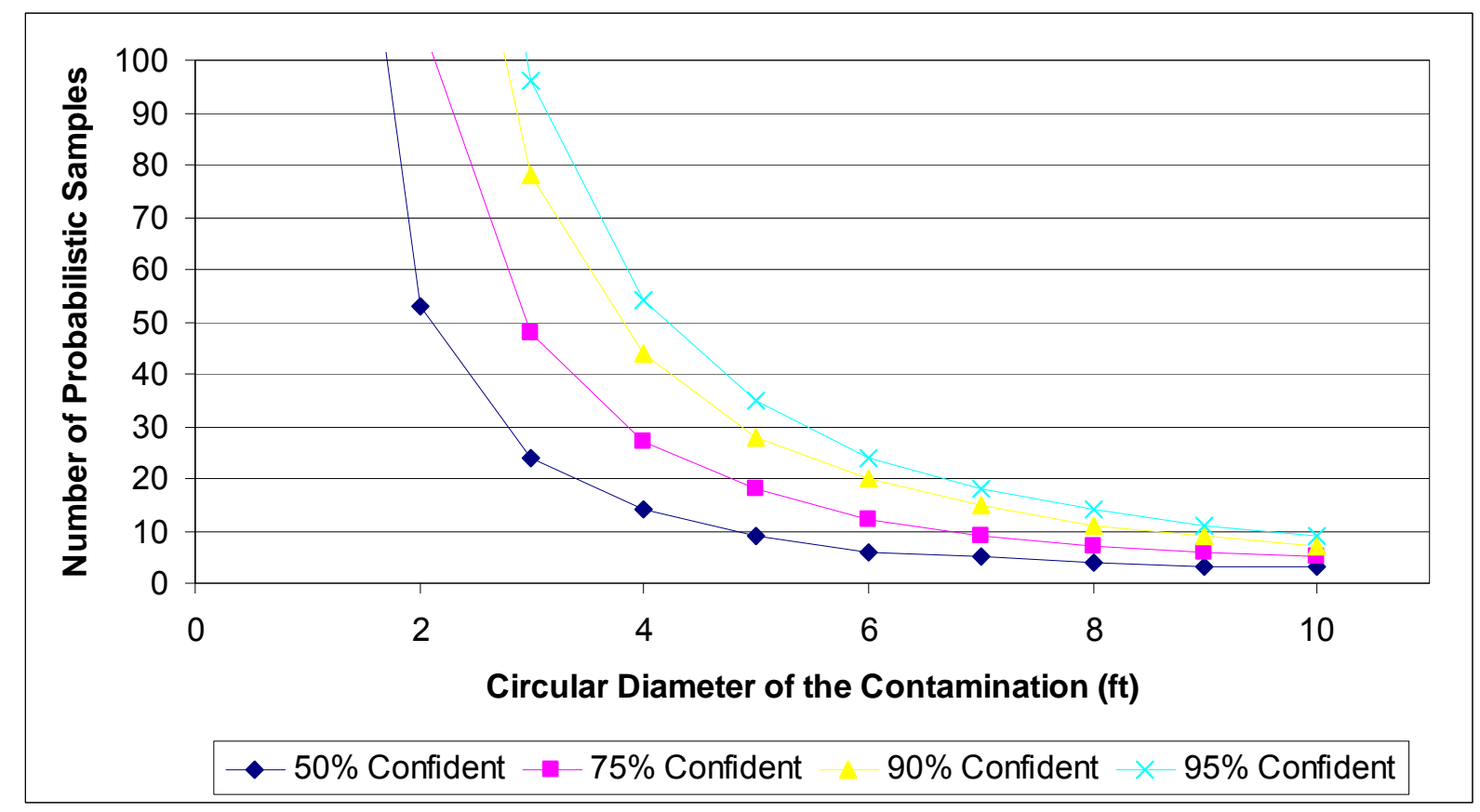

Figure A.9. Number of Probabilistic Samples Required to Detect with $40 \%$ False Negative Rate a Circular Contaminated Area of a Given Diameter with a Given Confidence (represented by the colored lines) within a Typical Room of the INL PBF-632 Building

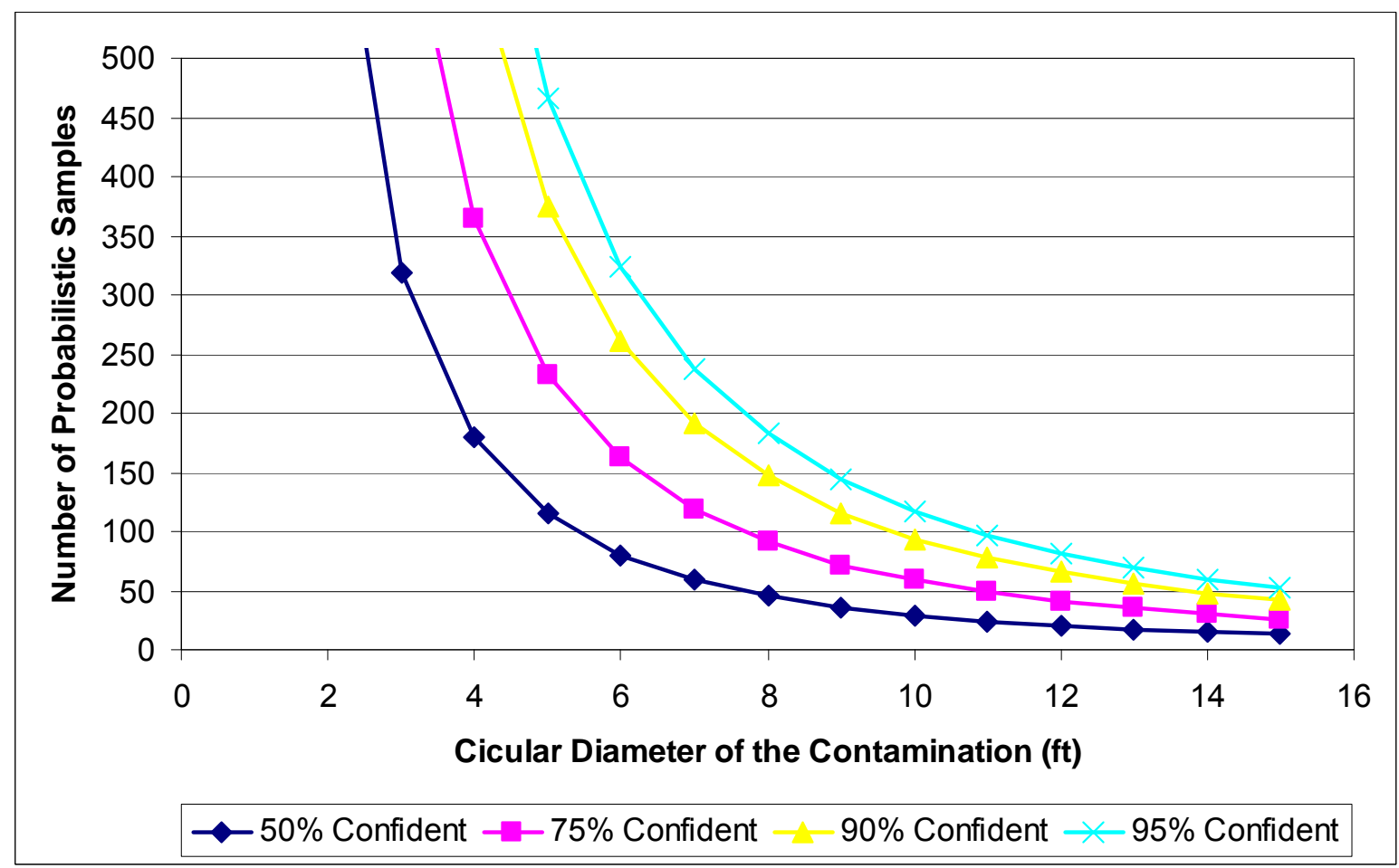

Figure A.10. Number of Probabilistic Samples Required to Detect with 40\% False Negative Rate a Circular Contaminated Area of a Given Diameter with a Given Confidence (represented by the colored lines) within a Single Floor of the INL PBF-632 Building 


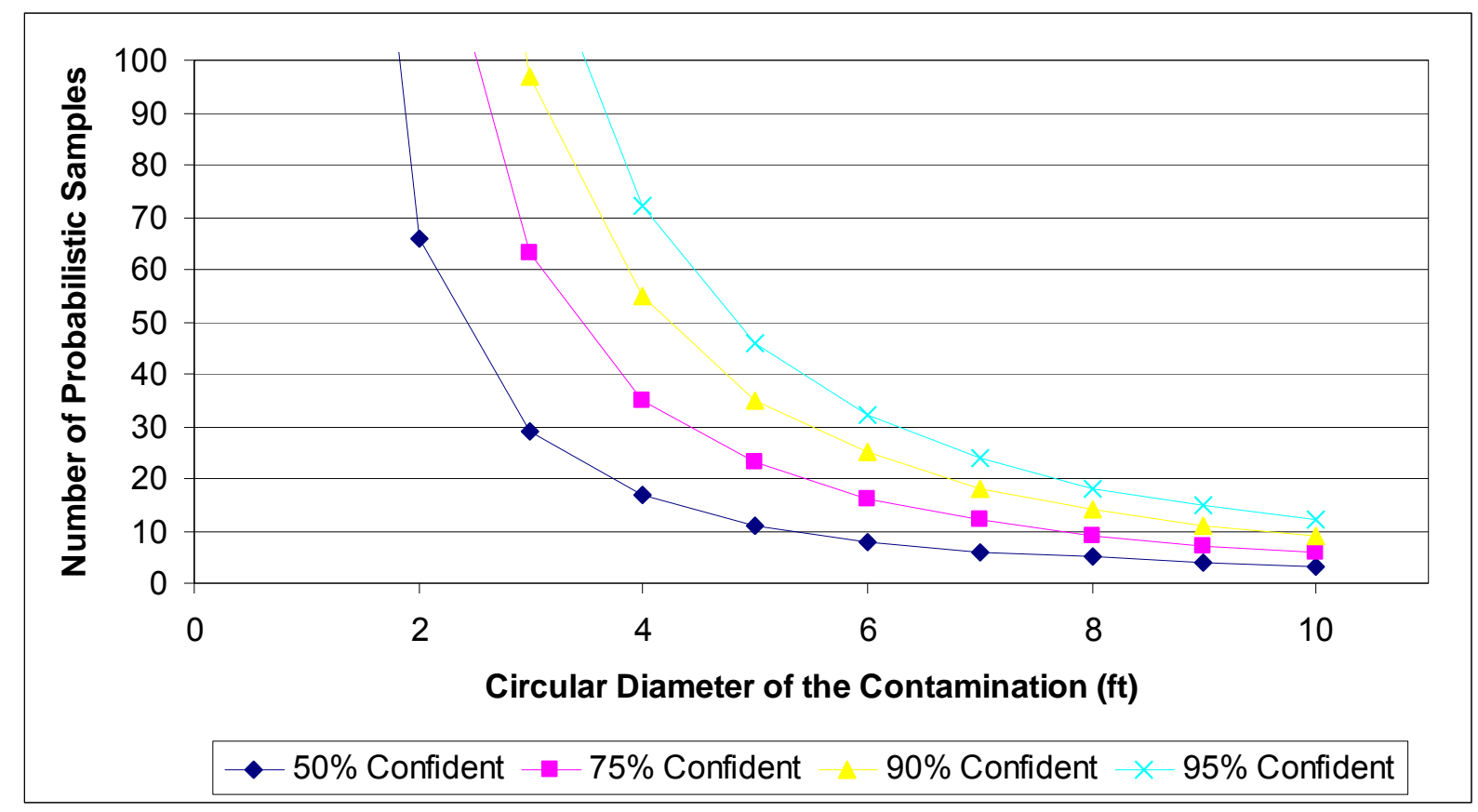

Figure A.11. Number of Probabilistic Samples Required to Detect with 50\% False Negative Rate a Circular Contaminated Area of a Given Diameter with a Given Confidence (represented by the colored lines) within a Typical Room of the INL PBF-632 Building

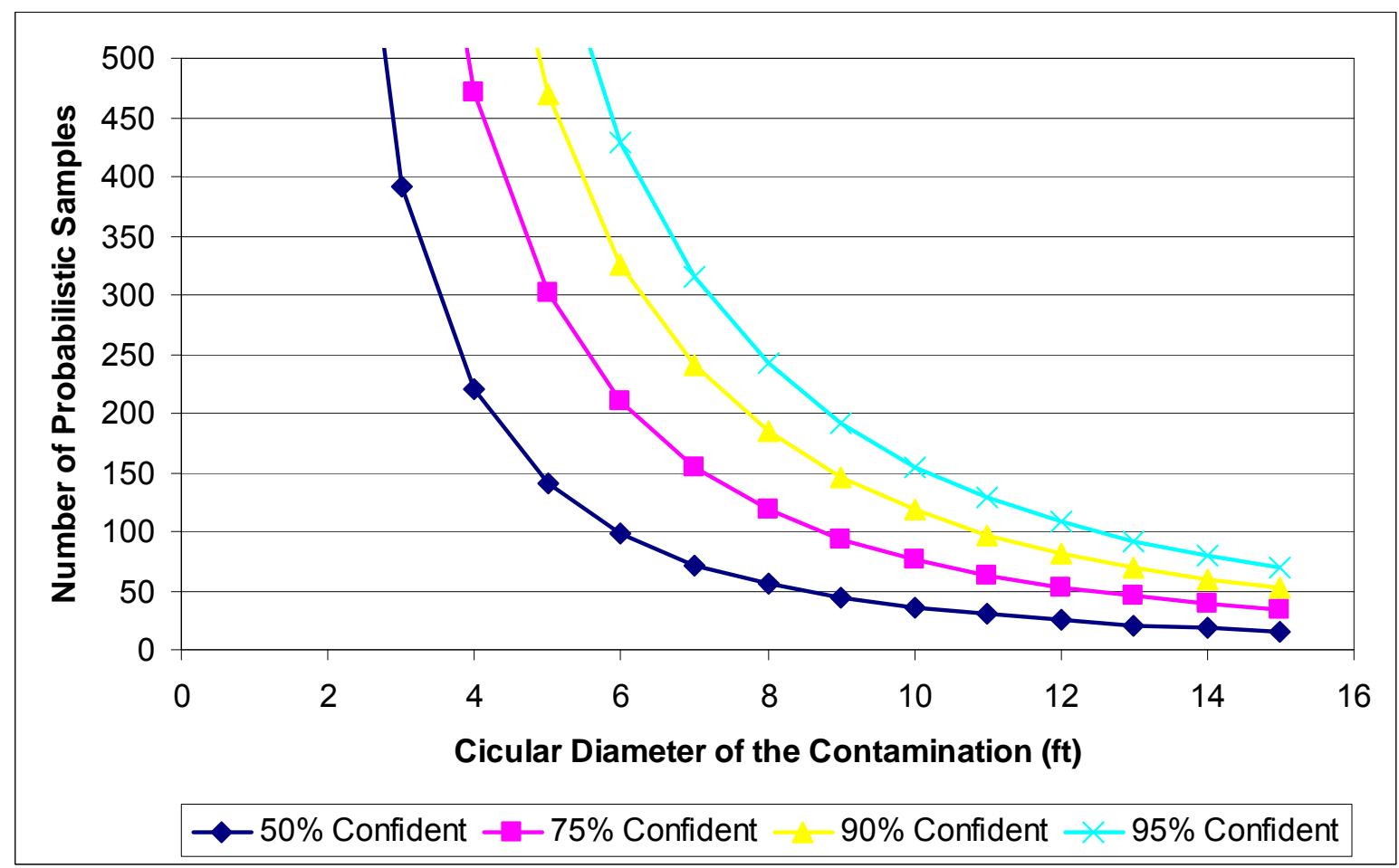

Figure A.12. Number of Probabilistic Samples Required to Detect with 50\% False Negative Rate a Circular Contaminated Area of a Given Diameter with a Given Confidence (represented by the colored lines) within a Single Floor of the INL PBF-632 Building 


\section{Appendix B: Details to be Included in the Eventual Complete Test Matrix}

Table B.1 illustrates the details to be contained in a test matrix prepared for each test event in the sampling design for contamination and decontamination testing during the INL-2 study in the PBF-632 building at the Idaho National Laboratory (INL). Details on probabilistic samples in Office 101 during Test Event 4 are used for illustration purposes. 
Table B.1. Illustration of Details to be Contained in an Eventual Complete Test Matrix for a Given Room in the INL PBF-632 Building. Entries for Office 101 during Test Event 4 are shown for illustrative purposes only, and do not represent the actual sampling order.

\begin{tabular}{|c|c|c|c|c|c|c|c|c|c|c|c|}
\hline $\begin{array}{c}\text { Order of } \\
\text { Sample } \\
\text { Collection }^{(a)}\end{array}$ & $\begin{array}{c}\text { Sample } \\
\text { ID }^{(\mathbf{b})}\end{array}$ & $\begin{array}{c}\text { Event ID } \\
(1 \text { to } 5) \\
\end{array}$ & $\begin{array}{c}\text { Sampling } \\
\text { Floor }(1,2) \\
\end{array}$ & $\begin{array}{l}\text { Sampling } \\
\text { Room } \\
\text { (Office \#) } \\
\end{array}$ & $\begin{array}{c}\text { Contam/ } \\
\text { Decon } \\
(\text { C,D) } \\
\end{array}$ & $\begin{array}{l}\text { Sampling } \\
\text { Approach } \\
\text { (Q,R,J, } \\
\text { JC,P) })^{(\mathbf{c})} \\
\end{array}$ & $\begin{array}{c}\begin{array}{c}\text { Surface } \\
\text { to }\end{array} \\
\text { Sample } \\
\end{array}$ & $\begin{array}{c}\text { Sample } \\
\text { Collection } \\
\text { Method (Wipe, } \\
\text { Swab, Vacuum) } \\
\end{array}$ & $\begin{array}{c}\text { Sampler } \\
\text { (Team) } \\
\text { (1 to 4) } \\
\end{array}$ & $\begin{array}{c}\text { Sample } x- \\
\text { Coordinate } \\
\text { within } \\
\text { Room } \\
\end{array}$ & $\begin{array}{c}\text { Sample } \\
\text { y-Coordinate } \\
\text { within Room } \\
\end{array}$ \\
\hline 1 & $4 \mathrm{C} 001$ & 4 & 1 & 101 & $\mathrm{C}$ & $\mathrm{J}$ & (d) & (d) & 1 & (d) & (d) \\
\hline 2 & 4C002 & 4 & 1 & 101 & $\mathrm{C}$ & $\mathrm{P}$ & (d) & vacuum & 1 & 682.4718 & 410.4892 \\
\hline 3 & 4C003 & 4 & 1 & 101 & $\mathrm{C}$ & $\mathrm{R}$ & (d) & (d) & 1 & (d) & (d) \\
\hline 4 & $4 \mathrm{C} 004$ & 4 & 1 & 101 & $\mathrm{C}$ & Q & (d) & (d) & 1 & (d) & (d) \\
\hline 5 & $4 \mathrm{C} 005$ & 4 & 1 & 101 & $\mathrm{C}$ & $\mathrm{P}$ & (d) & wipe & 1 & 749.1072 & 410.4892 \\
\hline 6 & 4C006 & 4 & 1 & 101 & $\mathrm{C}$ & $\mathrm{J}$ & (d) & (d) & 1 & (d) & (d) \\
\hline 7 & $4 \mathrm{C} 007$ & 4 & 1 & 101 & $\mathrm{C}$ & $\mathrm{P}$ & (d) & wipe & 1 & 815.7427 & 410.4892 \\
\hline 8 & 4C008 & 4 & 1 & 101 & $\mathrm{C}$ & $\mathrm{R}$ & (d) & (d) & 1 & (d) & (d) \\
\hline 9 & 4C009 & 4 & 1 & 101 & $\mathrm{C}$ & $\mathrm{J}$ & (d) & (d) & 1 & (d) & (d) \\
\hline 10 & $4 \mathrm{C} 010$ & 4 & 1 & 101 & $\mathrm{C}$ & $\mathrm{P}$ & (d) & vacuum & 1 & 649.1541 & 463.8049 \\
\hline 11 & 4C011 & 4 & 1 & 101 & $\mathrm{C}$ & Q & (d) & (d) & 1 & (d) & (d) \\
\hline 12 & $4 \mathrm{C} 012$ & 4 & 1 & 101 & $\mathrm{C}$ & $\mathrm{P}$ & (d) & wipe & 1 & 715.7895 & 463.8049 \\
\hline 13 & $4 \mathrm{C} 013$ & 4 & 1 & 101 & $\mathrm{C}$ & $\mathrm{J}$ & (d) & (d) & 1 & (d) & (d) \\
\hline 14 & $4 \mathrm{C} 014$ & 4 & 1 & 101 & $\mathrm{C}$ & $\mathrm{P}$ & (d) & vacuum & 1 & 782.4249 & 463.8049 \\
\hline 15 & $4 \mathrm{C} 015$ & 4 & 1 & 101 & $\mathrm{C}$ & $\mathrm{R}$ & (d) & (d) & 1 & (d) & (d) \\
\hline 16 & $4 \mathrm{C} 016$ & 4 & 1 & 101 & $\mathrm{C}$ & Q & (d) & (d) & 1 & (d) & (d) \\
\hline 17 & 4C016 & 4 & 1 & 101 & $\mathrm{C}$ & $P$ & (d) & vacuum & 1 & 849.0604 & 463.8049 \\
\hline
\end{tabular}

(a) The test matrix should list the samples in the order to be collected by the sampling team so that quality control, reference material coupon, judgmental, and probabilistic samples are collected in an intermingled order that minimizes as much as possible excess movement through a room (see the last paragraph of Section 3.1).

(b) In the proposed Sample ID number, the first character is a number (1, 2, 3, 4, or 5) representing the test event. The third character is a letter (C or D) denoting whether the sample is from the contamination or decontamination phase of the test event. The final three characters are numbers denoting the sample number within a test event.

(c) $\mathrm{Q}=$ quality assurance, $\mathrm{R}=$ reference material coupon, $\mathrm{J}=$ judgmental, $\mathrm{JC}=$ judgmental composite, and $\mathrm{P}=$ probabilistic. This column should not be included in the version of the test matrix used by a sampling team to sample a given room since the team is not to know whether samples are judgmental samples or probabilistic samples. If appropriate, QA and RMC samples can be identified in the test matrix.

(d) Not determined as part of the work in this report. 


\section{Appendix C: Breakdowns of Numbers and Types of Samples for Characterization and Clearance in INL-2 Test Events}

Tables C.1 to C.4 provide the breakdowns of the numbers of quality control, judgmental, and probabilistic samples collected using each sampling method for the characterization phases of Test Events 1 to 5. Choosing the locations of judgmental samples was not part of the PNNL work, so only the total numbers of judgmental samples are shown in Tables C. 1 to C.4. Tables C.5 and C.6 provide similar information for the clearance phases of Test Events 1 to 5.

Table C.1. Breakdown of Numbers and Types of Samples for Characterization of the First Floor of the INL PBF-632 Building in Covert Test Events $1 \& 2$

\begin{tabular}{|c|c|c|c|c|c|c|c|c|c|c|c|c|c|c|c|c|c|}
\hline \multirow[b]{2}{*}{$\begin{array}{l}\text { Area to } \\
\text { be } \\
\text { Sampled }\end{array}$} & \multirow[b]{2}{*}{ 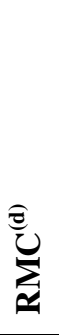 } & \multicolumn{3}{|c|}{ QC Samples } & \multicolumn{3}{|c|}{$\begin{array}{c}\text { Judgmental } \\
\text { Samples }\end{array}$} & \multicolumn{3}{|c|}{$\begin{array}{c}\text { Probabilistic } \\
\text { Samples }\end{array}$} & \multicolumn{3}{|c|}{$\begin{array}{c}\text { Number of } \\
\text { Samples Left in } \\
\text { Kit }^{(\mathbf{a})}\end{array}$} & \multicolumn{4}{|c|}{ Total Sample Types $^{(b),}$ (c) } \\
\hline & & 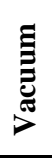 & 芦 & है & 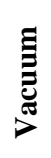 & $\stackrel{\dddot{3}}{3}$ & है & 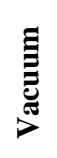 & $\stackrel{\dddot{m}}{3}$ & की & 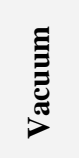 & $\stackrel{.}{3}$ & है & 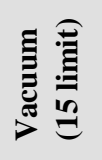 & 莺 & है & 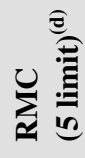 \\
\hline Vacuums & - & - & - & 8 & - & - & - & - & - & - & - & - & - & 0 & 0 & 8 & 0 \\
\hline Lobby & 3 & 1 & 1 & 1 & & & & 14 & 7 & 0 & $(0)^{(\mathrm{e})}$ & (6) & (4) & & & & 3 \\
\hline $101 \mathrm{~A}$ & 3 & 1 & 1 & 1 & & & & 3 & 3 & 1 & (11) & (10) & (3) & & & & 3 \\
\hline 101 & 3 & 1 & 1 & 1 & & & & 4 & 4 & 0 & (10) & (9) & (4) & & & & 3 \\
\hline 102 & 3 & 1 & 1 & 1 & & & & 3 & 3 & 1 & (11) & (10) & (3) & & & & 3 \\
\hline 103 & 3 & 1 & 1 & 1 & & & & 4 & 4 & 0 & (10) & (9) & (4) & & & & 3 \\
\hline 104 & 3 & 1 & 1 & 1 & & & & 3 & 2 & 0 & (11) & (11) & (4) & & & & 3 \\
\hline 105 & 3 & 1 & 1 & 1 & & & & 4 & 6 & 0 & (10) & (7) & (4) & & & & 3 \\
\hline 106 & 3 & 1 & 1 & 1 & & & & 5 & 4 & 1 & (9) & (9) & (3) & & & & 3 \\
\hline 107 & 3 & 1 & 1 & 1 & & & & 5 & 5 & 0 & (9) & (8) & (4) & & & & 3 \\
\hline 108 & 3 & 1 & 1 & 1 & & & & 3 & 5 & 0 & (11) & (8) & (3) & & & & 3 \\
\hline 109 & 3 & 1 & 1 & 1 & & & & 3 & 3 & 0 & (11) & (10) & (4) & & & & 3 \\
\hline 110 & 3 & 1 & 1 & 1 & & & & 3 & 3 & 2 & (11) & (10) & (2) & & & & 3 \\
\hline Totals & 36 & 12 & 12 & 20 & & $36^{(\mathrm{f})}$ & & 54 & 49 & 5 & & & & & & & 36 \\
\hline
\end{tabular}

(a) These columns indicate how many of each sample type are available in each room/kit after probabilistic and QC samples are taken. This information will be used by Dino Mattorano (EPA) in placing the judgmental samples.

(b) The totals of the sample types are to be completed by Dino Mattorano (EPA) after he has selected the judgmental sample locations.

(c) The limit given for each sample type is per room.

(d) The kits prepared for sampling rooms allowed for up to five RMCs to be collected per room during the characterization phase of sampling for each test event. However, it was ultimately decided to place and collect only three RMCs per room, as discussed in Section 5.1.

(e) These numbers are in parentheses to indicate that they are to help in placing judgmental samples and are not part of the total samples.

(f) The total allotted number of judgmental samples is 36. The distribution of these across the rooms and types of samples will be completed by Dino Mattorano. 
Table C.2. Breakdown of Numbers and Types of Samples for Characterization of the Second Floor of the INL PBF-632 Building in Covert Test Event 3

\begin{tabular}{|c|c|c|c|c|c|c|c|c|c|c|c|c|c|c|c|c|c|}
\hline \multirow[b]{2}{*}{$\begin{array}{c}\text { Area to } \\
\text { be } \\
\text { Sampled }\end{array}$} & \multirow[b]{2}{*}{ 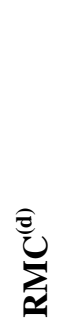 } & \multicolumn{3}{|c|}{ QC Samples } & \multicolumn{3}{|c|}{$\begin{array}{c}\text { Judgmental } \\
\text { Samples }\end{array}$} & \multicolumn{3}{|c|}{$\begin{array}{c}\text { Probabilistic } \\
\text { Samples }\end{array}$} & \multicolumn{3}{|c|}{$\begin{array}{c}\text { Number of } \\
\text { Samples Left in } \\
\text { Kit }^{(\mathbf{a})}\end{array}$} & \multicolumn{4}{|c|}{ Total Sample Types ${ }^{(b),(c)}$} \\
\hline & & 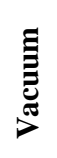 & $\stackrel{\pi}{\xi}$ & है & 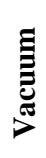 & 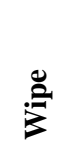 & 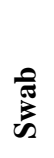 & 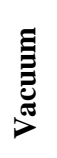 & $\stackrel{\check{3}}{\nexists}$ & 疍 & $\underset{\Xi}{\Xi}$ & $\stackrel{\check{3}}{\rightrightarrows}$ & की & 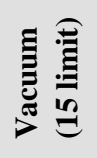 & ३气 & 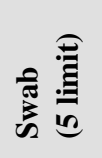 & 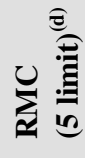 \\
\hline Vacuums & - & - & - & 8 & - & - & - & - & - & - & - & - & - & 0 & 0 & 8 & 0 \\
\hline 201 & 3 & 1 & 1 & 1 & & & & 2 & 2 & 1 & $(12)^{(\mathrm{e})}$ & (11) & (3) & & & & 3 \\
\hline $201 \mathrm{~A}$ & 3 & 1 & 1 & 1 & & & & 4 & 3 & 0 & (10) & (10) & (4) & & & & 3 \\
\hline 203 & 3 & 1 & 1 & 1 & & & & 1 & 2 & 2 & (13) & (11) & (2) & & & & 3 \\
\hline $203 \mathrm{~A}$ & 3 & 1 & 1 & 1 & & & & 2 & 5 & 0 & (12) & (8) & (4) & & & & 3 \\
\hline 202 & 3 & 1 & 1 & 1 & & & & 2 & 1 & 1 & (12) & (12) & (3) & & & & 3 \\
\hline 204 & 3 & 1 & 1 & 1 & & & & 2 & 1 & 1 & (12) & (12) & (3) & & & & 3 \\
\hline 205 & 3 & 1 & 1 & 1 & & & & 4 & 3 & 0 & (10) & (10) & (4) & & & & 3 \\
\hline 206 & 3 & 1 & 1 & 1 & & & & 4 & 2 & 1 & (10) & (11) & (3) & & & & 3 \\
\hline 207 & 3 & 1 & 1 & 1 & & & & 5 & 5 & 0 & (9) & (8) & (4) & & & & 3 \\
\hline 208 & 3 & 1 & 1 & 1 & & & & 4 & 3 & 1 & (10) & (10) & (3) & & & & 3 \\
\hline 209 & 3 & 1 & 1 & 1 & & & & 3 & 4 & 1 & (11) & (9) & (3) & & & & 3 \\
\hline 210 & 3 & 1 & 1 & 1 & & & & 5 & 3 & 0 & (9) & (10) & (4) & & & & 3 \\
\hline 211 & 3 & 1 & 1 & 1 & & & & 3 & 4 & 0 & (11) & (9) & (4) & & & & 3 \\
\hline 212 & 3 & 1 & 1 & 1 & & & & 6 & 4 & 0 & (8) & (9) & (4) & & & & 3 \\
\hline 213 & 3 & 1 & 1 & 1 & & & & 3 & 5 & 0 & (11) & (8) & (4) & & & & 3 \\
\hline Totals & 45 & 15 & 15 & 23 & & $45^{(f)}$ & & 50 & 47 & 8 & & & & & & & 45 \\
\hline
\end{tabular}

(a) These columns indicate how many of each sample type are available in each room/kit after probabilistic and QC samples are taken. This information will be used by Dino Mattorano (EPA) in placing the judgmental samples.

(b) The totals of the sample types are to be completed by Dino Mattorano (EPA) after he has selected the judgmental sample locations.

(c) The limit given for each sample type is per room.

(d) The kits prepared for sampling rooms allowed for up to five RMCs to be collected per room during the characterization phase of sampling for each test event. However, it was ultimately decided to place and collect only three RMCs per room, as discussed in Section 5.1 .

(e) These numbers are in parentheses to indicate that they are to help in placing judgmental samples and are not part of the total samples.

(f) The total allotted number of judgmental samples is 45. The distribution of these across the rooms and types of samples will be completed by Dino Mattorano. 
Table C.3. Breakdown of Numbers and Types of Samples for Characterization of the First Floor of the INL PBF-632 Building in Overt Test Event 4

\begin{tabular}{|c|c|c|c|c|c|c|c|c|c|c|c|c|c|c|c|c|c|}
\hline \multirow[b]{2}{*}{$\begin{array}{c}\begin{array}{c}\text { Area to } \\
\text { be }\end{array} \\
\text { Sampled } \\
\end{array}$} & \multirow[b]{2}{*}{ 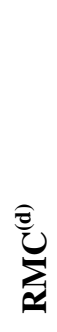 } & \multicolumn{3}{|c|}{ QC Samples } & \multicolumn{3}{|c|}{$\begin{array}{c}\text { Judgmental } \\
\text { Samples }\end{array}$} & \multicolumn{3}{|c|}{$\begin{array}{c}\text { Probabilistic } \\
\text { Samples }\end{array}$} & \multicolumn{3}{|c|}{$\begin{array}{c}\text { Number of } \\
\text { Samples Left in } \\
\text { Kit }^{(\mathbf{a})}\end{array}$} & \multicolumn{4}{|c|}{ Total Sample Types $^{(b),(c)}$} \\
\hline & & 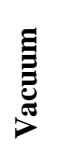 & $\stackrel{:}{3}$ & 芠 & $\underset{\Xi}{\Xi}$ & 总 & है & 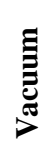 & 芦 & 芠 & $\underset{\Xi}{\Xi}$ & $\stackrel{\Xi}{3}$ & 㺃 & 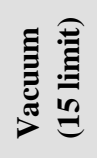 & 兽 & तิ & 氞 \\
\hline Vacuums & - & - & - & 8 & - & - & - & - & - & - & - & - & - & 0 & 0 & 8 & 0 \\
\hline 101 & 3 & 1 & 1 & 1 & & 4 & & 4 & 3 & 0 & $(10)^{(\mathrm{e})}$ & (10) & (4) & & & & 3 \\
\hline 102 & 3 & 1 & 1 & 1 & & 3 & & 4 & 3 & 0 & (10) & (10) & (4) & & & & 3 \\
\hline 103 & 3 & 1 & 1 & 1 & & 5 & & 9 & 3 & 0 & (5) & (10) & (4) & & & & 3 \\
\hline 104 & 3 & 1 & 1 & 1 & & 5 & & 4 & 8 & 0 & (10) & (5) & (4) & & & & 3 \\
\hline 105 & 3 & 1 & 1 & 1 & & $8^{(\mathrm{f})}$ & & 7 & 6 & 0 & (7) & (7) & (4) & & & & 3 \\
\hline 107 & 3 & 1 & 1 & 1 & & (f) & & 7 & 6 & 0 & (7) & (7) & (4) & & & & 3 \\
\hline 106 & 3 & 1 & 1 & 1 & & $8^{(\mathrm{g})}$ & & 7 & 6 & 0 & (7) & (7) & (4) & & & & 3 \\
\hline 108 & 3 & 1 & 1 & 1 & & $(g)$ & & 5 & 8 & 0 & (9) & (5) & (4) & & & & 3 \\
\hline 109 & 3 & 1 & 1 & 1 & & 3 & & 7 & 5 & 0 & (7) & (8) & (4) & & & & 3 \\
\hline 110 & 3 & 1 & 1 & 1 & & 5 & & 6 & 5 & 1 & (8) & (8) & (3) & & & & 3 \\
\hline Totals & 30 & 10 & 10 & 18 & & $41^{(\mathrm{h})}$ & & 60 & 53 & 1 & & & & & & & 30 \\
\hline
\end{tabular}

(a) These columns indicate how many of each sample type are available in each room/kit after probabilistic and QC samples are taken. This information will be used by Dino Mattorano (EPA) in placing the judgmental samples.

(b) The totals of the sample types are to be completed by Dino Mattorano (EPA) after he has selected the judgmental sample locations.

(c) The limit given for each sample type is per room.

(d) The kits prepared for sampling rooms allowed for up to five RMCs to be collected per room during the characterization phase of sampling for each test event. However, it was ultimately decided to place and collect only three RMCs per room, as discussed in Section 5.1.

(e) These numbers are in parentheses to indicate that they are to help in placing judgmental samples and are not part of the total samples.

(f) These eight judgmental samples are to be allocated between rooms 105 and 107.

(g) These eight judgmental samples are to be allocated between rooms 106 and 108.

(h) The total allotted number of judgmental samples is 41 , with the allotted numbers per room shown in the "Wipe" column. The distribution of these numbers of judgmental samples per room over the three types of samples will be completed by Dino Mattorano. 
Table C.4. Breakdown of Numbers and Types of Samples for Characterization of the Second Floor of the INL PBF-632 Building in Overt Test Event 5

\begin{tabular}{|c|c|c|c|c|c|c|c|c|c|c|c|c|c|c|c|c|c|}
\hline \multirow[b]{2}{*}{$\begin{array}{l}\text { Area to } \\
\text { be } \\
\text { Sampled }\end{array}$} & \multirow[b]{2}{*}{ 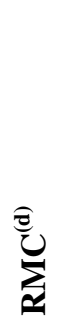 } & \multicolumn{3}{|c|}{ QC Samples } & \multicolumn{3}{|c|}{$\begin{array}{c}\text { Judgmental } \\
\text { Samples }\end{array}$} & \multicolumn{3}{|c|}{$\begin{array}{c}\text { Probabilistic } \\
\text { Samples }\end{array}$} & \multicolumn{3}{|c|}{$\begin{array}{c}\text { Number of } \\
\text { Samples Left in } \\
\text { Kit }^{(\mathbf{a})}\end{array}$} & \multicolumn{4}{|c|}{ Total Sample Types ${ }^{(b),(c)}$} \\
\hline & & 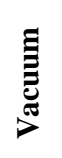 & $\stackrel{\Xi}{=}$ & की & 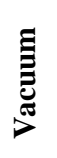 & $\stackrel{\Xi}{3}$ & की & 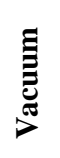 & $\stackrel{\check{3}}{\nexists}$ & की & 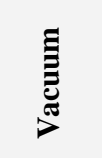 & $\stackrel{\Xi}{3}$ & की & 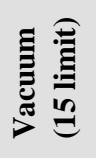 & 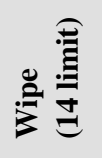 & 㺃 & 昰 \\
\hline Vacuums & - & - & - & 8 & - & - & - & - & - & - & - & - & - & 0 & 0 & 8 & 0 \\
\hline 201 & 3 & 1 & 1 & 1 & & 3 & & 4 & 3 & 0 & $(10)^{(\mathrm{e})}$ & (10) & (4) & & & & 3 \\
\hline 202 & 3 & 1 & 1 & 1 & & 4 & & 3 & 3 & 1 & (11) & (10) & (4) & & & & 3 \\
\hline 205 & 3 & 1 & 1 & 1 & & $8^{(\mathrm{f})}$ & & 7 & 5 & 1 & (7) & (8) & (3) & & & & 3 \\
\hline 207 & 3 & 1 & 1 & 1 & & (f) & & 7 & 5 & 1 & (7) & (8) & (3) & & & & 3 \\
\hline 206 & 3 & 1 & 1 & 1 & & $8^{(\mathrm{g})}$ & & 8 & 4 & 1 & (6) & (9) & (3) & & & & 3 \\
\hline 208 & 3 & 1 & 1 & 1 & & (g) & & 6 & 6 & 1 & (8) & (7) & (3) & & & & 3 \\
\hline 209 & 3 & 1 & 1 & 1 & & 5 & & 8 & 4 & 0 & (6) & (9) & (4) & & & & 3 \\
\hline 210 & 3 & 1 & 1 & 1 & & 5 & & 8 & 3 & 1 & (6) & (10) & (3) & & & & 3 \\
\hline 212 & 3 & 1 & 1 & 1 & & 5 & & 5 & 5 & 2 & (9) & $(8)$ & (2) & & & & 3 \\
\hline 213 & 3 & 1 & 1 & 1 & & 3 & & 8 & 4 & 0 & (6) & (9) & (4) & & & & 3 \\
\hline Totals & 30 & 10 & 10 & 18 & & $41^{(\mathrm{h})}$ & & 64 & 42 & 8 & & & & & & & 30 \\
\hline
\end{tabular}

(a) These columns indicate how many of each sample type are available in each room/kit after probabilistic and QC samples are taken. This information will be used by Dino Mattorano (EPA) in placing the judgmental samples.

(b) The totals of the sample types are to be completed by Dino Mattorano (EPA) after he has selected the judgmental sample locations.

(c) The limit given for each sample type is per room.

(d) The kits prepared for sampling rooms allowed for up to five RMCs to be collected per room during the characterization phase of sampling for each test event. However, it was ultimately decided to place and collect only three RMCs per room, as discussed in Section 5.1.

(e) These numbers are in parentheses to indicate that they are to help in placing judgmental samples and are not part of the total samples.

(f) These eight judgmental samples are to be allocated between rooms 205 and 207.

(g) These eight judgmental samples are to be allocated between rooms 206 and 208.

(h) The total allotted number of judgmental samples is 41 , with the allotted numbers per room shown in the "Wipe" column. The distribution of these numbers of judgmental samples per room over the three types of samples will be completed by Dino Mattorano. 
Table C.5. Breakdown of Numbers and Types of Samples for Clearance of the First Floor of the INL PBF-632 Building in Test Events 1, 2, and 4

\begin{tabular}{|c|c|c|c|c|c|c|c|c|c|c|c|c|c|c|c|c|c|}
\hline \multirow[b]{2}{*}{$\begin{array}{c}\begin{array}{c}\text { Area to } \\
\text { be }\end{array} \\
\text { Sampled } \\
\end{array}$} & \multirow[b]{2}{*}{ 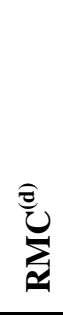 } & \multicolumn{3}{|c|}{ QC Samples } & \multicolumn{3}{|c|}{$\begin{array}{l}\text { Judgmental } \\
\text { Samples }\end{array}$} & \multicolumn{3}{|c|}{$\begin{array}{c}\text { Probabilistic } \\
\text { Samples }\end{array}$} & \multicolumn{3}{|c|}{$\begin{array}{c}\text { Number of Samples } \\
\text { Left in Kit }\end{array}$} & \multicolumn{4}{|c|}{ Total Sample Types ${ }^{(b),(c)}$} \\
\hline & & $\underset{\Xi}{\Xi}$ & $\stackrel{\check{3}}{3}$ & 趈 & $\underset{\Xi}{\Xi}$ & : & 营 & 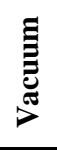 & $\stackrel{\check{\xi}}{\xi}$ & है & 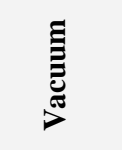 & $\stackrel{\Xi}{3}$ & है & 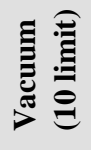 & 站 & 芠 & 记 \\
\hline Vacuums & - & - & - & 8 & - & - & - & - & - & - & - & - & - & 0 & 0 & 8 & 0 \\
\hline Lobby & 0 & 1 & 1 & 1 & & & & 13 & 7 & 1 & $(-4)^{(\mathrm{e}),(\mathrm{f})}$ & $(-2)^{(f)}$ & (1) & & & & 0 \\
\hline $101 \mathrm{~A}$ & 0 & 1 & 1 & 1 & & & & 6 & 6 & 0 & (3) & $(-1)^{(f)}$ & (2) & & & & 0 \\
\hline 101 & 0 & 1 & 1 & 1 & & & & 5 & 4 & 0 & (4) & (1) & (2) & & & & 0 \\
\hline 102 & 0 & 1 & 1 & 1 & & & & 3 & 2 & 0 & (6) & (3) & (2) & & & & 0 \\
\hline 103 & 0 & 1 & 1 & 1 & & & & 7 & 3 & 0 & (2) & (2) & (2) & & & & 0 \\
\hline 104 & 0 & 1 & 1 & 1 & & & & 2 & 2 & 1 & (7) & (3) & (1) & & & & 0 \\
\hline 105 & 0 & 1 & 1 & 1 & & & & 4 & 6 & 0 & (5) & $(-1)^{(\mathrm{f})}$ & (2) & & & & 0 \\
\hline 106 & 0 & 1 & 1 & 1 & & & & 5 & 5 & 0 & (4) & $(0)$ & (2) & & & & 0 \\
\hline 107 & 0 & 1 & 1 & 1 & & & & 5 & 5 & 0 & (4) & (0) & (2) & & & & 0 \\
\hline 108 & 0 & 1 & 1 & 1 & & & & 2 & 7 & 0 & (7) & $(-2)^{(f)}$ & (2) & & & & 0 \\
\hline 109 & 0 & 1 & 1 & 1 & & & & 4 & 6 & 0 & (5) & $(-1)^{(f)}$ & (2) & & & & 0 \\
\hline 110 & 0 & 1 & 1 & 1 & & & & 4 & 6 & 0 & (5) & $(-1)^{(f)}$ & (2) & & & & 0 \\
\hline Totals & 0 & 12 & 12 & 20 & & $20^{(\mathrm{g})}$ & & 60 & 59 & 2 & & & & & & & 0 \\
\hline
\end{tabular}

(a) These columns indicate how many of each sample type are available in each room/kit after probabilistic and QC samples are taken. This information will be used by Dino Mattorano (EPA) in placing the judgmental samples.

(b) The totals of the sample types are to be completed by Dino Mattorano (EPA) after he has selected the judgmental sample locations.

(c) The limit given for each sample type is per room.

(d) The kits prepared for sampling rooms allowed for up to five RMCs to be collected per room during the clearance phase of sampling for each test event. However, it was ultimately decided not to place RMCs and collect them after decontamination, as discussed in Section 5.1.

(e) These numbers are in parentheses to indicate that they are to help in placing judgmental samples and are not part of the total samples.

(f) A negative number of samples left in the kit indicates that more samples need to be allocated into the kits for these rooms.

(g) The total allotted number of judgmental samples is 20. The distribution of these across the rooms and types of samples will be completed by Dino Mattorano, as appropriate for the clearance objective with a hybrid sampling approach. 
Table C.6. Breakdown of Numbers and Types of Samples for Clearance of the Second Floor of the INL PBF-632 Building in Test Events 3 and 5

\begin{tabular}{|c|c|c|c|c|c|c|c|c|c|c|c|c|c|c|c|c|c|}
\hline \multirow[b]{2}{*}{$\begin{array}{c}\begin{array}{c}\text { Area to } \\
\text { be }\end{array} \\
\text { Sampled }\end{array}$} & \multirow[b]{2}{*}{ 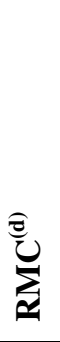 } & \multicolumn{3}{|c|}{ QC Samples } & \multicolumn{3}{|c|}{$\begin{array}{l}\text { Judgmental } \\
\text { Samples }\end{array}$} & \multicolumn{3}{|c|}{$\begin{array}{c}\text { Probabilistic } \\
\text { Samples }\end{array}$} & \multicolumn{3}{|c|}{$\begin{array}{c}\text { Number of } \\
\text { Samples Left in } \\
\text { Kit }^{(\mathbf{a})}\end{array}$} & \multicolumn{4}{|c|}{ Total Sample Types ${ }^{(\mathbf{b}),(c)}$} \\
\hline & & 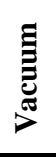 & : & 敷 & $\stackrel{\Xi}{\bar{E}}$ & 芦 & 敷 & 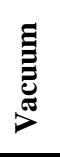 & 芦 & 营 & 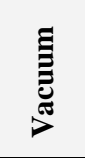 & 芦 & 营 & 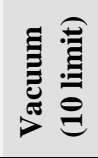 & 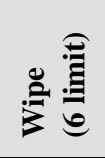 & 吾 & 记葛 \\
\hline Vacuums & - & - & - & 8 & - & - & - & - & - & - & - & - & - & 0 & 0 & 8 & 0 \\
\hline 201 & 0 & 1 & 1 & 1 & & & & 3 & 3 & 0 & $(6)^{(\mathrm{e})}$ & (2) & (2) & & & & 0 \\
\hline $201 \mathrm{~A}$ & 0 & 1 & 1 & 1 & & & & 3 & 4 & 0 & (6) & (1) & (2) & & & & 0 \\
\hline 203 & 0 & 1 & 1 & 1 & & & & 1 & 5 & 0 & (8) & (0) & (2) & & & & 0 \\
\hline $203 \mathrm{~A}$ & 0 & 1 & 1 & 1 & & & & 1 & 6 & 0 & (8) & $(-1)^{(\mathrm{f})}$ & (2) & & & & 0 \\
\hline 202 & 0 & 1 & 1 & 1 & & & & 2 & 1 & 1 & (7) & (4) & (1) & & & & 0 \\
\hline 204 & 0 & 1 & 1 & 1 & & & & 2 & 2 & 0 & (7) & (3) & (2) & & & & 0 \\
\hline 205 & 0 & 1 & 1 & 1 & & & & 6 & 4 & 0 & (3) & (1) & (2) & & & & 0 \\
\hline 206 & 0 & 1 & 1 & 1 & & & & 6 & 4 & 0 & (3) & (1) & (2) & & & & 0 \\
\hline 207 & 0 & 1 & 1 & 1 & & & & 6 & 3 & 1 & (3) & (2) & (1) & & & & 0 \\
\hline 208 & 0 & 1 & 1 & 1 & & & & 6 & 4 & 0 & (3) & (1) & (2) & & & & 0 \\
\hline 209 & 0 & 1 & 1 & 1 & & & & 6 & 4 & 0 & (3) & (1) & (2) & & & & 0 \\
\hline 210 & 0 & 1 & 1 & 1 & & & & 3 & 3 & 1 & (6) & (2) & (1) & & & & 0 \\
\hline 211 & 0 & 1 & 1 & 1 & & & & 8 & 2 & 0 & (1) & (3) & (2) & & & & 0 \\
\hline 212 & 0 & 1 & 1 & 1 & & & & 6 & 4 & 0 & (3) & (1) & (2) & & & & 0 \\
\hline 213 & 0 & 1 & 1 & 1 & & & & 5 & 4 & 1 & (4) & (1) & (1) & & & & 0 \\
\hline Totals & 0 & 15 & 15 & 23 & & $20^{(\mathrm{g})}$ & & 64 & 53 & 4 & & & & & & & 0 \\
\hline
\end{tabular}

(a) These columns indicate how many of each sample type are available in each room/kit after probabilistic and QC samples are taken. This information will be used by Dino Mattorano (EPA) in placing the judgmental samples.

(b) The totals of the sample types are to be completed by Dino Mattorano (EPA) after he has selected the judgmental sample locations.

(c) The limit given for each sample type is per room.

(d) The kits prepared for sampling rooms allowed for up to five RMCs to be collected per room during the clearance phase of sampling for each test event. However, it was ultimately decided not to place RMCs and collect them after decontamination, as discussed in Section 5.1.

(e) These numbers are in parentheses to indicate that they are to help in placing judgmental samples and are not part of the total samples.

(f) A negative number of samples left in the kit indicates that more samples need to be allocated into the kits for these rooms.

(g) The total allotted number of judgmental samples is 20. The distribution of these across the rooms and types of samples will be completed by Dino Mattorano, as appropriate for the clearance objective with a hybrid sampling approach. 


\section{Appendix D: Coordinates and Sample Types for Probabilistic Sample Locations}

Tables D.1 to D.6 contain the coordinates of probabilistic sample locations output by the Visual Sampling Plan (VSP) software, as well as the sample types. Note that the samples types are not part of the VSP output and were added separately. The VSP coordinates may need to be translated to the INL PBF-632 building coordinates for use in the BROOM software. Tables D.1 to D.6 contain the locations and types of probabilistic samples for

- Events 1 and 2, Floor 1 characterization

- Event 3, Floor 2 characterization

- Event 4, Floor 1 characterization

- Event 5, Floor 2 characterization

- Events 1, 2, and 4, Floor 1 clearance

- Events 3 and 5, Floor 2 clearance,

respectively.

Note that Tables D.1 to D.6 each contain a column "Label" that is blank and a column "Value" containing zeros. These are columns provided for in the output of the VSP software but that were not used for the INL-2 study. However, for completeness, those columns are included in Tables D.1 to D.6.

The "Type", "Row", and "Col" columns in Tables D.1 to D.6 provide information about the types and row/column locations of samples. When "Type" = "Hot Spot Cell", the sample is a grid point (on a triangular grid for INL-2) selected with an objective of detecting contamination of a given size. When "Type" = "Grid Cell", the sample typically is grid point selected for a clearance objective. However, this led to an uneven coverage of the half-size Office 202, so an adaptive fill algorithm to better space samples was used. 
Table D.1. Coordinates and Sample Types for Probabilistic Sample Locations of Characterization Samples on Floor 1 of INL PBF-632 for INL-2 Test Events 1 and 2

\begin{tabular}{|c|c|c|c|c|c|c|c|c|}
\hline Area & X Center & Y Center & Label & Value & Type & Row & Col & Sample Type \\
\hline \multirow[t]{21}{*}{ Lobby } & 875.0559 & 262.9762 & & 0 & Hot Spot Cell & 1 & 0 & vacuum \\
\hline & 940.4949 & 262.9762 & & 0 & Hot Spot Cell & 1 & 1 & vacuum \\
\hline & 1005.9339 & 262.9762 & & 0 & Hot Spot Cell & 1 & 2 & vacuum \\
\hline & 1071.3729 & 262.9762 & & 0 & Hot Spot Cell & 1 & 3 & vacuum \\
\hline & 907.7754 & 315.2557 & & 0 & Hot Spot Cell & 2 & 1 & wipe \\
\hline & 973.2144 & 315.2557 & & 0 & Hot Spot Cell & 2 & 2 & wipe \\
\hline & 1038.6534 & 315.2557 & & 0 & Hot Spot Cell & 2 & 3 & wipe \\
\hline & 875.0559 & 367.5353 & & 0 & Hot Spot Cell & 3 & 0 & vacuum \\
\hline & 940.4949 & 367.5353 & & 0 & Hot Spot Cell & 3 & 1 & vacuum \\
\hline & 1005.9339 & 367.5353 & & 0 & Hot Spot Cell & 3 & 2 & vacuum \\
\hline & 1071.3729 & 367.5353 & & 0 & Hot Spot Cell & 3 & 3 & vacuum \\
\hline & 907.7754 & 419.8148 & & 0 & Hot Spot Cell & 4 & 1 & vacuum \\
\hline & 973.2144 & 419.8148 & & 0 & Hot Spot Cell & 4 & 2 & wipe \\
\hline & 1038.6534 & 419.8148 & & 0 & Hot Spot Cell & 4 & 3 & wipe \\
\hline & 875.0559 & 472.0944 & & 0 & Hot Spot Cell & 5 & 0 & vacuum \\
\hline & 940.4949 & 472.0944 & & 0 & Hot Spot Cell & 5 & 1 & wipe \\
\hline & 1005.9339 & 472.0944 & & 0 & Hot Spot Cell & 5 & 2 & vacuum \\
\hline & 1071.3729 & 472.0944 & & 0 & Hot Spot Cell & 5 & 3 & vacuum \\
\hline & 907.7754 & 524.3739 & & 0 & Hot Spot Cell & 6 & 1 & vacuum \\
\hline & 973.2144 & 524.3739 & & 0 & Hot Spot Cell & 6 & 2 & wipe \\
\hline & 1038.6534 & 524.3739 & & 0 & Hot Spot Cell & 6 & 3 & vacuum \\
\hline \multirow[t]{8}{*}{ Office 101} & 669.2894 & 391.2868 & & 0 & Hot Spot Cell & 1 & 1 & vacuum \\
\hline & 734.7285 & 391.2868 & & 0 & Hot Spot Cell & 1 & 2 & wipe \\
\hline & 800.1675 & 391.2868 & & 0 & Hot Spot Cell & 1 & 3 & wipe \\
\hline & 865.6065 & 391.2868 & & 0 & Hot Spot Cell & 1 & 4 & wipe \\
\hline & 636.5699 & 443.5663 & & 0 & Hot Spot Cell & 2 & 1 & vacuum \\
\hline & 702.0090 & 443.5663 & & 0 & Hot Spot Cell & 2 & 2 & wipe \\
\hline & 767.4480 & 443.5663 & & 0 & Hot Spot Cell & 2 & 3 & vacuum \\
\hline & 832.8870 & 443.5663 & & 0 & Hot Spot Cell & 2 & 4 & vacuum \\
\hline \multirow[t]{7}{*}{ Office 101A } & 677.9060 & 282.1718 & & 0 & Hot Spot Cell & 2 & 1 & swab grill \\
\hline & 743.3450 & 282.1718 & & 0 & Hot Spot Cell & 2 & 2 & wipe \\
\hline & 808.7840 & 282.1718 & & 0 & Hot Spot Cell & 2 & 3 & wipe \\
\hline & 645.1865 & 334.4513 & & 0 & Hot Spot Cell & 3 & 0 & vacuum \\
\hline & 710.6255 & 334.4513 & & 0 & Hot Spot Cell & 3 & 1 & vacuum \\
\hline & 776.0645 & 334.4513 & & 0 & Hot Spot Cell & 3 & 2 & vacuum \\
\hline & 841.5035 & 334.4513 & & 0 & Hot Spot Cell & 3 & 3 & wipe \\
\hline \multirow[t]{7}{*}{ Office 102} & 695.8001 & 573.6097 & & 0 & Hot Spot Cell & 1 & 1 & wipe \\
\hline & 754.4243 & 573.6097 & & 0 & Hot Spot Cell & 1 & 2 & vacuum \\
\hline & 666.4880 & 619.9875 & & 0 & Hot Spot Cell & 2 & 1 & vacuum \\
\hline & 725.1122 & 619.9875 & & 0 & Hot Spot Cell & 2 & 2 & swab grill \\
\hline & 783.7364 & 619.9875 & & 0 & Hot Spot Cell & 2 & 3 & vacuum \\
\hline & 695.8001 & 666.3652 & & 0 & Hot Spot Cell & 3 & 1 & wipe \\
\hline & 754.4243 & 666.3652 & & 0 & Hot Spot Cell & 3 & 2 & wipe \\
\hline
\end{tabular}


Table D.1. Coordinates and Sample Types for Probabilistic Sample Locations of Characterization Samples on Floor 1 of INL PBF-632 for INL-2 Test Events 1 and 2 (contd)

\begin{tabular}{|c|c|c|c|c|c|c|c|c|}
\hline Area & X Center & Y Center & Label & Value & Type & Row & Col & Sample Type \\
\hline \multirow[t]{8}{*}{ Office 103} & 526.581 & 285.1029 & & 0 & Hot Spot Cell & 2 & $\overline{1}$ & wipe \\
\hline & 592.0201 & 285.1029 & & 0 & Hot Spot Cell & 2 & 2 & vacuum \\
\hline & 559.3005 & 337.3825 & & 0 & Hot Spot Cell & 3 & 1 & vacuum \\
\hline & 624.7396 & 337.3825 & & 0 & Hot Spot Cell & 3 & 2 & wipe \\
\hline & 526.581 & 389.6620 & & 0 & Hot Spot Cell & 4 & 1 & wipe \\
\hline & 592.0201 & 389.6620 & & 0 & Hot Spot Cell & 4 & 2 & vacuum \\
\hline & 559.3005 & 441.9416 & & 0 & Hot Spot Cell & 5 & 1 & wipe \\
\hline & 624.7396 & 441.9416 & & 0 & Hot Spot Cell & 5 & 2 & vacuum \\
\hline \multirow[t]{5}{*}{ Office 104} & 510.8124 & 732.2643 & & 0 & Hot Spot Cell & 2 & 1 & vacuum \\
\hline & 576.2514 & 732.2643 & & 0 & Hot Spot Cell & 2 & 2 & vacuum \\
\hline & 641.6905 & 732.2643 & & 0 & Hot Spot Cell & 2 & 3 & wipe \\
\hline & 543.5319 & 784.5438 & & 0 & Hot Spot Cell & 3 & 1 & wipe \\
\hline & 608.971 & 784.5438 & & 0 & Hot Spot Cell & 3 & 2 & vacuum \\
\hline \multirow[t]{10}{*}{ Office 105} & 393.1366 & 275.3355 & & 0 & Hot Spot Cell & 1 & 0 & wipe \\
\hline & 458.5756 & 275.3355 & & 0 & Hot Spot Cell & 1 & 1 & wipe \\
\hline & 425.8561 & 327.6151 & & 0 & Hot Spot Cell & 2 & 1 & vacuum \\
\hline & 491.2951 & 327.6151 & & 0 & Hot Spot Cell & 2 & 2 & wipe \\
\hline & 393.1366 & 379.8946 & & 0 & Hot Spot Cell & 3 & 0 & wipe \\
\hline & 458.5756 & 379.8946 & & 0 & Hot Spot Cell & 3 & 1 & wipe \\
\hline & 425.8561 & 432.1742 & & 0 & Hot Spot Cell & 4 & 1 & vacuum \\
\hline & 491.2951 & 432.1742 & & 0 & Hot Spot Cell & 4 & 2 & wipe \\
\hline & 393.1366 & 484.4537 & & 0 & Hot Spot Cell & 5 & 0 & vacuum \\
\hline & 458.5756 & 484.4537 & & 0 & Hot Spot Cell & 5 & 1 & vacuum \\
\hline \multirow[t]{10}{*}{ Office 106} & 431.0181 & 610.3778 & & 0 & Hot Spot Cell & 2 & 1 & vacuum \\
\hline & 496.4571 & 610.3778 & & 0 & Hot Spot Cell & 2 & 2 & wipe \\
\hline & 398.2986 & 662.6573 & & 0 & Hot Spot Cell & 3 & 0 & wipe \\
\hline & 463.7376 & 662.6573 & & 0 & Hot Spot Cell & 3 & 1 & vacuum \\
\hline & 431.0181 & 714.9369 & & 0 & Hot Spot Cell & 4 & 1 & vacuum \\
\hline & 496.4571 & 714.9369 & & 0 & Hot Spot Cell & 4 & 2 & vacuum \\
\hline & 398.2986 & 767.2164 & & 0 & Hot Spot Cell & 5 & 0 & vacuum \\
\hline & 463.7376 & 767.2164 & & 0 & Hot Spot Cell & 5 & 1 & swab grill \\
\hline & 431.0181 & 819.4960 & & 0 & Hot Spot Cell & 6 & 1 & wipe \\
\hline & 496.4571 & 819.4960 & & 0 & Hot Spot Cell & 6 & 2 & wipe \\
\hline \multirow[t]{11}{*}{ Office 107} & 311.3559 & 264.1128 & & 0 & Hot Spot Cell & 1 & 1 & wipe \\
\hline & 376.7949 & 264.1128 & & 0 & Hot Spot Cell & 1 & 2 & wipe \\
\hline & 278.6364 & 316.3924 & & 0 & Hot Spot Cell & 2 & 1 & vacuum \\
\hline & 344.0754 & 316.3924 & & 0 & Hot Spot Cell & 2 & 2 & vacuum \\
\hline & 311.3559 & 368.6719 & & 0 & Hot Spot Cell & 3 & 1 & wipe \\
\hline & 376.7949 & 368.6719 & & 0 & Hot Spot Cell & 3 & 2 & wipe \\
\hline & 278.6364 & 420.9515 & & 0 & Hot Spot Cell & 4 & 1 & vacuum \\
\hline & 344.0754 & 420.9515 & & 0 & Hot Spot Cell & 4 & 2 & wipe \\
\hline & 311.3559 & 473.2310 & & 0 & Hot Spot Cell & 5 & 1 & vacuum \\
\hline & 376.7949 & 473.2310 & & 0 & Hot Spot Cell & 5 & 2 & vacuum \\
\hline & 311.3559 & 264.1128 & & 0 & Hot Spot Cell & 1 & 1 & wipe \\
\hline
\end{tabular}


Table D.1. Coordinates and Sample Types for Probabilistic Sample Locations of Characterization Samples on Floor 1 of INL PBF-632 for INL-2 Test Events 1 and 2 (contd)

\begin{tabular}{|c|c|c|c|c|c|c|c|c|}
\hline Area & X Center & Y Center & Label & Value & Type & Row & Col & Sample Type \\
\hline \multirow[t]{8}{*}{ Office 108} & 314.9008 & 610.7505 & & 0 & Hot Spot Cell & 2 & 1 & wipe \\
\hline & 380.3398 & 610.7505 & & 0 & Hot Spot Cell & 2 & 2 & wipe \\
\hline & 282.1813 & 663.0301 & & 0 & Hot Spot Cell & 3 & 0 & vacuum \\
\hline & 347.6203 & 663.0301 & & 0 & Hot Spot Cell & 3 & 1 & vacuum \\
\hline & 314.9008 & 715.3096 & & 0 & Hot Spot Cell & 4 & 1 & vacuum \\
\hline & 380.3398 & 715.3096 & & 0 & Hot Spot Cell & 4 & 2 & wipe \\
\hline & 282.1813 & 767.5892 & & 0 & Hot Spot Cell & 5 & 0 & vacuum \\
\hline & 347.6203 & 767.5892 & & 0 & Hot Spot Cell & 5 & 1 & wipe \\
\hline \multirow[t]{6}{*}{ Office 109} & 180.3254 & 282.9416 & & 0 & Hot Spot Cell & 2 & 1 & wipe \\
\hline & 245.7645 & 282.9416 & & 0 & Hot Spot Cell & 2 & 2 & wipe \\
\hline & 213.0449 & 335.2211 & & 0 & Hot Spot Cell & 3 & 1 & vacuum \\
\hline & 180.3254 & 387.5007 & & 0 & Hot Spot Cell & 4 & 1 & wipe \\
\hline & 245.7645 & 387.5007 & & 0 & Hot Spot Cell & 4 & 2 & vacuum \\
\hline & 213.0449 & 439.7802 & & 0 & Hot Spot Cell & 5 & 1 & vacuum \\
\hline \multirow[t]{8}{*}{ Office 110} & 187.4826 & 613.5805 & & 0 & Hot Spot Cell & 2 & 1 & wipe \\
\hline & 252.9217 & 613.5805 & & 0 & Hot Spot Cell & 2 & 2 & vacuum \\
\hline & 154.7631 & 665.8600 & & 0 & Hot Spot Cell & 3 & 0 & swab monitor \\
\hline & 220.2022 & 665.8600 & & 0 & Hot Spot Cell & 3 & 1 & vacuum \\
\hline & 187.4826 & 718.1396 & & 0 & Hot Spot Cell & 4 & 1 & vacuum \\
\hline & 252.9217 & 718.1396 & & 0 & Hot Spot Cell & 4 & 2 & wipe \\
\hline & 154.7631 & 770.4192 & & 0 & Hot Spot Cell & 5 & 0 & wipe \\
\hline & 220.2022 & 770.4192 & & 0 & Hot Spot Cell & 5 & 1 & swab grill \\
\hline
\end{tabular}


Table D.2. Coordinates and Sample Types for Probabilistic Sample Locations of Characterization Samples on Floor 2 of INL PBF-632 for INL-2 Test Event 3

\begin{tabular}{|c|c|c|c|c|c|c|c|c|}
\hline Area & X Center & Y Center & Label & Value & Type & Row & Col & Sample Type \\
\hline \multirow[t]{5}{*}{ Office 201} & 1062.134 & 419.9414 & & 0 & Hot Spot Cell & 1 & 1 & vacuum \\
\hline & 1129.108 & 419.9414 & & 0 & Hot Spot Cell & 1 & 2 & wipe \\
\hline & 1028.647 & 473.5503 & & 0 & Hot Spot Cell & 2 & 1 & vacuum \\
\hline & 1095.621 & 473.5503 & & 0 & Hot Spot Cell & 2 & 2 & wipe \\
\hline & 1162.595 & 473.5503 & & 0 & Hot Spot Cell & 2 & 3 & swab monitor \\
\hline \multirow[t]{7}{*}{ Office $201 \mathrm{~A}$} & 1057.281 & 273.8041 & & 0 & Hot Spot Cell & 1 & 1 & wipe \\
\hline & 1123.904 & 273.8041 & & 0 & Hot Spot Cell & 1 & 2 & wipe \\
\hline & 1023.969 & 327.1091 & & 0 & Hot Spot Cell & 2 & 1 & vacuum \\
\hline & 1090.592 & 327.1091 & & 0 & Hot Spot Cell & 2 & 2 & vacuum \\
\hline & 1157.216 & 327.1091 & & 0 & Hot Spot Cell & 2 & 3 & wipe \\
\hline & 1057.281 & 380.4140 & & 0 & Hot Spot Cell & 3 & 1 & vacuum \\
\hline & 1123.904 & 380.4140 & & 0 & Hot Spot Cell & 3 & 2 & vacuum \\
\hline \multirow[t]{4}{*}{ Office 202} & 876.5383 & 593.7855 & & 0 & Hot Spot Cell & 1 & 1 & vacuum \\
\hline & 844.7463 & 644.4586 & & 0 & Hot Spot Cell & 2 & 1 & vacuum \\
\hline & 908.3303 & 644.4586 & & 0 & Hot Spot Cell & 2 & 2 & wipe \\
\hline & 876.5383 & 695.1316 & & 0 & Hot Spot Cell & 3 & 1 & swab monitor \\
\hline \multirow[t]{5}{*}{ Office 203} & 847.4285 & 409.3645 & & 0 & Hot Spot Cell & 1 & 0 & swab monitor \\
\hline & 914.0515 & 409.3645 & & 0 & Hot Spot Cell & 1 & 1 & wipe \\
\hline & 980.6745 & 409.3645 & & 0 & Hot Spot Cell & 1 & 2 & wipe \\
\hline & 880.7400 & 462.6694 & & 0 & Hot Spot Cell & 2 & 1 & swab grill \\
\hline & 947.3630 & 462.6694 & & 0 & Hot Spot Cell & 2 & 2 & vacuum \\
\hline \multirow[t]{7}{*}{ Office $203 \mathrm{~A}$} & 899.4484 & 247.1297 & & 0 & Hot Spot Cell & 1 & 1 & wipe \\
\hline & 966.0715 & 247.1297 & & 0 & Hot Spot Cell & 1 & 2 & wipe \\
\hline & 866.1369 & 300.4347 & & 0 & Hot Spot Cell & 2 & 1 & wipe \\
\hline & 932.7599 & 300.4347 & & 0 & Hot Spot Cell & 2 & 2 & vacuum \\
\hline & 999.3830 & 300.4347 & & 0 & Hot Spot Cell & 2 & 3 & wipe \\
\hline & 899.4484 & 353.7396 & & 0 & Hot Spot Cell & 3 & 1 & wipe \\
\hline & 966.0715 & 353.7396 & & 0 & Hot Spot Cell & 3 & 2 & vacuum \\
\hline \multirow[t]{4}{*}{ Office 204} & 774.6132 & 578.8964 & & 0 & Hot Spot Cell & 1 & 1 & vacuum \\
\hline & 741.3016 & 632.2014 & & 0 & Hot Spot Cell & 2 & 1 & wipe \\
\hline & 807.9247 & 632.2014 & & 0 & Hot Spot Cell & 2 & 2 & vacuum \\
\hline & 774.6132 & 685.5063 & & 0 & Hot Spot Cell & 3 & 1 & swab grill \\
\hline \multirow[t]{7}{*}{ Office 205} & 776.8733 & 245.0875 & & 0 & Hot Spot Cell & 1 & 1 & wipe \\
\hline & 743.5618 & 298.3924 & & 0 & Hot Spot Cell & 2 & 1 & vacuum \\
\hline & 810.1848 & 298.3924 & & 0 & Hot Spot Cell & 2 & 2 & wipe \\
\hline & 776.8733 & 351.6974 & & 0 & Hot Spot Cell & 3 & 1 & vacuum \\
\hline & 743.5618 & 405.0023 & & 0 & Hot Spot Cell & 4 & 1 & vacuum \\
\hline & 810.1848 & 405.0023 & & 0 & Hot Spot Cell & 4 & 2 & vacuum \\
\hline & 776.8733 & 458.3073 & & 0 & Hot Spot Cell & 5 & 1 & wipe \\
\hline
\end{tabular}


Table D.2. Coordinates and Sample Types for Probabilistic Sample Locations of Characterization Samples on Floor 2 of INL PBF-632 for INL-2 Test Event 3 (contd)

\begin{tabular}{|c|c|c|c|c|c|c|c|c|}
\hline Area & X Center & Y Center & Label & Value & Type & Row & Col & Sample Type \\
\hline \multirow[t]{7}{*}{ Office 206} & 660.3499 & 586.4829 & & 0 & Hot Spot Cell & 1 & 1 & vacuum \\
\hline & 627.0384 & 639.7879 & & 0 & Hot Spot Cell & 2 & 1 & vacuum \\
\hline & 693.6614 & 639.7879 & & 0 & Hot Spot Cell & 2 & 2 & wipe \\
\hline & 660.3499 & 693.0928 & & 0 & Hot Spot Cell & 3 & 1 & vacuum \\
\hline & 627.0384 & 746.3978 & & 0 & Hot Spot Cell & 4 & 1 & vacuum \\
\hline & 693.6614 & 746.3978 & & 0 & Hot Spot Cell & 4 & 2 & wipe \\
\hline & 660.3499 & 799.7027 & & 0 & Hot Spot Cell & 5 & 1 & swab monitor \\
\hline \multirow[t]{10}{*}{ Office 207} & 606.9418 & 240.0361 & & 0 & Hot Spot Cell & 1 & 0 & wipe \\
\hline & 673.5648 & 240.0361 & & 0 & Hot Spot Cell & 1 & 1 & vacuum \\
\hline & 640.2533 & 293.3410 & & 0 & Hot Spot Cell & 2 & 1 & vacuum \\
\hline & 706.8763 & 293.3410 & & 0 & Hot Spot Cell & 2 & 2 & wipe \\
\hline & 606.9418 & 346.6460 & & 0 & Hot Spot Cell & 3 & 0 & wipe \\
\hline & 673.5648 & 346.6460 & & 0 & Hot Spot Cell & 3 & 1 & wipe \\
\hline & 640.2533 & 399.9509 & & 0 & Hot Spot Cell & 4 & 1 & vacuum \\
\hline & 706.8763 & 399.9509 & & 0 & Hot Spot Cell & 4 & 2 & wipe \\
\hline & 606.9418 & 453.2559 & & 0 & Hot Spot Cell & 5 & 0 & vacuum \\
\hline & 673.5648 & 453.2559 & & 0 & Hot Spot Cell & 5 & 1 & vacuum \\
\hline \multirow[t]{8}{*}{ Office 208} & 523.3028 & 607.3784 & & 0 & Hot Spot Cell & 2 & 1 & wipe \\
\hline & 589.9258 & 607.3784 & & 0 & Hot Spot Cell & 2 & 2 & vacuum \\
\hline & 489.9913 & 660.6834 & & 0 & Hot Spot Cell & 3 & 0 & wipe \\
\hline & 556.6143 & 660.6834 & & 0 & Hot Spot Cell & 3 & 1 & vacuum \\
\hline & 523.3028 & 713.9883 & & 0 & Hot Spot Cell & 4 & 1 & vacuum \\
\hline & 589.9258 & 713.9883 & & 0 & Hot Spot Cell & 4 & 2 & wipe \\
\hline & 489.9913 & 767.2933 & & 0 & Hot Spot Cell & 5 & 0 & vacuum \\
\hline & 556.6143 & 767.2933 & & 0 & Hot Spot Cell & 5 & 1 & swab grill \\
\hline \multirow[t]{8}{*}{ Office 209} & 505.7497 & 245.6547 & & 0 & Hot Spot Cell & 1 & 0 & wipe \\
\hline & 572.3727 & 245.6547 & & 0 & Hot Spot Cell & 1 & 1 & wipe \\
\hline & 539.0612 & 298.9597 & & 0 & Hot Spot Cell & 2 & 1 & swab grill \\
\hline & 505.7497 & 352.2646 & & 0 & Hot Spot Cell & 3 & 0 & wipe \\
\hline & 572.3727 & 352.2646 & & 0 & Hot Spot Cell & 3 & 1 & vacuum \\
\hline & 539.0612 & 405.5695 & & 0 & Hot Spot Cell & 4 & 1 & vacuum \\
\hline & 505.7497 & 458.8745 & & 0 & Hot Spot Cell & 5 & 0 & wipe \\
\hline & 572.3727 & 458.8745 & & 0 & Hot Spot Cell & 5 & 1 & vacuum \\
\hline \multirow[t]{8}{*}{ Office 210} & 383.8727 & 584.9502 & & 0 & Hot Spot Cell & 1 & 0 & vacuum \\
\hline & 450.4957 & 584.9502 & & 0 & Hot Spot Cell & 1 & 1 & wipe \\
\hline & 417.1842 & 638.2552 & & 0 & Hot Spot Cell & 2 & 1 & vacuum \\
\hline & 383.8727 & 691.5601 & & 0 & Hot Spot Cell & 3 & 0 & vacuum \\
\hline & 450.4957 & 691.5601 & & 0 & Hot Spot Cell & 3 & 1 & wipe \\
\hline & 417.1842 & 744.8651 & & 0 & Hot Spot Cell & 4 & 1 & vacuum \\
\hline & 383.8727 & 798.1700 & & 0 & Hot Spot Cell & 5 & 0 & wipe \\
\hline & 450.4957 & 798.1700 & & 0 & Hot Spot Cell & 5 & 1 & vacuum \\
\hline
\end{tabular}


Table D.2. Coordinates and Sample Types for Probabilistic Sample Locations of Characterization Samples on Floor 2 of INL PBF-632 for INL-2 Test Event 3 (contd)

\begin{tabular}{|c|c|c|c|c|c|c|c|c|}
\hline Area & X Center & Y Center & Label & Value & Type & Row & Col & Sample Type \\
\hline \multirow[t]{7}{*}{ Office 211} & 420.0035 & 249.8492 & & 0 & Hot Spot Cell & 1 & 1 & wipe \\
\hline & 386.6920 & 303.1541 & & 0 & Hot Spot Cell & 2 & 1 & vacuum \\
\hline & 453.3151 & 303.1541 & & 0 & Hot Spot Cell & 2 & 2 & wipe \\
\hline & 420.0035 & 356.4591 & & 0 & Hot Spot Cell & 3 & 1 & vacuum \\
\hline & 386.6920 & 409.7640 & & 0 & Hot Spot Cell & 4 & 1 & wipe \\
\hline & 453.3151 & 409.7640 & & 0 & Hot Spot Cell & 4 & 2 & vacuum \\
\hline & 420.0035 & 463.0690 & & 0 & Hot Spot Cell & 5 & 1 & wipe \\
\hline \multirow{10}{*}{ Office 212} & 250.7538 & 583.4267 & & 0 & Hot Spot Cell & 1 & 0 & vacuum \\
\hline & 317.3768 & 583.4267 & & 0 & Hot Spot Cell & 1 & 1 & wipe \\
\hline & 284.0653 & 636.7317 & & 0 & Hot Spot Cell & 2 & 1 & vacuum \\
\hline & 350.6883 & 636.7317 & & 0 & Hot Spot Cell & 2 & 2 & wipe \\
\hline & 250.7538 & 690.0366 & & 0 & Hot Spot Cell & 3 & 0 & wipe \\
\hline & 317.3768 & 690.0366 & & 0 & Hot Spot Cell & 3 & 1 & vacuum \\
\hline & 284.0653 & 743.3415 & & 0 & Hot Spot Cell & 4 & 1 & vacuum \\
\hline & 350.6883 & 743.3415 & & 0 & Hot Spot Cell & 4 & 2 & vacuum \\
\hline & 250.7538 & 796.6465 & & 0 & Hot Spot Cell & 5 & 0 & vacuum \\
\hline & 317.3768 & 796.6465 & & 0 & Hot Spot Cell & 5 & 1 & wipe \\
\hline \multirow[t]{8}{*}{ Office 213} & 289.8700 & 275.3860 & & 0 & Hot Spot Cell & 1 & 1 & vacuum \\
\hline & 356.4930 & 275.3860 & & 0 & Hot Spot Cell & 1 & 2 & wipe \\
\hline & 256.5585 & 328.6909 & & 0 & Hot Spot Cell & 2 & 1 & wipe \\
\hline & 323.1815 & 328.6909 & & 0 & Hot Spot Cell & 2 & 2 & wipe \\
\hline & 289.8700 & 381.9958 & & 0 & Hot Spot Cell & 3 & 1 & vacuum \\
\hline & 356.4930 & 381.9958 & & 0 & Hot Spot Cell & 3 & 2 & wipe \\
\hline & 256.5585 & 435.3008 & & 0 & Hot Spot Cell & 4 & 1 & vacuum \\
\hline & 323.1815 & 435.3008 & & 0 & Hot Spot Cell & 4 & 2 & wipe \\
\hline
\end{tabular}


Table D.3. Coordinates and Sample Types for Probabilistic Sample Locations of Characterization Samples on Floor 1 of INL PBF-632 for INL-2 Test Event 4

\begin{tabular}{|c|c|c|c|c|c|c|c|c|}
\hline Area & X Center & Y Center & Label & Value & Type & Row & Col & Sample Type \\
\hline \multirow[t]{7}{*}{ Office 101} & 682.4718 & 410.4892 & & 0 & Hot Spot Cell & 1 & 1 & vacuum \\
\hline & 749.1072 & 410.4892 & & 0 & Hot Spot Cell & 1 & 2 & wipe \\
\hline & 815.7427 & 410.4892 & & 0 & Hot Spot Cell & 1 & 3 & wipe \\
\hline & 649.1541 & 463.8049 & & 0 & Hot Spot Cell & 2 & 1 & vacuum \\
\hline & 715.7895 & 463.8049 & & 0 & Hot Spot Cell & 2 & 2 & wipe \\
\hline & 782.4249 & 463.8049 & & 0 & Hot Spot Cell & 2 & 3 & vacuum \\
\hline & 849.0604 & 463.8049 & & 0 & Hot Spot Cell & 2 & 4 & vacuum \\
\hline \multirow{7}{*}{ Office 102} & 711.4785 & 577.3680 & & 0 & Hot Spot Cell & 1 & 1 & wipe \\
\hline & 774.5852 & 577.3680 & & 0 & Hot Spot Cell & 1 & 2 & vacuum \\
\hline & 679.9251 & 627.6277 & & 0 & Hot Spot Cell & 2 & 1 & vacuum \\
\hline & 743.0319 & 627.6277 & & 0 & Hot Spot Cell & 2 & 2 & vacuum \\
\hline & 806.1386 & 627.6277 & & 0 & Hot Spot Cell & 2 & 3 & vacuum \\
\hline & 711.4785 & 677.8875 & & 0 & Hot Spot Cell & 3 & 1 & wipe \\
\hline & 774.5852 & 677.8875 & & 0 & Hot Spot Cell & 3 & 2 & wipe \\
\hline \multirow[t]{11}{*}{ Office 103} & 516.8157 & 266.5276 & & 0 & Hot Spot Cell & 1 & 0 & wipe \\
\hline & 572.2008 & 266.5276 & & 0 & Hot Spot Cell & 1 & 1 & vacuum \\
\hline & 544.5083 & 310.1002 & & 0 & Hot Spot Cell & 2 & 1 & vacuum \\
\hline & 599.8933 & 310.1002 & & 0 & Hot Spot Cell & 2 & 2 & vacuum \\
\hline & 516.8157 & 353.6727 & & 0 & Hot Spot Cell & 3 & 0 & vacuum \\
\hline & 572.2008 & 353.6727 & & 0 & Hot Spot Cell & 3 & 1 & vacuum \\
\hline & 544.5083 & 397.2453 & & 0 & Hot Spot Cell & 4 & 1 & wipe \\
\hline & 599.8933 & 397.2453 & & 0 & Hot Spot Cell & 4 & 2 & vacuum \\
\hline & 516.8157 & 440.8179 & & 0 & Hot Spot Cell & 5 & 0 & vacuum \\
\hline & 572.2008 & 440.8179 & & 0 & Hot Spot Cell & 5 & 1 & wipe \\
\hline & 544.5083 & 484.3905 & & 0 & Hot Spot Cell & 6 & 1 & vacuum \\
\hline \multirow[t]{12}{*}{ Office 104} & 543.9542 & 699.7594 & & 0 & Hot Spot Cell & 1 & 1 & vacuum \\
\hline & 588.1645 & 699.7594 & & 0 & Hot Spot Cell & 1 & 2 & wipe \\
\hline & 632.3747 & 699.7594 & & 0 & Hot Spot Cell & 1 & 3 & wipe \\
\hline & 521.8491 & 733.6542 & & 0 & Hot Spot Cell & 2 & 1 & vacuum \\
\hline & 566.0594 & 733.6542 & & 0 & Hot Spot Cell & 2 & 2 & vacuum \\
\hline & 610.2696 & 733.6542 & & 0 & Hot Spot Cell & 2 & 3 & wipe \\
\hline & 543.9542 & 767.5491 & & 0 & Hot Spot Cell & 3 & 1 & wipe \\
\hline & 588.1645 & 767.5491 & & 0 & Hot Spot Cell & 3 & 2 & wipe \\
\hline & 632.3747 & 767.5491 & & 0 & Hot Spot Cell & 3 & 3 & wipe \\
\hline & 521.8491 & 801.4440 & & 0 & Hot Spot Cell & 4 & 1 & wipe \\
\hline & 566.0594 & 801.4440 & & 0 & Hot Spot Cell & 4 & 2 & wipe \\
\hline & 610.2696 & 801.4440 & & 0 & Hot Spot Cell & 4 & 3 & vacuum \\
\hline
\end{tabular}


Table D.3. Coordinates and Sample Types for Probabilistic Sample Locations of Characterization Samples on Floor 1 of INL PBF-632 for INL-2 Test Event 4 (contd)

\begin{tabular}{|c|c|c|c|c|c|c|c|c|}
\hline Area & X Center & Y Center & Label & Value & Type & Row & Col & Sample Type \\
\hline \multirow[t]{13}{*}{ Office 105} & 419.25 & 245.5 & & 0 & Grid Cell & 1 & 3 & vacuum \\
\hline & 455.25 & 269.5 & & 0 & Grid Cell & 3 & 6 & wipe \\
\hline & 491.25 & 293.5 & & 0 & Grid Cell & 5 & 9 & vacuum \\
\hline & 407.25 & 305.5 & & 0 & Grid Cell & 6 & 2 & wipe \\
\hline & 455.25 & 329.5 & & 0 & Grid Cell & 8 & 6 & vacuum \\
\hline & 395.25 & 341.5 & & 0 & Grid Cell & 9 & 1 & wipe \\
\hline & 467.25 & 377.5 & & 0 & Grid Cell & 12 & 7 & wipe \\
\hline & 419.25 & 389.5 & & 0 & Grid Cell & 13 & 3 & vacuum \\
\hline & 503.25 & 413.5 & & 0 & Grid Cell & 15 & 10 & wipe \\
\hline & 395.25 & 437.5 & & 0 & Grid Cell & 17 & 1 & vacuum \\
\hline & 443.25 & 449.5 & & 0 & Grid Cell & 18 & 5 & vacuum \\
\hline & 503.25 & 473.5 & & 0 & Grid Cell & 20 & 10 & wipe \\
\hline & 407.25 & 485.5 & & 0 & Grid Cell & 21 & 2 & vacuum \\
\hline \multirow{13}{*}{ Office 106} & 395 & 576 & & 0 & Grid Cell & 1 & 1 & vacuum \\
\hline & 431 & 588 & & 0 & Grid Cell & 2 & 4 & vacuum \\
\hline & 503 & 588 & & 0 & Grid Cell & 2 & 10 & wipe \\
\hline & 467 & 624 & & 0 & Grid Cell & 5 & 7 & wipe \\
\hline & 419 & 648 & & 0 & Grid Cell & 7 & 3 & wipe \\
\hline & 467 & 684 & & 0 & Grid Cell & 10 & 7 & wipe \\
\hline & 419 & 708 & & 0 & Grid Cell & 12 & 3 & vacuum \\
\hline & 491 & 720 & & 0 & Grid Cell & 13 & 9 & vacuum \\
\hline & 395 & 756 & & 0 & Grid Cell & 16 & 1 & vacuum \\
\hline & 455 & 756 & & 0 & Grid Cell & 16 & 6 & vacuum \\
\hline & 455 & 792 & & 0 & Grid Cell & 19 & 6 & vacuum \\
\hline & 503 & 804 & & 0 & Grid Cell & 20 & 10 & wipe \\
\hline & 419 & 816 & & 0 & Grid Cell & 21 & 3 & wipe \\
\hline \multirow[t]{13}{*}{ Office 107} & 325 & 245.5 & & 0 & Grid Cell & 1 & 5 & wipe \\
\hline & 277 & 257.5 & & 0 & Grid Cell & 2 & 1 & wipe \\
\hline & 361 & 281.5 & & 0 & Grid Cell & 4 & 8 & vacuum \\
\hline & 325 & 293.5 & & 0 & Grid Cell & 5 & 5 & wipe \\
\hline & 277 & 305.5 & & 0 & Grid Cell & 6 & 1 & vacuum \\
\hline & 349 & 329.5 & & 0 & Grid Cell & 8 & 7 & vacuum \\
\hline & 301 & 353.5 & & 0 & Grid Cell & 10 & 3 & vacuum \\
\hline & 349 & 377.5 & & 0 & Grid Cell & 12 & 7 & vacuum \\
\hline & 277 & 389.5 & & 0 & Grid Cell & 13 & 1 & wipe \\
\hline & 337 & 425.5 & & 0 & Grid Cell & 16 & 6 & wipe \\
\hline & 289 & 449.5 & & 0 & Grid Cell & 18 & 2 & wipe \\
\hline & 373 & 461.5 & & 0 & Grid Cell & 19 & 9 & vacuum \\
\hline & 325 & 485.5 & & 0 & Grid Cell & 21 & 5 & vacuum \\
\hline
\end{tabular}


Table D.3. Coordinates and Sample Types for Probabilistic Sample Locations of Characterization Samples on Floor 1 of INL PBF-632 for INL-2 Test Event 4 (contd)

\begin{tabular}{|c|c|c|c|c|c|c|c|c|}
\hline Area & X Center & Y Center & Label & Value & Type & Row & Col & Sample Type \\
\hline \multirow[t]{13}{*}{ Office 108} & 336.25 & 576 & & 0 & Grid Cell & 1 & 6 & vacuum \\
\hline & 372.25 & 576 & & 0 & Grid Cell & 1 & 9 & wipe \\
\hline & 288.25 & 588 & & 0 & Grid Cell & 2 & 2 & vacuum \\
\hline & 336.25 & 624 & & 0 & Grid Cell & 5 & 6 & wipe \\
\hline & 300.25 & 636 & & 0 & Grid Cell & 6 & 3 & vacuum \\
\hline & 324.25 & 672 & & 0 & Grid Cell & 9 & 5 & vacuum \\
\hline & 372.25 & 696 & & 0 & Grid Cell & 11 & 9 & wipe \\
\hline & 288.25 & 708 & & 0 & Grid Cell & 12 & 2 & wipe \\
\hline & 324.25 & 744 & & 0 & Grid Cell & 15 & 5 & vacuum \\
\hline & 372.25 & 744 & & 0 & Grid Cell & 15 & 9 & wipe \\
\hline & 288.25 & 780 & & 0 & Grid Cell & 18 & 2 & wipe \\
\hline & 384.25 & 792 & & 0 & Grid Cell & 19 & 10 & wipe \\
\hline & 336.25 & 804 & & 0 & Grid Cell & 20 & 6 & wipe \\
\hline \multirow[t]{12}{*}{ Office 109} & 188.6864 & 249.6813 & & 0 & Hot Spot Cell & 1 & 1 & wipe \\
\hline & 244.1247 & 249.6813 & & 0 & Hot Spot Cell & 1 & 2 & wipe \\
\hline & 160.9673 & 293.3000 & & 0 & Hot Spot Cell & 2 & 1 & vacuum \\
\hline & 216.4056 & 293.3000 & & 0 & Hot Spot Cell & 2 & 2 & vacuum \\
\hline & 188.6864 & 336.9186 & & 0 & Hot Spot Cell & 3 & 1 & vacuum \\
\hline & 244.1247 & 336.9186 & & 0 & Hot Spot Cell & 3 & 2 & wipe \\
\hline & 160.9673 & 380.5373 & & 0 & Hot Spot Cell & 4 & 1 & wipe \\
\hline & 216.4056 & 380.5373 & & 0 & Hot Spot Cell & 4 & 2 & vacuum \\
\hline & 188.6864 & 424.1560 & & 0 & Hot Spot Cell & 5 & 1 & wipe \\
\hline & 244.1247 & 424.1560 & & 0 & Hot Spot Cell & 5 & 2 & vacuum \\
\hline & 160.9673 & 467.7747 & & 0 & Hot Spot Cell & 6 & 1 & vacuum \\
\hline & 216.4056 & 467.7747 & & 0 & Hot Spot Cell & 6 & 2 & vacuum \\
\hline \multirow[t]{12}{*}{ Office 110} & 202.8835 & 581.4392 & & 0 & Hot Spot Cell & 1 & 1 & vacuum \\
\hline & 258.1514 & 581.4392 & & 0 & Hot Spot Cell & 1 & 2 & vacuum \\
\hline & 175.2496 & 624.9103 & & 0 & Hot Spot Cell & 2 & 1 & wipe \\
\hline & 230.5175 & 624.9103 & & 0 & Hot Spot Cell & 2 & 2 & wipe \\
\hline & 202.8835 & 668.3813 & & 0 & Hot Spot Cell & 3 & 1 & vacuum \\
\hline & 258.1514 & 668.3813 & & 0 & Hot Spot Cell & 3 & 2 & wipe \\
\hline & 175.2496 & 711.8524 & & 0 & Hot Spot Cell & 4 & 1 & vacuum \\
\hline & 230.5175 & 711.8524 & & 0 & Hot Spot Cell & 4 & 2 & vacuum \\
\hline & 202.8835 & 755.3235 & & 0 & Hot Spot Cell & 5 & 1 & swab grill \\
\hline & 258.1514 & 755.3235 & & 0 & Hot Spot Cell & 5 & 2 & wipe \\
\hline & 175.2496 & 798.7945 & & 0 & Hot Spot Cell & 6 & 1 & wipe \\
\hline & 230.5175 & 798.7945 & & 0 & Hot Spot Cell & 6 & 2 & vacuum \\
\hline
\end{tabular}


Table D.4. Coordinates and Sample Types for Probabilistic Sample Locations of Characterization Samples on Floor 2 of INL PBF-632 for INL-2 Test Event 5

\begin{tabular}{|c|c|c|c|c|c|c|c|c|}
\hline Area & X Center & Y Center & Label & Value & Type & Row & Col & Sample Type \\
\hline \multirow[t]{7}{*}{ Office 201} & 1012.379 & 413.7051 & & 0 & Hot Spot Cell & 1 & 0 & vacuum \\
\hline & 1070.587 & 413.7051 & & 0 & Hot Spot Cell & 1 & 1 & wipe \\
\hline & 1128.796 & 413.7051 & & 0 & Hot Spot Cell & 1 & 2 & vacuum \\
\hline & 1187.004 & 413.7051 & & 0 & Hot Spot Cell & 1 & 3 & wipe \\
\hline & 1041.483 & 459.7225 & & 0 & Hot Spot Cell & 2 & 1 & vacuum \\
\hline & 1099.691 & 459.7225 & & 0 & Hot Spot Cell & 2 & 2 & vacuum \\
\hline & 1157.900 & 459.7225 & & 0 & Hot Spot Cell & 2 & 3 & wipe \\
\hline \multirow[t]{7}{*}{ Office 202} & 898 & 572 & & 0 & Grid Cell & 1 & 7 & vacuum \\
\hline & 850 & 584 & & 0 & Grid Cell & 2 & 3 & vacuum \\
\hline & 898 & 620 & & 0 & Grid Cell & 5 & 7 & wipe \\
\hline & 826 & 632 & & 0 & Grid Cell & 6 & 1 & wipe \\
\hline & 862 & 644 & & 0 & Grid Cell & 7 & 4 & vacuum \\
\hline & 874 & 692 & & 0 & Grid Cell & 11 & 5 & swab monitor \\
\hline & 826 & 704 & & 0 & Grid Cell & 12 & 1 & wipe \\
\hline \multirow{13}{*}{ Office 205} & 730.5 & 253.5 & & 0 & Grid Cell & 2 & 2 & wipe \\
\hline & 802.5 & 265.5 & & 0 & Grid Cell & 3 & 8 & wipe \\
\hline & 766.5 & 301.5 & & 0 & Grid Cell & 6 & 5 & vacuum \\
\hline & 718.5 & 325.5 & & 0 & Grid Cell & 8 & 1 & vacuum \\
\hline & 814.5 & 325.5 & & 0 & Grid Cell & 8 & 9 & wipe \\
\hline & 778.5 & 349.5 & & 0 & Grid Cell & 10 & 6 & vacuum \\
\hline & 802.5 & 385.5 & & 0 & Grid Cell & 13 & 8 & wipe \\
\hline & 742.5 & 397.5 & & 0 & Grid Cell & 14 & 3 & swab monitor \\
\hline & 766.5 & 433.5 & & 0 & Grid Cell & 17 & 5 & wipe \\
\hline & 718.5 & 445.5 & & 0 & Grid Cell & 18 & 1 & vacuum \\
\hline & 790.5 & 457.5 & & 0 & Grid Cell & 19 & 7 & vacuum \\
\hline & 718.5 & 481.5 & & 0 & Grid Cell & 21 & 1 & vacuum \\
\hline & 826.5 & 481.5 & & 0 & Grid Cell & 21 & 10 & vacuum \\
\hline \multirow[t]{13}{*}{ Office 206} & 661 & 584 & & 0 & Grid Cell & 2 & 5 & vacuum \\
\hline & 709 & 608 & & 0 & Grid Cell & 4 & 9 & vacuum \\
\hline & 613 & 620 & & 0 & Grid Cell & 5 & 1 & vacuum \\
\hline & 637 & 644 & & 0 & Grid Cell & 7 & 3 & vacuum \\
\hline & 685 & 656 & & 0 & Grid Cell & 8 & 7 & wipe \\
\hline & 661 & 680 & & 0 & Grid Cell & 10 & 5 & vacuum \\
\hline & 613 & 704 & & 0 & Grid Cell & 12 & 1 & wipe \\
\hline & 721 & 716 & & 0 & Grid Cell & 13 & 10 & wipe \\
\hline & 661 & 728 & & 0 & Grid Cell & 14 & 5 & vacuum \\
\hline & 709 & 752 & & 0 & Grid Cell & 16 & 9 & vacuum \\
\hline & 637 & 764 & & 0 & Grid Cell & 17 & 3 & wipe \\
\hline & 673 & 800 & & 0 & Grid Cell & 20 & 6 & swab monitor \\
\hline & 613 & 812 & & 0 & Grid Cell & 21 & 1 & vacuum \\
\hline
\end{tabular}


Table D.4. Coordinates and Sample Types for Probabilistic Sample Locations of Characterization Samples on Floor 2 of INL PBF-632 for INL-2 Test Event 5 (contd)

\begin{tabular}{|c|c|c|c|c|c|c|c|c|}
\hline Area & X Center & Y Center & Label & Value & Type & Row & Col & Sample Type \\
\hline \multirow{13}{*}{ Office 207} & 629.25 & 265.5 & & 0 & Grid Cell & 3 & 3 & swab monitor \\
\hline & 701.25 & 265.5 & & 0 & Grid Cell & 3 & 9 & vacuum \\
\hline & 629.25 & 313.5 & & 0 & Grid Cell & 7 & 3 & vacuum \\
\hline & 665.25 & 313.5 & & 0 & Grid Cell & 7 & 6 & vacuum \\
\hline & 701.25 & 337.5 & & 0 & Grid Cell & 9 & 9 & wipe \\
\hline & 617.25 & 349.5 & & 0 & Grid Cell & 10 & 2 & wipe \\
\hline & 653.25 & 373.5 & & 0 & Grid Cell & 12 & 5 & wipe \\
\hline & 701.25 & 385.5 & & 0 & Grid Cell & 13 & 9 & wipe \\
\hline & 605.25 & 409.5 & & 0 & Grid Cell & 15 & 1 & wipe \\
\hline & 665.25 & 409.5 & & 0 & Grid Cell & 15 & 6 & vacuum \\
\hline & 641.25 & 445.5 & & 0 & Grid Cell & 18 & 4 & vacuum \\
\hline & 701.25 & 445.5 & & 0 & Grid Cell & 18 & 9 & vacuum \\
\hline & 617.25 & 481.5 & & 0 & Grid Cell & 21 & 2 & vacuum \\
\hline \multirow[t]{13}{*}{ Office 208} & 505 & 572 & & 0 & Grid Cell & 1 & 2 & wipe \\
\hline & 553 & 572 & & 0 & Grid Cell & 1 & 6 & vacuum \\
\hline & 505 & 608 & & 0 & Grid Cell & 4 & 2 & vacuum \\
\hline & 565 & 632 & & 0 & Grid Cell & 6 & 7 & vacuum \\
\hline & 541 & 656 & & 0 & Grid Cell & 8 & 5 & wipe \\
\hline & 493 & 680 & & 0 & Grid Cell & 10 & 1 & wipe \\
\hline & 541 & 704 & & 0 & Grid Cell & 12 & 5 & vacuum \\
\hline & 589 & 704 & & 0 & Grid Cell & 12 & 9 & vacuum \\
\hline & 505 & 728 & & 0 & Grid Cell & 14 & 2 & vacuum \\
\hline & 601 & 740 & & 0 & Grid Cell & 15 & 10 & wipe \\
\hline & 565 & 752 & & 0 & Grid Cell & 16 & 7 & swab grill \\
\hline & 517 & 788 & & 0 & Grid Cell & 19 & 3 & wipe \\
\hline & 577 & 812 & & 0 & Grid Cell & 21 & 8 & wipe \\
\hline \multirow[t]{12}{*}{ Office 209} & 497.3562 & 251.4881 & & 0 & Hot Spot Cell & 1 & 0 & wipe \\
\hline & 551.4910 & 251.4881 & & 0 & Hot Spot Cell & 1 & 1 & vacuum \\
\hline & 524.4236 & 293.9779 & & 0 & Hot Spot Cell & 2 & 1 & vacuum \\
\hline & 578.5584 & 293.9779 & & 0 & Hot Spot Cell & 2 & 2 & vacuum \\
\hline & 497.3562 & 336.4677 & & 0 & Hot Spot Cell & 3 & 0 & vacuum \\
\hline & 551.4910 & 336.4677 & & 0 & Hot Spot Cell & 3 & 1 & vacuum \\
\hline & 524.4236 & 378.9575 & & 0 & Hot Spot Cell & 4 & 1 & wipe \\
\hline & 578.5584 & 378.9575 & & 0 & Hot Spot Cell & 4 & 2 & vacuum \\
\hline & 497.3562 & 421.4473 & & 0 & Hot Spot Cell & 5 & 0 & wipe \\
\hline & 551.4910 & 421.4473 & & 0 & Hot Spot Cell & 5 & 1 & vacuum \\
\hline & 524.4236 & 463.9372 & & 0 & Hot Spot Cell & 6 & 1 & wipe \\
\hline & 578.5584 & 463.9372 & & 0 & Hot Spot Cell & 6 & 2 & vacuum \\
\hline
\end{tabular}


Table D.4. Coordinates and Sample Types for Probabilistic Sample Locations of Characterization Samples on Floor 2 of INL PBF-632 for INL-2 Test Event 5 (contd)

\begin{tabular}{|c|c|c|c|c|c|c|c|c|}
\hline Area & X Center & Y Center & Label & Value & Type & Row & Col & Sample Type \\
\hline \multirow[t]{12}{*}{ Office 210} & 415.8897 & 577.0364 & & $\overline{0}$ & Hot Spot Cell & 1 & 1 & vacuum \\
\hline & 471.2986 & 577.0364 & & 0 & Hot Spot Cell & 1 & 2 & wipe \\
\hline & 388.1853 & 620.6296 & & 0 & Hot Spot Cell & 2 & 1 & vacuum \\
\hline & 443.5942 & 620.6296 & & 0 & Hot Spot Cell & 2 & 2 & vacuum \\
\hline & 415.8897 & 664.2227 & & 0 & Hot Spot Cell & 3 & 1 & vacuum \\
\hline & 471.2986 & 664.2227 & & 0 & Hot Spot Cell & 3 & 2 & wipe \\
\hline & 388.1853 & 707.8159 & & 0 & Hot Spot Cell & 4 & 1 & vacuum \\
\hline & 443.5942 & 707.8159 & & 0 & Hot Spot Cell & 4 & 2 & vacuum \\
\hline & 415.8897 & 751.4091 & & 0 & Hot Spot Cell & 5 & 1 & vacuum \\
\hline & 471.2986 & 751.4091 & & 0 & Hot Spot Cell & 5 & 2 & swab monitor \\
\hline & 388.1853 & 795.0023 & & 0 & Hot Spot Cell & 6 & 1 & wipe \\
\hline & 443.5942 & 795.0023 & & 0 & Hot Spot Cell & 6 & 2 & vacuum \\
\hline \multirow[t]{12}{*}{ Office 212} & 255.9664 & 592.0109 & & 0 & Hot Spot Cell & 1 & 0 & vacuum \\
\hline & 311.9433 & 592.0109 & & 0 & Hot Spot Cell & 1 & 1 & wipe \\
\hline & 283.9548 & 636.0961 & & 0 & Hot Spot Cell & 2 & 1 & vacuum \\
\hline & 339.9318 & 636.0961 & & 0 & Hot Spot Cell & 2 & 2 & vacuum \\
\hline & 255.9664 & 680.1812 & & 0 & Hot Spot Cell & 3 & 0 & swab monitor \\
\hline & 311.9433 & 680.1812 & & 0 & Hot Spot Cell & 3 & 1 & vacuum \\
\hline & 283.9548 & 724.2664 & & 0 & Hot Spot Cell & 4 & 1 & vacuum \\
\hline & 339.9318 & 724.2664 & & 0 & Hot Spot Cell & 4 & 2 & wipe \\
\hline & 255.9664 & 768.3515 & & 0 & Hot Spot Cell & 5 & 0 & wipe \\
\hline & 311.9433 & 768.3515 & & 0 & Hot Spot Cell & 5 & 1 & swab grill \\
\hline & 283.9548 & 812.4366 & & 0 & Hot Spot Cell & 6 & 1 & wipe \\
\hline & 339.9318 & 812.4366 & & 0 & Hot Spot Cell & 6 & 2 & wipe \\
\hline \multirow[t]{12}{*}{ Office 213} & 299.5618 & 241.8135 & & 0 & Hot Spot Cell & 1 & 1 & vacuum \\
\hline & 354.8550 & 241.8135 & & 0 & Hot Spot Cell & 1 & 2 & wipe \\
\hline & 271.9151 & 285.3065 & & 0 & Hot Spot Cell & 2 & 1 & wipe \\
\hline & 327.2084 & 285.3065 & & 0 & Hot Spot Cell & 2 & 2 & wipe \\
\hline & 299.5618 & 328.7996 & & 0 & Hot Spot Cell & 3 & 1 & vacuum \\
\hline & 354.8550 & 328.7996 & & 0 & Hot Spot Cell & 3 & 2 & vacuum \\
\hline & 271.9151 & 372.2927 & & 0 & Hot Spot Cell & 4 & 1 & vacuum \\
\hline & 327.2084 & 372.2927 & & 0 & Hot Spot Cell & 4 & 2 & wipe \\
\hline & 299.5618 & 415.7858 & & 0 & Hot Spot Cell & 5 & 1 & vacuum \\
\hline & 354.8550 & 415.7858 & & 0 & Hot Spot Cell & 5 & 2 & vacuum \\
\hline & 271.9151 & 459.2789 & & 0 & Hot Spot Cell & 6 & 1 & vacuum \\
\hline & 327.2084 & 459.2789 & & 0 & Hot Spot Cell & 6 & 2 & vacuum \\
\hline
\end{tabular}


Table D.5. Coordinates and Sample Types for Probabilistic Sample Locations of Clearance Samples on Floor 1 of INL PBF-632 for INL-2 Test Events 1, 2, and 4

\begin{tabular}{|c|c|c|c|c|c|c|c|c|}
\hline Area & X Center & Y Center & Label & Value & Type & Row & Col & Sample Type \\
\hline \multirow[t]{21}{*}{ Lobby } & 905.1964 & 271.7238 & & 0 & Hot Spot Cell & 1 & 1 & swab grill \\
\hline & 967.1662 & 271.7238 & & 0 & Hot Spot Cell & 1 & 2 & vacuum \\
\hline & 1029.136 & 271.7238 & & 0 & Hot Spot Cell & 1 & 3 & vacuum \\
\hline & 874.2115 & 320.9989 & & 0 & Hot Spot Cell & 2 & 1 & vacuum \\
\hline & 936.1813 & 320.9989 & & 0 & Hot Spot Cell & 2 & 2 & wipe \\
\hline & 998.151 & 320.9989 & & 0 & Hot Spot Cell & 2 & 3 & wipe \\
\hline & 1060.121 & 320.9989 & & 0 & Hot Spot Cell & 2 & 4 & vacuum \\
\hline & 905.1964 & 370.2740 & & 0 & Hot Spot Cell & 3 & 1 & vacuum \\
\hline & 967.1662 & 370.2740 & & 0 & Hot Spot Cell & 3 & 2 & wipe \\
\hline & 1029.136 & 370.2740 & & 0 & Hot Spot Cell & 3 & 3 & vacuum \\
\hline & 874.2115 & 419.5491 & & 0 & Hot Spot Cell & 4 & 1 & vacuum \\
\hline & 936.1813 & 419.5491 & & 0 & Hot Spot Cell & 4 & 2 & wipe \\
\hline & 998.151 & 419.5491 & & 0 & Hot Spot Cell & 4 & 3 & wipe \\
\hline & 1060.121 & 419.5491 & & 0 & Hot Spot Cell & 4 & 4 & wipe \\
\hline & 905.1964 & 468.8241 & & 0 & Hot Spot Cell & 5 & 1 & vacuum \\
\hline & 967.1662 & 468.8241 & & 0 & Hot Spot Cell & 5 & 2 & vacuum \\
\hline & 1029.136 & 468.8241 & & 0 & Hot Spot Cell & 5 & 3 & vacuum \\
\hline & 874.2115 & 518.0992 & & 0 & Hot Spot Cell & 6 & 1 & vacuum \\
\hline & 936.1813 & 518.0992 & & 0 & Hot Spot Cell & 6 & 2 & wipe \\
\hline & 998.1510 & 518.0992 & & 0 & Hot Spot Cell & 6 & 3 & vacuum \\
\hline & 1060.121 & 518.0992 & & 0 & Hot Spot Cell & 6 & 4 & vacuum \\
\hline \multirow[t]{9}{*}{ Office 101} & 630.8571 & 402.3126 & & 0 & Hot Spot Cell & 1 & 0 & vacuum \\
\hline & 689.2283 & 402.3126 & & 0 & Hot Spot Cell & 1 & 1 & wipe \\
\hline & 747.5994 & 402.3126 & & 0 & Hot Spot Cell & 1 & 2 & wipe \\
\hline & 805.9706 & 402.3126 & & 0 & Hot Spot Cell & 1 & 3 & wipe \\
\hline & 864.3418 & 402.3126 & & 0 & Hot Spot Cell & 1 & 4 & wipe \\
\hline & 660.0427 & 448.4712 & & 0 & Hot Spot Cell & 2 & 1 & vacuum \\
\hline & 718.4138 & 448.4712 & & 0 & Hot Spot Cell & 2 & 2 & vacuum \\
\hline & 776.7850 & 448.4712 & & 0 & Hot Spot Cell & 2 & 3 & vacuum \\
\hline & 835.1562 & 448.4712 & & 0 & Hot Spot Cell & 2 & 4 & vacuum \\
\hline \multirow[t]{12}{*}{ Office 101A } & 663.0169 & 257.8554 & & 0 & Hot Spot Cell & 1 & 1 & wipe \\
\hline & 724.9866 & 257.8554 & & 0 & Hot Spot Cell & 1 & 2 & vacuum \\
\hline & 786.9564 & 257.8554 & & 0 & Hot Spot Cell & 1 & 3 & vacuum \\
\hline & 848.9261 & 257.8554 & & 0 & Hot Spot Cell & 1 & 4 & wipe \\
\hline & 632.0320 & 307.1305 & & 0 & Hot Spot Cell & 2 & 1 & wipe \\
\hline & 694.0018 & 307.1305 & & 0 & Hot Spot Cell & 2 & 2 & vacuum \\
\hline & 755.9715 & 307.1305 & & 0 & Hot Spot Cell & 2 & 3 & vacuum \\
\hline & 817.9413 & 307.1305 & & 0 & Hot Spot Cell & 2 & 4 & vacuum \\
\hline & 663.0169 & 356.4056 & & 0 & Hot Spot Cell & 3 & 1 & vacuum \\
\hline & 724.9866 & 356.4056 & & 0 & Hot Spot Cell & 3 & 2 & wipe \\
\hline & 786.9564 & 356.4056 & & 0 & Hot Spot Cell & 3 & 3 & wipe \\
\hline & 848.9261 & 356.4056 & & 0 & Hot Spot Cell & 3 & 4 & wipe \\
\hline
\end{tabular}


Table D.5. Coordinates and Sample Types for Probabilistic Sample Locations of Clearance Samples on Floor 1 of INL PBF-632 for INL-2 Test Events 1, 2, and 4 (contd)

\begin{tabular}{|c|c|c|c|c|c|c|c|c|}
\hline Area & X Center & Y Center & Label & Value & Type & Row & Col & Sample Type \\
\hline \multirow[t]{5}{*}{ Office 102} & 690.5869 & 611.1912 & & 0 & Hot Spot Cell & 2 & 1 & wipe \\
\hline & 753.6963 & 611.1912 & & 0 & Hot Spot Cell & 2 & 2 & vacuum \\
\hline & 659.0323 & 661.4532 & & 0 & Hot Spot Cell & 3 & 0 & vacuum \\
\hline & 722.1416 & 661.4532 & & 0 & Hot Spot Cell & 3 & 1 & vacuum \\
\hline & 785.2509 & 661.4532 & & 0 & Hot Spot Cell & 3 & 2 & wipe \\
\hline \multirow[t]{10}{*}{ Office 103} & 556.5035 & 264.0828 & & 0 & Hot Spot Cell & 1 & 1 & wipe \\
\hline & 618.4732 & 264.0828 & & 0 & Hot Spot Cell & 1 & 2 & wipe \\
\hline & 525.5186 & 313.3579 & & 0 & Hot Spot Cell & 2 & 1 & vacuum \\
\hline & 587.4883 & 313.3579 & & 0 & Hot Spot Cell & 2 & 2 & vacuum \\
\hline & 556.5035 & 362.6330 & & 0 & Hot Spot Cell & 3 & 1 & wipe \\
\hline & 618.4732 & 362.6330 & & 0 & Hot Spot Cell & 3 & 2 & vacuum \\
\hline & 525.5186 & 411.9081 & & 0 & Hot Spot Cell & 4 & 1 & vacuum \\
\hline & 587.4883 & 411.9081 & & 0 & Hot Spot Cell & 4 & 2 & vacuum \\
\hline & 556.5035 & 461.1831 & & 0 & Hot Spot Cell & 5 & 1 & vacuum \\
\hline & 618.4732 & 461.1831 & & 0 & Hot Spot Cell & 5 & 2 & vacuum \\
\hline \multirow[t]{5}{*}{ Office 104} & 550.0930 & 727.4776 & & 0 & Hot Spot Cell & 1 & 1 & vacuum \\
\hline & 617.1208 & 727.4776 & & 0 & Hot Spot Cell & 1 & 2 & wipe \\
\hline & 516.5792 & 781.1331 & & 0 & Hot Spot Cell & 2 & 1 & vacuum \\
\hline & 583.6069 & 781.1331 & & 0 & Hot Spot Cell & 2 & 2 & swab monitor \\
\hline & 650.6346 & 781.1331 & & 0 & Hot Spot Cell & 2 & 3 & wipe \\
\hline \multirow[t]{10}{*}{ Office 105} & 436.5812 & 275.3192 & & 0 & Hot Spot Cell & 1 & 1 & wipe \\
\hline & 498.5509 & 275.3192 & & 0 & Hot Spot Cell & 1 & 2 & wipe \\
\hline & 405.5963 & 324.5943 & & 0 & Hot Spot Cell & 2 & 1 & wipe \\
\hline & 467.5661 & 324.5943 & & 0 & Hot Spot Cell & 2 & 2 & vacuum \\
\hline & 436.5812 & 373.8693 & & 0 & Hot Spot Cell & 3 & 1 & vacuum \\
\hline & 498.5509 & 373.8693 & & 0 & Hot Spot Cell & 3 & 2 & wipe \\
\hline & 405.5963 & 423.1444 & & 0 & Hot Spot Cell & 4 & 1 & vacuum \\
\hline & 467.5661 & 423.1444 & & 0 & Hot Spot Cell & 4 & 2 & wipe \\
\hline & 436.5812 & 472.4195 & & 0 & Hot Spot Cell & 5 & 1 & vacuum \\
\hline & 498.5509 & 472.4195 & & 0 & Hot Spot Cell & 5 & 2 & wipe \\
\hline \multirow[t]{10}{*}{ Office 106} & 401.4339 & 609.7976 & & 0 & Hot Spot Cell & 2 & 1 & vacuum \\
\hline & 463.4037 & 609.7976 & & 0 & Hot Spot Cell & 2 & 2 & vacuum \\
\hline & 432.4188 & 659.0726 & & 0 & Hot Spot Cell & 3 & 1 & vacuum \\
\hline & 494.3885 & 659.0726 & & 0 & Hot Spot Cell & 3 & 2 & wipe \\
\hline & 401.4339 & 708.3477 & & 0 & Hot Spot Cell & 4 & 1 & wipe \\
\hline & 463.4037 & 708.3477 & & 0 & Hot Spot Cell & 4 & 2 & wipe \\
\hline & 432.4188 & 757.6228 & & 0 & Hot Spot Cell & 5 & 1 & vacuum \\
\hline & 494.3885 & 757.6228 & & 0 & Hot Spot Cell & 5 & 2 & vacuum \\
\hline & 401.4339 & 806.8979 & & 0 & Hot Spot Cell & 6 & 1 & wipe \\
\hline & 463.4037 & 806.8979 & & 0 & Hot Spot Cell & 6 & 2 & wipe \\
\hline
\end{tabular}


Table D.5. Coordinates and Sample Types for Probabilistic Sample Locations of Clearance Samples on Floor 1 of INL PBF-632 for INL-2 Test Events 1, 2, and 4 (contd)

\begin{tabular}{|c|c|c|c|c|c|c|c|c|}
\hline Area & X Center & Y Center & Label & Value & Type & Row & Col & Sample Type \\
\hline \multirow[t]{10}{*}{ Office 107} & 274.4811 & 246.6699 & & 0 & Hot Spot Cell & 1 & 0 & wipe \\
\hline & 336.4508 & 246.6699 & & 0 & Hot Spot Cell & 1 & 1 & wipe \\
\hline & 305.4660 & 295.9450 & & 0 & Hot Spot Cell & 2 & 1 & vacuum \\
\hline & 367.4357 & 295.9450 & & 0 & Hot Spot Cell & 2 & 2 & wipe \\
\hline & 274.4811 & 345.2201 & & 0 & Hot Spot Cell & 3 & 0 & wipe \\
\hline & 336.4508 & 345.2201 & & 0 & Hot Spot Cell & 3 & 1 & vacuum \\
\hline & 305.4660 & 394.4951 & & 0 & Hot Spot Cell & 4 & 1 & vacuum \\
\hline & 367.4357 & 394.4951 & & 0 & Hot Spot Cell & 4 & 2 & vacuum \\
\hline & 274.4811 & 443.7702 & & 0 & Hot Spot Cell & 5 & 0 & vacuum \\
\hline & 336.4508 & 443.7702 & & 0 & Hot Spot Cell & 5 & 1 & wipe \\
\hline \multirow[t]{9}{*}{ Office 108} & 319.6228 & 617.8642 & & 0 & Hot Spot Cell & 2 & 1 & wipe \\
\hline & 381.5926 & 617.8642 & & 0 & Hot Spot Cell & 2 & 2 & wipe \\
\hline & 288.6379 & 667.1393 & & 0 & Hot Spot Cell & 3 & 0 & wipe \\
\hline & 350.6077 & 667.1393 & & 0 & Hot Spot Cell & 3 & 1 & wipe \\
\hline & 319.6228 & 716.4144 & & 0 & Hot Spot Cell & 4 & 1 & vacuum \\
\hline & 381.5926 & 716.4144 & & 0 & Hot Spot Cell & 4 & 2 & wipe \\
\hline & 288.6379 & 765.6895 & & 0 & Hot Spot Cell & 5 & 0 & vacuum \\
\hline & 350.6077 & 765.6895 & & 0 & Hot Spot Cell & 5 & 1 & wipe \\
\hline & 319.6228 & 814.9645 & & 0 & Hot Spot Cell & 6 & 1 & wipe \\
\hline \multirow[t]{10}{*}{ Office 109} & 185.6624 & 272.0587 & & 0 & Hot Spot Cell & 1 & 1 & wipe \\
\hline & 247.6321 & 272.0587 & & 0 & Hot Spot Cell & 1 & 2 & wipe \\
\hline & 154.6775 & 321.3338 & & 0 & Hot Spot Cell & 2 & 1 & wipe \\
\hline & 216.6473 & 321.3338 & & 0 & Hot Spot Cell & 2 & 2 & vacuum \\
\hline & 185.6624 & 370.6089 & & 0 & Hot Spot Cell & 3 & 1 & wipe \\
\hline & 247.6321 & 370.6089 & & 0 & Hot Spot Cell & 3 & 2 & vacuum \\
\hline & 154.6775 & 419.8840 & & 0 & Hot Spot Cell & 4 & 1 & wipe \\
\hline & 216.6473 & 419.8840 & & 0 & Hot Spot Cell & 4 & 2 & vacuum \\
\hline & 185.6624 & 469.1590 & & 0 & Hot Spot Cell & 5 & 1 & wipe \\
\hline & 247.6321 & 469.1590 & & 0 & Hot Spot Cell & 5 & 2 & vacuum \\
\hline \multirow[t]{10}{*}{ Office 110} & 203.4891 & 597.2734 & & 0 & Hot Spot Cell & 1 & 1 & wipe \\
\hline & 265.4588 & 597.2734 & & 0 & Hot Spot Cell & 1 & 2 & vacuum \\
\hline & 172.5042 & 646.5484 & & 0 & Hot Spot Cell & 2 & 1 & wipe \\
\hline & 234.4740 & 646.5484 & & 0 & Hot Spot Cell & 2 & 2 & vacuum \\
\hline & 203.4891 & 695.8235 & & 0 & Hot Spot Cell & 3 & 1 & vacuum \\
\hline & 265.4588 & 695.8235 & & 0 & Hot Spot Cell & 3 & 2 & wipe \\
\hline & 172.5042 & 745.0986 & & 0 & Hot Spot Cell & 4 & 1 & wipe \\
\hline & 234.4740 & 745.0986 & & 0 & Hot Spot Cell & 4 & 2 & vacuum \\
\hline & 203.4891 & 794.3737 & & 0 & Hot Spot Cell & 5 & 1 & wipe \\
\hline & 265.4588 & 794.3737 & & 0 & Hot Spot Cell & 5 & 2 & wipe \\
\hline
\end{tabular}


Table D.6. Coordinates and Sample Types for Probabilistic Sample Locations of Clearance Samples on Floor 2 of INL PBF-632 for INL-2 Test Events 3 and 5

\begin{tabular}{|c|c|c|c|c|c|c|c|c|}
\hline Area & X Center & Y Center & Label & Value & Type & Row & Col & Sample Type \\
\hline \multirow[t]{6}{*}{ Office 201} & 1058.329 & 431.3752 & & 0 & Hot Spot Cell & 2 & 1 & vacuum \\
\hline & 1120.572 & 431.3752 & & 0 & Hot Spot Cell & 2 & 2 & vacuum \\
\hline & 1182.815 & 431.3752 & & 0 & Hot Spot Cell & 2 & 3 & wipe \\
\hline & 1027.208 & 480.8868 & & 0 & Hot Spot Cell & 3 & 0 & vacuum \\
\hline & 1089.451 & 480.8868 & & 0 & Hot Spot Cell & 3 & 1 & wipe \\
\hline & 1151.693 & 480.8868 & & 0 & Hot Spot Cell & 3 & 2 & wipe \\
\hline \multirow[t]{7}{*}{ Office 201A } & 1071.766 & 240.5494 & & 0 & Hot Spot Cell & 1 & 1 & wipe \\
\hline & 1134.009 & 240.5494 & & 0 & Hot Spot Cell & 1 & 2 & wipe \\
\hline & 1040.644 & 290.0610 & & 0 & Hot Spot Cell & 2 & 1 & wipe \\
\hline & 1102.887 & 290.0610 & & 0 & Hot Spot Cell & 2 & 2 & vacuum \\
\hline & 1165.130 & 290.0610 & & 0 & Hot Spot Cell & 2 & 3 & wipe \\
\hline & 1071.766 & 339.5725 & & 0 & Hot Spot Cell & 3 & 1 & vacuum \\
\hline & 1134.009 & 339.5725 & & 0 & Hot Spot Cell & 3 & 2 & vacuum \\
\hline \multirow[t]{4}{*}{ Office 202} & 860.7741 & 602.5726 & & 0 & Hot Spot Cell & 1 & 1 & vacuum \\
\hline & 829.6527 & 652.0842 & & 0 & Hot Spot Cell & 2 & 1 & vacuum \\
\hline & 891.8955 & 652.0842 & & 0 & Hot Spot Cell & 2 & 2 & wipe \\
\hline & 860.7741 & 701.5957 & & 0 & Hot Spot Cell & 3 & 1 & swab monitor \\
\hline \multirow[t]{6}{*}{ Office 203} & 881.7774 & 412.9497 & & 0 & Hot Spot Cell & 1 & 1 & wipe \\
\hline & 944.0202 & 412.9497 & & 0 & Hot Spot Cell & 1 & 2 & vacuum \\
\hline & 1006.263 & 412.9497 & & 0 & Hot Spot Cell & 1 & 3 & wipe \\
\hline & 850.6560 & 462.4613 & & 0 & Hot Spot Cell & 2 & 1 & wipe \\
\hline & 912.8988 & 462.4613 & & 0 & Hot Spot Cell & 2 & 2 & wipe \\
\hline & 975.1416 & 462.4613 & & 0 & Hot Spot Cell & 2 & 3 & wipe \\
\hline \multirow[t]{7}{*}{ Office 203A } & 886.6639 & 244.2941 & & 0 & Hot Spot Cell & 1 & 1 & wipe \\
\hline & 948.9068 & 244.2941 & & 0 & Hot Spot Cell & 1 & 2 & wipe \\
\hline & 855.5425 & 293.8056 & & 0 & Hot Spot Cell & 2 & 1 & wipe \\
\hline & 917.7854 & 293.8056 & & 0 & Hot Spot Cell & 2 & 2 & vacuum \\
\hline & 980.0282 & 293.8056 & & 0 & Hot Spot Cell & 2 & 3 & wipe \\
\hline & 886.6639 & 343.3172 & & 0 & Hot Spot Cell & 3 & 1 & wipe \\
\hline & 948.9068 & 343.3172 & & 0 & Hot Spot Cell & 3 & 2 & wipe \\
\hline \multirow[t]{4}{*}{ Office 204} & 782.9838 & 596.3914 & & 0 & Hot Spot Cell & 1 & 1 & vacuum \\
\hline & 751.8624 & 645.9029 & & 0 & Hot Spot Cell & 2 & 1 & wipe \\
\hline & 814.1052 & 645.9029 & & 0 & Hot Spot Cell & 2 & 2 & vacuum \\
\hline & 782.9838 & 695.4145 & & 0 & Hot Spot Cell & 3 & 1 & wipe \\
\hline
\end{tabular}


Table D.6. Coordinates and Sample Types for Probabilistic Sample Locations of Clearance Samples on Floor 2 of INL PBF-632 for INL-2 Test Events 3 and 5 (contd)

\begin{tabular}{|c|c|c|c|c|c|c|c|c|}
\hline Area & X Center & Y Center & Label & Value & Type & Row & Col & Sample Type \\
\hline \multirow[t]{10}{*}{ Office 205} & 726.7541 & 282.8966 & & 0 & Hot Spot Cell & 2 & 1 & wipe \\
\hline & 788.9969 & 282.8966 & & 0 & Hot Spot Cell & 2 & 2 & vacuum \\
\hline & 757.8755 & 332.4081 & & 0 & Hot Spot Cell & 3 & 1 & vacuum \\
\hline & 820.1183 & 332.4081 & & 0 & Hot Spot Cell & 3 & 2 & wipe \\
\hline & 726.7541 & 381.9197 & & 0 & Hot Spot Cell & 4 & 1 & wipe \\
\hline & 788.9969 & 381.9197 & & 0 & Hot Spot Cell & 4 & 2 & vacuum \\
\hline & 757.8755 & 431.4312 & & 0 & Hot Spot Cell & 5 & 1 & wipe \\
\hline & 820.1183 & 431.4312 & & 0 & Hot Spot Cell & 5 & 2 & vacuum \\
\hline & 726.7541 & 480.9428 & & 0 & Hot Spot Cell & 6 & 1 & vacuum \\
\hline & 788.9969 & 480.9428 & & 0 & Hot Spot Cell & 6 & 2 & vacuum \\
\hline \multirow[t]{10}{*}{ Office 206} & 640.2574 & 579.6158 & & 0 & Hot Spot Cell & 1 & 1 & vacuum \\
\hline & 702.5002 & 579.6158 & & 0 & Hot Spot Cell & 1 & 2 & wipe \\
\hline & 609.1360 & 629.1273 & & 0 & Hot Spot Cell & 2 & 1 & vacuum \\
\hline & 671.3788 & 629.1273 & & 0 & Hot Spot Cell & 2 & 2 & vacuum \\
\hline & 640.2574 & 678.6389 & & 0 & Hot Spot Cell & 3 & 1 & vacuum \\
\hline & 702.5002 & 678.6389 & & 0 & Hot Spot Cell & 3 & 2 & wipe \\
\hline & 609.1360 & 728.1504 & & 0 & Hot Spot Cell & 4 & 1 & vacuum \\
\hline & 671.3788 & 728.1504 & & 0 & Hot Spot Cell & 4 & 2 & wipe \\
\hline & 640.2574 & 777.6620 & & 0 & Hot Spot Cell & 5 & 1 & wipe \\
\hline & 702.5002 & 777.6620 & & 0 & Hot Spot Cell & 5 & 2 & vacuum \\
\hline \multirow[t]{10}{*}{ Office 207} & 613.6646 & 247.4172 & & 0 & Hot Spot Cell & 1 & 0 & wipe \\
\hline & 675.9074 & 247.4172 & & 0 & Hot Spot Cell & 1 & 1 & vacuum \\
\hline & 644.7860 & 296.9287 & & 0 & Hot Spot Cell & 2 & 1 & vacuum \\
\hline & 707.0288 & 296.9287 & & 0 & Hot Spot Cell & 2 & 2 & swab monitor \\
\hline & 613.6646 & 346.4403 & & 0 & Hot Spot Cell & 3 & 0 & wipe \\
\hline & 675.9074 & 346.4403 & & 0 & Hot Spot Cell & 3 & 1 & vacuum \\
\hline & 644.7860 & 395.9518 & & 0 & Hot Spot Cell & 4 & 1 & vacuum \\
\hline & 707.0288 & 395.9518 & & 0 & Hot Spot Cell & 4 & 2 & wipe \\
\hline & 613.6646 & 445.4634 & & 0 & Hot Spot Cell & 5 & 0 & vacuum \\
\hline & 675.9074 & 445.4634 & & 0 & Hot Spot Cell & 5 & 1 & vacuum \\
\hline \multirow[t]{10}{*}{ Office 208} & 489.0392 & 610.5625 & & 0 & Hot Spot Cell & 2 & 1 & vacuum \\
\hline & 551.2820 & 610.5625 & & 0 & Hot Spot Cell & 2 & 2 & wipe \\
\hline & 520.1606 & 660.0740 & & 0 & Hot Spot Cell & 3 & 1 & wipe \\
\hline & 582.4035 & 660.0740 & & 0 & Hot Spot Cell & 3 & 2 & vacuum \\
\hline & 489.0392 & 709.5856 & & 0 & Hot Spot Cell & 4 & 1 & vacuum \\
\hline & 551.2820 & 709.5856 & & 0 & Hot Spot Cell & 4 & 2 & vacuum \\
\hline & 520.1606 & 759.0971 & & 0 & Hot Spot Cell & 5 & 1 & vacuum \\
\hline & 582.4035 & 759.0971 & & 0 & Hot Spot Cell & 5 & 2 & vacuum \\
\hline & 489.0392 & 808.6087 & & 0 & Hot Spot Cell & 6 & 1 & wipe \\
\hline & 551.2820 & 808.6087 & & 0 & Hot Spot Cell & 6 & 2 & wipe \\
\hline
\end{tabular}


Table D.6. Coordinates and Sample Types for Probabilistic Sample Locations of Clearance Samples on Floor 2 of INL PBF-632 for INL-2 Test Events 3 and 5 (contd)

\begin{tabular}{|c|c|c|c|c|c|c|c|c|}
\hline Area & X Center & Y Center & Label & Value & Type & Row & Col & Sample Type \\
\hline \multirow[t]{10}{*}{ Office 209} & 525.3797 & 278.4087 & & 0 & Hot Spot Cell & 2 & 1 & wipe \\
\hline & 587.6225 & 278.4087 & & 0 & Hot Spot Cell & 2 & 2 & vacuum \\
\hline & 494.2583 & 327.9202 & & 0 & Hot Spot Cell & 3 & 0 & vacuum \\
\hline & 556.5011 & 327.9202 & & 0 & Hot Spot Cell & 3 & 1 & vacuum \\
\hline & 525.3797 & 377.4318 & & 0 & Hot Spot Cell & 4 & 1 & wipe \\
\hline & 587.6225 & 377.4318 & & 0 & Hot Spot Cell & 4 & 2 & vacuum \\
\hline & 494.2583 & 426.9433 & & 0 & Hot Spot Cell & 5 & 0 & wipe \\
\hline & 556.5011 & 426.9433 & & 0 & Hot Spot Cell & 5 & 1 & vacuum \\
\hline & 525.3797 & 476.4549 & & 0 & Hot Spot Cell & 6 & 1 & wipe \\
\hline & 587.6225 & 476.4549 & & 0 & Hot Spot Cell & 6 & 2 & vacuum \\
\hline \multirow[t]{7}{*}{ Office 210} & 427.2668 & 575.6266 & & 0 & Hot Spot Cell & 1 & 1 & wipe \\
\hline & 396.1454 & 625.1381 & & 0 & Hot Spot Cell & 2 & 1 & vacuum \\
\hline & 458.3882 & 625.1381 & & 0 & Hot Spot Cell & 2 & 2 & wipe \\
\hline & 427.2668 & 674.6497 & & 0 & Hot Spot Cell & 3 & 1 & wipe \\
\hline & 396.1454 & 724.1612 & & 0 & Hot Spot Cell & 4 & 1 & vacuum \\
\hline & 458.3882 & 724.1612 & & 0 & Hot Spot Cell & 4 & 2 & vacuum \\
\hline & 427.2668 & 773.6728 & & 0 & Hot Spot Cell & 5 & 1 & swab grill \\
\hline \multirow[t]{10}{*}{ Office 211} & 382.5532 & 282.0610 & & 0 & Hot Spot Cell & 2 & 1 & wipe \\
\hline & 444.7960 & 282.0610 & & 0 & Hot Spot Cell & 2 & 2 & vacuum \\
\hline & 413.6746 & 331.5725 & & 0 & Hot Spot Cell & 3 & 1 & vacuum \\
\hline & 475.9174 & 331.5725 & & 0 & Hot Spot Cell & 3 & 2 & vacuum \\
\hline & 382.5532 & 381.0841 & & 0 & Hot Spot Cell & 4 & 1 & wipe \\
\hline & 444.7960 & 381.0841 & & 0 & Hot Spot Cell & 4 & 2 & vacuum \\
\hline & 413.6746 & 430.5956 & & 0 & Hot Spot Cell & 5 & 1 & vacuum \\
\hline & 475.9174 & 430.5956 & & 0 & Hot Spot Cell & 5 & 2 & vacuum \\
\hline & 382.5532 & 480.1072 & & 0 & Hot Spot Cell & 6 & 1 & vacuum \\
\hline & 444.7960 & 480.1072 & & 0 & Hot Spot Cell & 6 & 2 & vacuum \\
\hline \multirow[t]{10}{*}{ Office 212} & 253.1032 & 596.0517 & & 0 & Hot Spot Cell & 1 & 0 & vacuum \\
\hline & 315.3461 & 596.0517 & & 0 & Hot Spot Cell & 1 & 1 & wipe \\
\hline & 284.2246 & 645.5632 & & 0 & Hot Spot Cell & 2 & 1 & vacuum \\
\hline & 346.4675 & 645.5632 & & 0 & Hot Spot Cell & 2 & 2 & wipe \\
\hline & 253.1032 & 695.0748 & & 0 & Hot Spot Cell & 3 & 0 & wipe \\
\hline & 315.3461 & 695.0748 & & 0 & Hot Spot Cell & 3 & 1 & vacuum \\
\hline & 284.2246 & 744.5863 & & 0 & Hot Spot Cell & 4 & 1 & vacuum \\
\hline & 346.4675 & 744.5863 & & 0 & Hot Spot Cell & 4 & 2 & vacuum \\
\hline & 253.1032 & 794.0979 & & 0 & Hot Spot Cell & 5 & 0 & vacuum \\
\hline & 315.3461 & 794.0979 & & 0 & Hot Spot Cell & 5 & 1 & wipe \\
\hline
\end{tabular}


Table D.6. Coordinates and Sample Types for Probabilistic Sample Locations of Clearance Samples on Floor 2 of INL PBF-632 for INL-2 Test Events 3 and 5 (contd)

\begin{tabular}{ccccccccc}
\hline Area & X Center & Y Center & Label & Value & Type & Row & Col & Sample Type \\
\hline Office 213 & 259.5028 & 272.4577 & & 0 & Hot Spot Cell & 2 & 1 & wipe \\
& 321.7456 & 272.4577 & 0 & Hot Spot Cell & 2 & 2 & swab grill \\
& 290.6242 & 321.9692 & & 0 & Hot Spot Cell & 3 & 1 & vacuum \\
& 352.8670 & 321.9692 & & 0 & Hot Spot Cell & 3 & 2 & wipe \\
& 259.5028 & 371.4808 & & 0 & Hot Spot Cell & 4 & 1 & vacuum \\
& 321.7456 & 371.4808 & & 0 & Hot Spot Cell & 4 & 2 & wipe \\
& 290.6242 & 420.9923 & & 0 & Hot Spot Cell & 5 & 1 & vacuum \\
& 352.8670 & 420.9923 & & 0 & Hot Spot Cell & 5 & 2 & wipe \\
& 259.5028 & 470.5039 & 0 & Hot Spot Cell & 6 & 1 & vacuum \\
& 321.7456 & 470.5039 & & 0 & Hot Spot Cell & 6 & 2 & vacuum \\
\hline
\end{tabular}




\section{Electronic Distribution List}

No. of

$\underline{\text { Copies }}$

\section{External Distribution}

9 Department of Homeland Security John Bridges (john.bridges@dhs.gov) Lance Brooks (lance.brooks@dhs.gov) Tod Companion (tod.companion@dhs.gov) Bert Coursey (bert.coursey@dhs.gov) Elizabeth George (elizabeth.george@dhs.gov) Randy Long (randolph.long@dhs.gov) Kristin Pasternak (kristin.pasternak@associates.dhs.gov) Segaran Pillai (segaran.pillai@dhs.gov) Randolph Thur (randolph.thur@associates.dhs.gov)

11 Environmental Protection Agency Allan Antley (antley.allan@epa.gov) Michelle Burgess (burgess.michele@epa.gov) Shatzi Fitz-James (fitz-james.schatzi@epa.gov) Romy Lee (lee.romy@epa.gov) Dino Mattorano (mattorano.dino@epa.gov) Marissa Mullins (mullins.marissa@epa.gov) Tonya Nichols (nichols.tonya@epamail.epa.gov) Shawn Ryan (ryan.shawn@epa.gov)

Lindsay Saskowsky (saskowsky.lindsay@epa.gov) Sanjiv Shah (shah.sanjiv@epa.gov) Oba Vincent (vincent.oba@epa.gov)

3 Joint Program Executive Office for Chemical and Biological Defense

Kristin Korté (kristin.korte@jpeocbd.osd.mil) Carolyn Tolchinsky (carolyn.tolchinsky@jpeocbd.osd.mil)

Michael Walter (michael.walter@jpeocbd.osd.mil)

4 National Institute of Standards \& Technology Stuart Dols (wsdols@nist.gov) James Filliben (filliben@nist.gov) Jayne Morrow (jayne.morrow@nist.gov) Andrew Persily (andrew.persily@nist.gov)

1 Johns Hopkins University Applied Physics Laboratory Eric Van Gieson (eric.van.gieson@jhuapl.edu)
No. of

$\underline{\text { Copies }}$

8 Center for Disease Control and Protection Matthew Arduino (marduino@cdc.gov)

Lisa Delaney (ldelaney1@cdc.gov)

Richard Kellogg (rbk1@cdc.gov)

Aida Mahmutovic (atj8@cdc.gov)

Ken Martinez (kmartinez@cdc.gov)

Stephen Morse (sam1@cdc.gov)

Angela Weber (aweber@cdc.gov)

Betsy Weirich (eweirich@cdc.gov)

4 Federal Bureau of Investigation

Doug Anders (douglas.anders@ic.fbi.gov)

Kristine Beardsley

(kristine.beardsley@ic.fbi.gov)

Doug Beecher (douglas.beecher@ic.fbi.gov)

Nick Paquette (nicholas.paquette@ic.fbi.gov)

1 Sandia National Laboratory

Bob Knowlton (rgknowl@sandia.gov)

2 Institute for Defense Analyses

Jeff Grotte (jgrotte@ida.org)

Margaret Hebner (mhebner@ida.org)

3 Homeland Security Institute

Phil Hammar (philip.hammar@hsi.dhs.gov)

Ed Hildebrand (carl.hildebrand@hsi.dhs.gov)

Eric Sylwester (eric.sylwester@hsi.dhs.gov)

1 Signature Science Molly Isbell (misbell@signaturescience.com)

1 CSC Systems and Solutions Sean Kolb (skolb4@fedcsc.com)

\section{Internal Distribution}

Pacific Northwest National Laboratory Brett Amidan (brett.amidan@pnl.gov) Brett Matzke (brett.matzke@pnl.gov) Greg Piepel (greg.piepel@pnl.gov) Brent Pulsipher (brent.pulsipher@pnl.gov)

Landon Sego (landon.sego@pnl.gov)

Information Release 